\title{
WestVirginiaUniversity
}

THE RESEARCH REPOSITORY @ WVU

Graduate Theses, Dissertations, and Problem Reports

2003

\section{Bone fracture toughness of estrogen deficient rabbits}

Matthew S. Smith

West Virginia University

Follow this and additional works at: https://researchrepository.wvu.edu/etd

\section{Recommended Citation}

Smith, Matthew S., "Bone fracture toughness of estrogen deficient rabbits" (2003). Graduate Theses, Dissertations, and Problem Reports. 1358.

https://researchrepository.wvu.edu/etd/1358

This Thesis is protected by copyright and/or related rights. It has been brought to you by the The Research Repository @WVU with permission from the rights-holder(s). You are free to use this Thesis in any way that is permitted by the copyright and related rights legislation that applies to your use. For other uses you must obtain permission from the rights-holder(s) directly, unless additional rights are indicated by a Creative Commons license in the record and/ or on the work itself. This Thesis has been accepted for inclusion in WVU Graduate Theses, Dissertations, and Problem Reports collection by an authorized administrator of The Research Repository @ WVU. For more information, please contact researchrepository@mail.wvu.edu. 


\title{
Bone Fracture Toughness of Estrogen Deficient Rabbits
}

\author{
Matthew S. Smith
}

Thesis Submitted to the College of Engineering and Mineral Resources

At West Virginia University In partial fulfillment of the requirements

For the degree of

\author{
Master of Science \\ In \\ Mechanical Engineering
}

Timothy Norman, Ph. D., Chair

Nilay Mukherjee, Ph. D.

Charles Stanley, Ph. D.

Department of Mechanical and Aerospace Engineering

Morgantown, West Virginia

2003

Keywords: Fracture Toughness, Animal Model, Osteoporosis, Bone 


\section{ABSTRACT \\ Bone Fracture Toughness of Estrogen Deficient Rabbits}

\section{Matthew S. Smith}

Bone mass is commonly used as an indicator of fracture risk. It has been shown in numerous studies that bone loss causes increased bone fragility and risk of fracture. It has also been shown that $50 \%$ of patients with osteoporotic vertebral compression fractures have the same bone mass as normal age matched controls. Thus, bone mass alone is not the only indicator of bone quality and ability to resist fracture.

The objective of this study was to qualitatively assess bone's mechanical and histomorphometric changes with drug treatment, and estrogen deficiency, using fracture toughness, femoral neck fracture and histomorphometric analysis in an ovarectomized rabbit model.

No significant differences were found in fracture toughness, porosity, or femoral neck ultimate strength for any treatment group, which may have be from a lack sufficient time for the difference caused by estrogen deficiency and drug treatment to manifest in the rabbit model. 


\section{Acknowledgements:}

There are many people that I must thank for making this all possible. I would like to thank Dr. Timothy Norman for giving me opportunities in the lab, and for mentoring me while I was still growing in my quest to become a physician. To the members of my board Dr. Nilay Mukrejee for his help in coming up with hard questions for me to try and answer, and Dr. Charles Stanley for his support and help in making this possible.

Thanks to all of the staff at the MSRC, Nina for her experimental help and support, Suzanne for all the trips to the rabbit room, Vince for helping me make it all work, Sydha for her help in preparation of presentations. The whole lab, including those mentioned and some of the students, faculty, and residents that have moved on to other things, deserve a great thanks for making the lab an enjoyable place to work.

I must acknowledge my family and friends for helping to support me through this process. Much thanks goes to Marissa, who in her tough-love way, never let me feel sorry for myself.

I want to give special thanks to my mother, who always knew that I could do it, and to the memory of my father, which helped fuel my efforts. I also must acknowledge my father, whose memory drives me to achieve.

Last but certainly not least; I would like to give my thanks to God, without which I could do nothing. "I can do all things through Christ who strengthens me," (Philippians $4: 13)$. 


\section{TABLE OF CONTENTS}

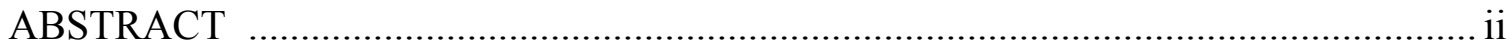

Acknowledgements:

TABLE OF CONTENTS .......................................................................................... iv

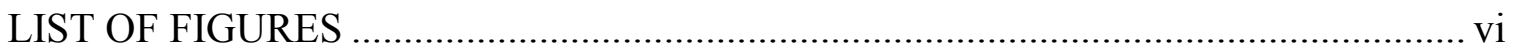

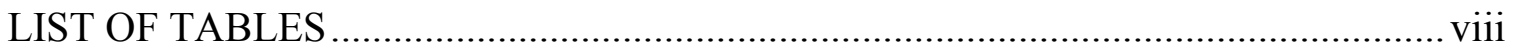

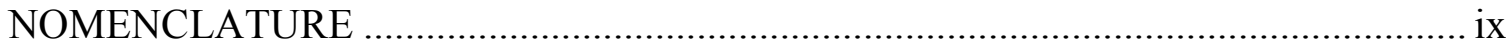

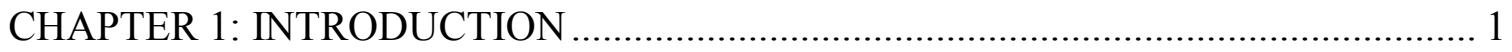

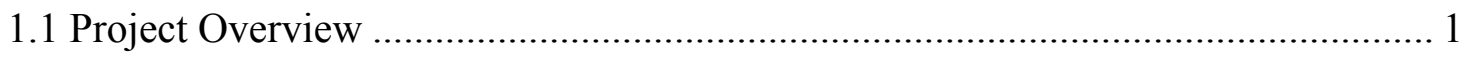

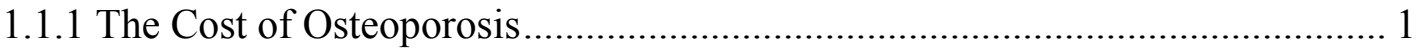

1.1.2 Clinical Significance ............................................................................... 2

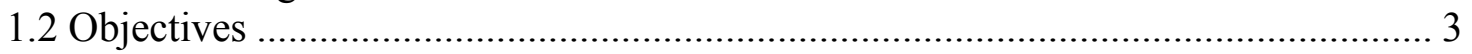

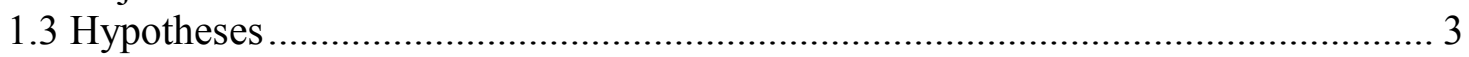

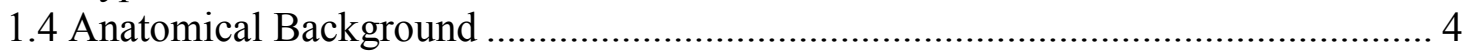

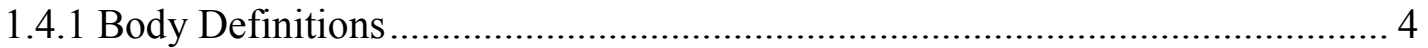

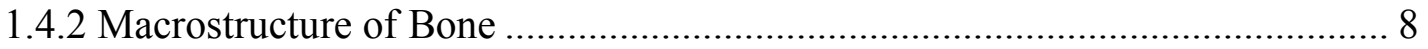

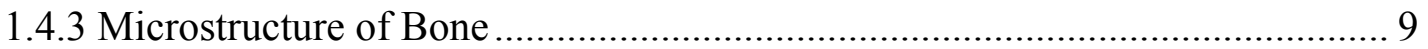

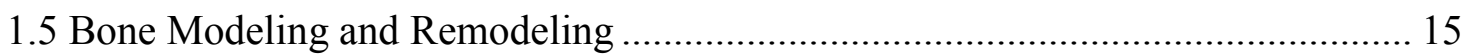

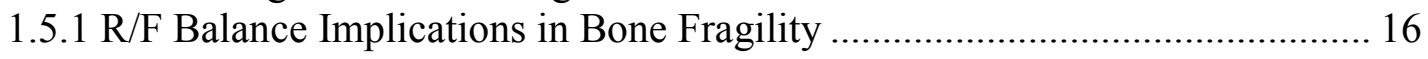

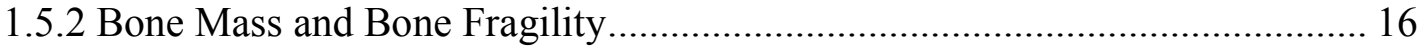

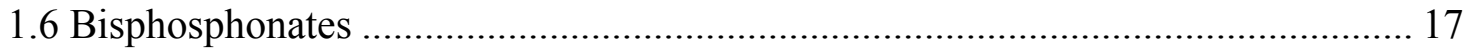

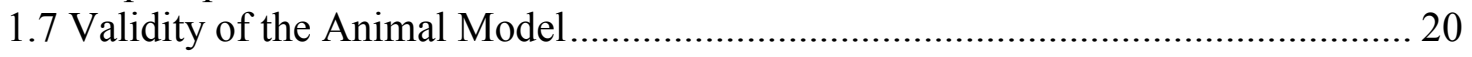

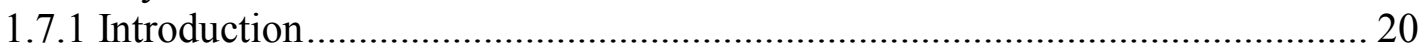

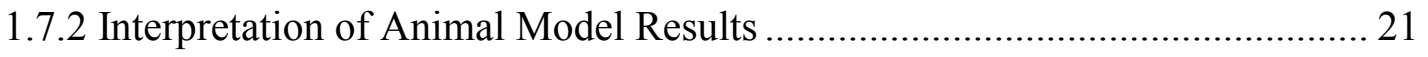

1.7.3 Selection of an Animal Model ................................................................. 21

CHAPTER 2: FRACTURE TOUGHNESS OF BONE .............................................. 23

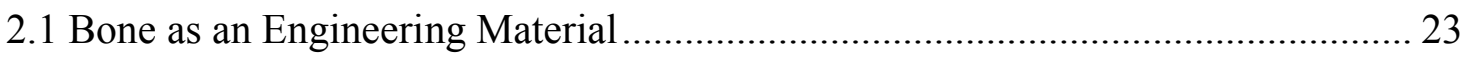

2.2 Introduction to Linear Elastic Fracture Mechanics (LEFM) ……………………... 23

2.3 Introduction to Fracture Toughness Testing (Stress Analysis Approach) .............. 25

2.3.1 Modes of Testing ...................................................................................... 25

2.3.2 Fracture Mechanics of Composite Materials ……………………………....... 26

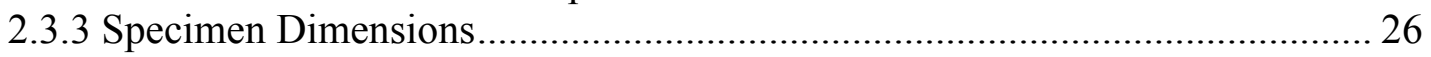

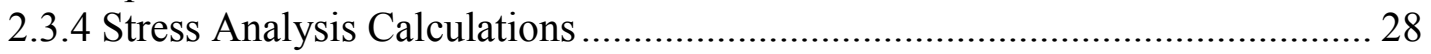

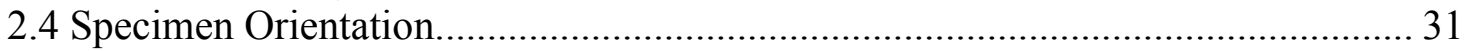

2.5 Tibial Fracture Toughness Values from the Literature ......................................... 32

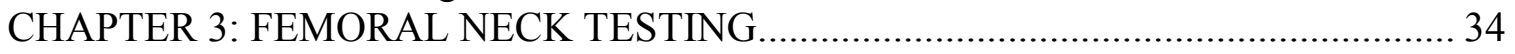

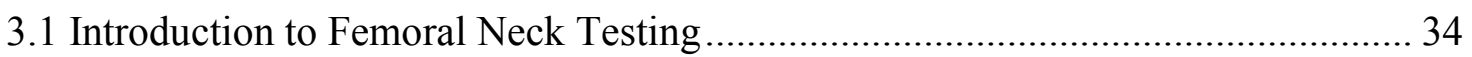

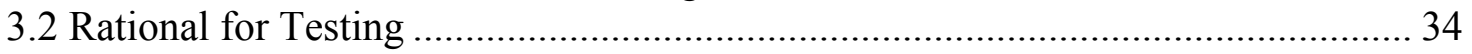

CHAPTER 4 HISTOMORPHOMETRY OF BONE ………….................................. 36

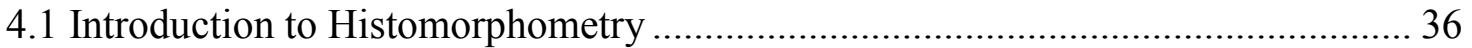

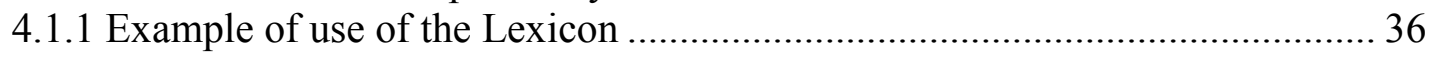

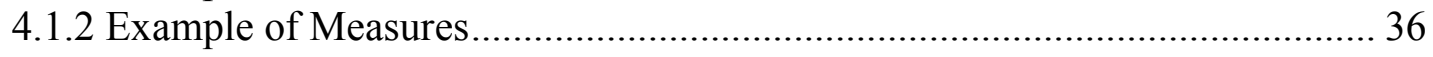

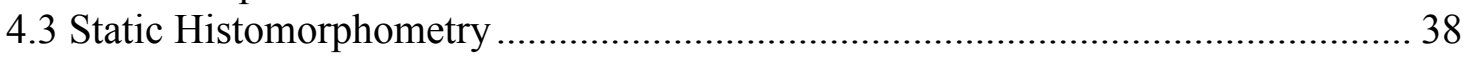

4.4 Compositional Analysis (R Cain et al, 2003) ……............................................... 42

CHAPTER 5 ANIMAL CARE AND EXPERIMENTAL PROCEDURE........................ 44 


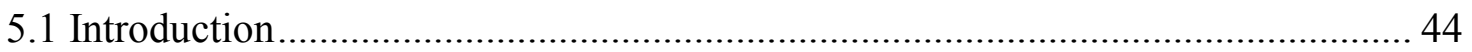

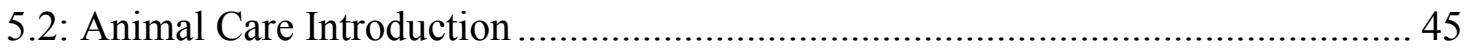

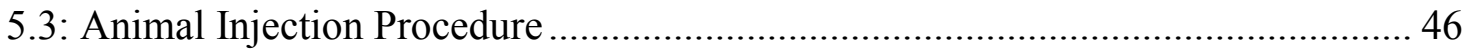

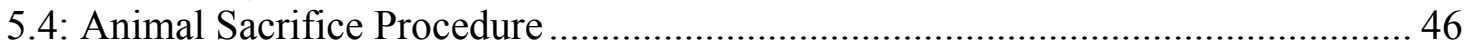

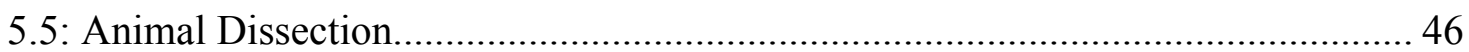

CHAPTER 6: SPECIMEN PREPARATION, MACHINING, AND ANALYSIS .......... 48

6.1 Bone Selection and Bone Availability ................................................................. 48

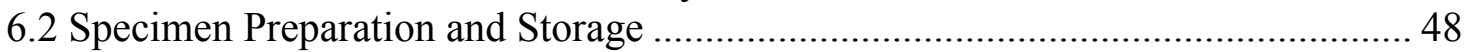

6.3 Fracture Toughness Machining.......................................................................... 48

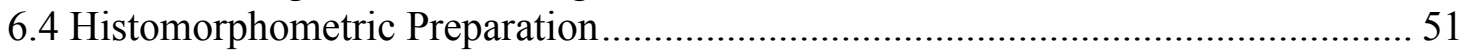

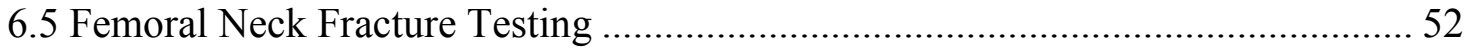

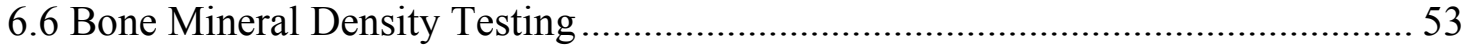

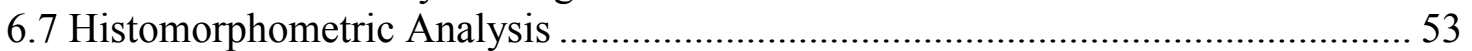

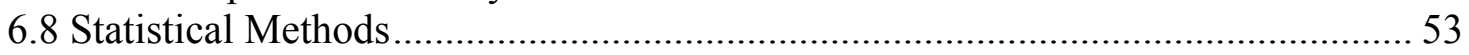

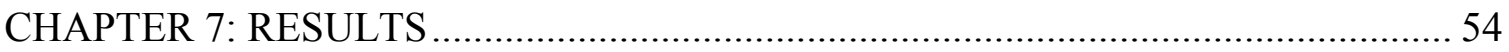

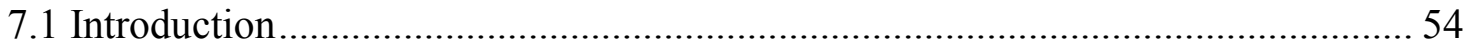

7.2 Fracture Toughness Results (Stress Intensity Factor)............................................. 54

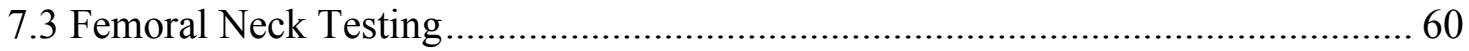

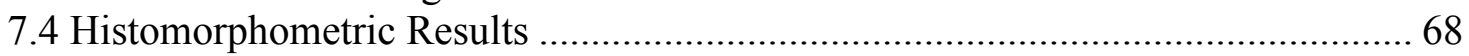

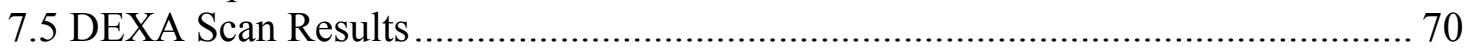

7.6 Weight Measurements ................................................................................ 71

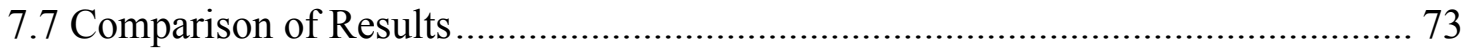

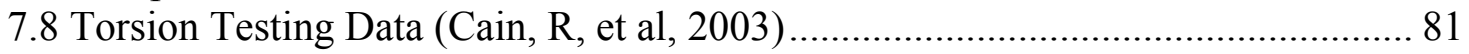

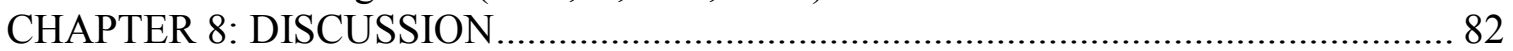

8.1 Discussion Fracture Toughness Data.................................................................... 82

8.2 Discussion of Histomorphometry Data.............................................................. 83

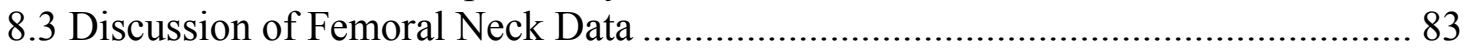

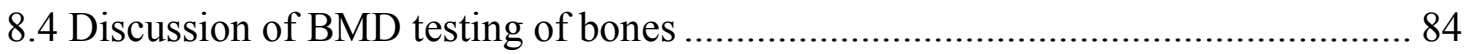

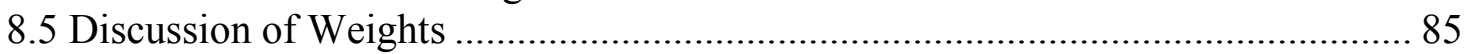

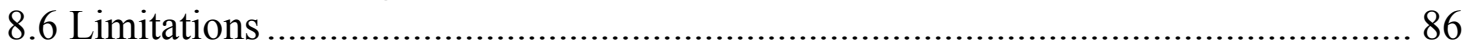

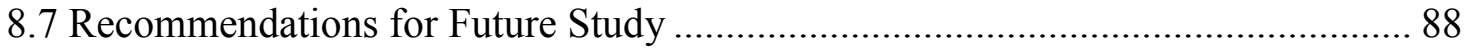

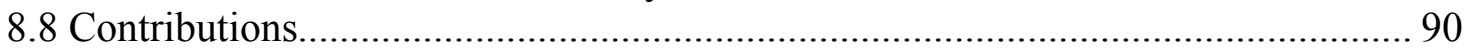

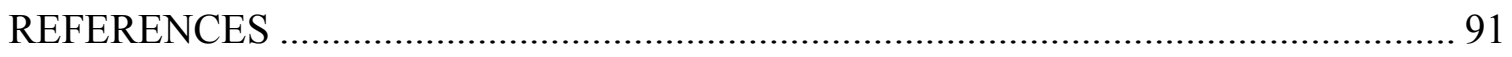

APPENDIX A: H \& E STAINING PROCEDURE ....................................................... 97

APPENDIX B: PLASTIC EMBEDDING PROCEDURE ………………………........ 98

APPENDIX C: MMA EMBEDDED CROSS-SECTION POLISHING PROCEDURE. 99

APPENDIX D: IN-VIVO STAIN PREPARATION ................................................ 100 


\section{LIST OF FIGURES}

Figure 1.1.2-1: Fracture Types and Percentages Related to Osteoporosis (adapted from NIH ORBD data) (NIH, 2003)............................................................ 2

Figure 1.4.1 - 1: Schematic representation of anatomical terms for the rabbit (Wingerd,

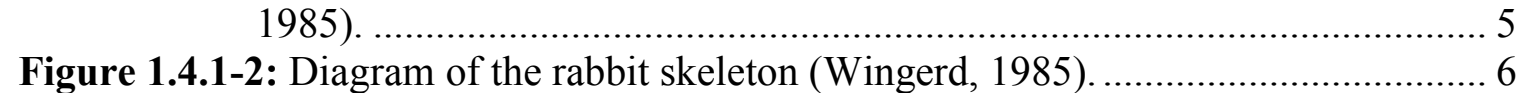

figure 1.4.1-3: Definition of locations and Anatomy of the Femur (Wingerd, 1985) ...... 7

Figure 1.4.1-4: Direction and Anatomy Illustration of the tibia (Wingerd, 1985) ............. 8

Higure 1.4.2-1: Cross-section of the Proximal Femur Showing Cortical and Cancellous

Bone (Albright and Skinner, 1987, with labels added) .............................. 9

Figure 1.4.3-1: Composition of Cartilage, Fibrocartilage, and Bone (Albright, ).......... 11

Figure 1.4.3-2: Diagram of an osteoclast (Fleisch, 2000, with additional label)............ 13

pigure 1.4.3-3: Role of Osteoblastic cells on Osteoclast's and therefore bone resorption

(Fleisch, 2000) ........................................................................ 13

pigure 2.3.3-1: Schematic of the Compact Tension (CT) specimen............................. 28

1Figure 2.3.4-1: Fracture toughness test results plots with 5\% secant line plotted...........29

itigure 2.3.4-2: Hracture foughness fest resulf analysis, showing the three possible outcomes of the $5 \%$ secant line being plotted on the graph (Anderson, 1991)

igure 2.4-1: Crack direction definition for cylindrical geometries (ASTM, 1989;

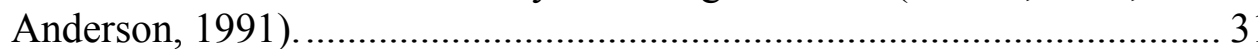

higure 4.3-1: Merged osteons (Wang, 1995) ............................................................ 40

figure 4.3-2: Osteons connected by a Volkmann's canal (Wang, 1995)........................ 40

pigure 4.3-3: Merged osteons with independent Haversian canals (Wang, 1995).......... 41

pigure 4.3-4: Osteon fragment cut by edge of the field (Wang, 1995).......................... 41

pigure 4.3-5: Osteon fragment with a clear cement line (Wang, 1995)........................ 41

pigure 4.3-6: Osteon, which appears to have two cement lines (Wang, 1995), ............. 42

ipigure 6.3.1: Machining Fixture for Milling and Drilling Processes ........................... 49

pigure 6.3-2: Fracture Toughness Specimen Location and Dimensions (Adapted from Wingerd 1085 with (T) snecimen added)

Figure 6.3-3: Making of the precrack (Yeni, 1998)

Higure 6.5-1: Femoral neck testing configuration with the arrow indicating the load. ...52

igure 7.2-1: Stress intensity factor results for Group I (The average value for Normal is $38.9 \pm 7.91$ and the only value for Ovx was 24.27).

igure 7.2-2: Stress intensity factor results for Group II (The average values are

$43.88 \pm 11.78 \mathrm{~N} / \mathrm{mm}^{\wedge} 1.5$ for Ovx- $\mathrm{NaCl}$ and $54.16 \pm 15.63 \mathrm{~N} / \mathrm{mm}^{\wedge} 1.5$ for the

Ovx-Ris group) ...................................................................... 56

1igure 7.2-3: Stress intensity factor results for Group III (The average values were 43.65

$\pm 17.38 \mathrm{~N} / \mathrm{mm}^{\wedge} 1.5$ for Normal, $44.67 \pm 14.21 \mathrm{~N} / \mathrm{mm}^{\wedge} 1.5$ for Ovx-NaCl, $61.37 \pm 11.41 \mathrm{~N} / \mathrm{mm}^{\wedge} 1.5$ for Ovx-Ris , and $55.91 \pm 8.58 \mathrm{~N} / \mathrm{mm}^{\wedge} 1.5$ for

Higure 7.2-4: Stress infensity factor results for Groups 1 , II, and III (The average values were $40.93 \pm 11.77 \mathrm{~N} / \mathrm{mm}^{\wedge} 15$ for Normal. $57.71 \pm 22.36 \mathrm{~N} / \mathrm{mm}^{\wedge} 1.5$ for Ovx-NaCl, $76.23 \pm 26.83 \mathrm{~N} / \mathrm{mm}^{\wedge} 1.5$ for Ovx-Ris , and $49.58 \pm 15.98$ $\mathrm{N} / \mathrm{mm}^{\wedge} 1.5$ for Ovx.). 
Figure 7.3-1: Comparison of Displacement at Fracture for Group I (Averages are for Normal $-2.45 \pm 0.04 \mathrm{~mm}$ and for Ovx $-3.32 \pm 0.14 \mathrm{~mm}) . \ldots \ldots \ldots \ldots \ldots \ldots . . \ldots 1$

Figure 7.3-2: Graph of Force at Fracture for Group I (Averages are for Normal $-1099 \pm$ $340 \mathrm{~N}$ and for Ovx $-1111 \pm 103 \mathrm{~N})$.

Figure 7.3-3: Femoral Head Displacement at Fracture for Group II (The average values

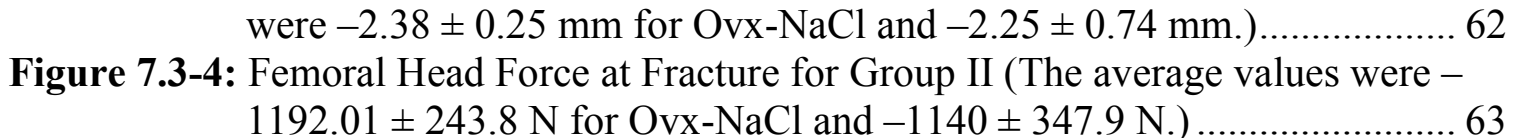

Higure 7.3-5: Load at Fracture of Femoral Neck for Group III (The average values were $1041.0 \pm 235.2 \mathrm{~N}$ for Normal, 1283.4 $\pm 253.1 \mathrm{~N}$ for Ovx. 1084.6 $\pm 124.3 \mathrm{~N}$ Ovx-NaCl, and $1087.4 \pm 153.2 \mathrm{~N}$ for Ovx-Ris.).

Higure 7.3-6: Femoral head displacement at fracture for Group III (The average values were $-3.21 \pm 0.59 \mathrm{~mm}$ for Normal, $-2.95 \pm 0.33 \mathrm{~mm}$ for Ovx, $-2.83 \pm 0.36$ $\mathrm{mm}$ Ovx-NaCl, and $-2.71 \pm 0.78 \mathrm{~mm}$ for Ovx-Ris.) ............................6 66

igure 7.3-7: Femoral neck ultimate strength for all three groups (The average values were $1060 \pm 239.3 \mathrm{~N}$ for Normal, $1225.8 \pm 220.3 \mathrm{~N}$ for Ovx, $1138.3 \pm$ $188.1 \mathrm{~N}$ for Ovx-NaCl, and $1116.7 \pm 264.7 \mathrm{~N}$ for Ovx-Ris.) .................. 67

Figure 7.3-8: Femoral head displacement at time of fracture for all three groups (The average values were $-2.96 \pm 0.60 \mathrm{~mm}$ for Vormal, $-3.08 \pm 0.32 \mathrm{~mm}$ for Ovx $-2.60 \pm 0.37 \mathrm{~mm}$ for $\mathrm{Ovx}-\mathrm{NaCl}$ and $-2.45 \pm 0.75 \mathrm{~N}$ for Ovx-Ris.) 67

Higure 7.4-1: Porosity Percentage ( $\mathrm{Po}$ ) for Group I (The average values were $1.86 \pm 0.74$ for Normal, and $2.10 \pm 1.07$ for Ovx.)

figure 7.4-2: Porosity Percentage ( $\mathrm{Po}$ ) for Group II (The average values were $2.86 \pm$ 0.64 for $\mathrm{Ovx}-\mathrm{NaCl}$, and $2.88 \pm 0.82$ for Ovx-Ris.) ................................ 69

Figure 7.5-1: DEXA scan results versus body mass.................................................. 71

Figure 7.6-1: Mass Results for Groups II and III ............................................. 73

Higure 7.7-1: Compliance versus body mass for Group III, shown with a second degree polynomial fit.................................................................................... 74

Figure 7.7-2: Compliance versus body mass data for Group 1II, with a linear trend line Fioure 7 7-3: added 75

Higure 7.7-4: Femoral head displacement data for Groups II and III versus body mass. 77

Higure 7.7-5: Displacement of the femoral head at fracture of Group III versus bodv

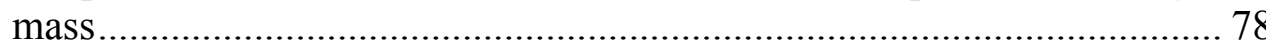

Figure 7.7-6: Plot of BMD and BMC versus body mass for Group II. ...................... 78

Figure 7.7-7: Stress Intensity Factor versus \%Po for Group I............................... 79

Figure 7.7-8: The stress intensity factor versus the \%Po for Group II. ....................... 80

igure 7.7-9: Relationship of \%Po versus body mass for Group II.......................... 80

Higure 7.8-1: Torsional test data versus body mass for Group III. .......................... 81 


\section{LIST OF TABLES}

able 1.6.3-1: FDA approved bisphosphonates for the treatment and prevention of osteoporosis in postmenopausal women and their chemical structure

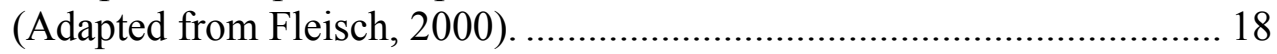

able 1.6.3-2: Etfects of $k$ isedronate Treatment on BMD) (adapted from Clummins, et al With additions)

Table 1.6.3-3: Effects of Alendronate on BMD in Postmenopausal Woman (adapted from Cummins, et al, with additions)

able 2.4-1: Stress Concentration Factors for the Literature for the Tibia (Adapted from Yeni, 1998).

able 4.1.1: Abbreviations and Symbols of Terms Used in Bone Histomorphometry (Parfitt, 1987) ............................................................................. 37

Table 5.1-1: Animal Treatment and Group Distribution Table .................................. 45

Table 7.2-1: Fracture Toughness Test Data for Group I.......................................... 55

able 7.2-2: Fracture toughness test values for Group II ........................................ 56

Table 7.2-3: Fracture toughness test data for Group III.......................................... 57

ahle 7.3-1: Hemoral Neck Test Results tor Group 1 on

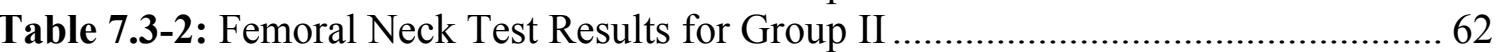

Table 7.3-3: Femoral neck test data for Group لل للس 64

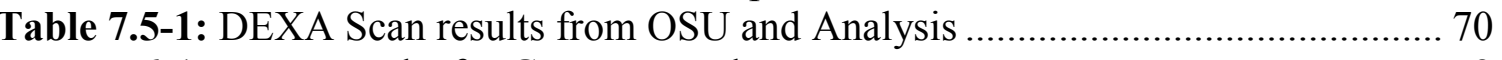

Table 7.6-1: Mass Results for Groups II and III ................................................. 72 


\section{NOMENCLATURE}

General:

ACUC: Animal Care and Use Committee

ASTM: American Society of Testing Mechanics

BMC: Bone Mineral Content

BMD: Bone Mineral Density

CT: Compact Tension

DEXA: Dual Energy X-ray Analysis

EIA: Energy Information Administration

FDA: Food and Drug Administration

Fem: Fem(ur)(oral)

Fx: Fracture

GDP: Gross Domestic Product

ID: Internal Diameter

L-spine: Lumbar Spine

$\mathrm{N}$ : Number (of specimens) (of patients)

$\mathrm{NaCl}$ : Saline Solution

NIH: National Institute of Health

NS: Normal Saline

OSU: Ohio State University

Ovx: Ovariectomized

Ris: Residronate

SD: Standard Deviation

Fracture Toughness:

a: Length from hole center to crack tip in fracture toughness specimen

B: Specimen thickness

C: Compliance

EPFM: Elastic Plastic Fracture Mechanics

F: Work from External Forces

$\mathrm{f}(\mathrm{a} / \mathrm{W})$ : Shape Factor

G: Strain Energy Release Rate

$\mathrm{K}$ : Stress Intensity Factor

Kc: Critical Stress Intensity Factor

LEFM: Linear Elastic Fracture Mechanics

$\mathrm{P}_{\mathrm{c}}$ : Critical Force or Load

$\mathrm{P}_{\max }$ : Maximum load

r: Radial Distance

R/F: Resorption/ Formation

$\sigma:$ Stress

$\mathrm{T}$ : Thickness of fracture toughness specimen

U: Total Energy

$\mathrm{U}_{\mathrm{a}}$ : Internal Strain Energy 
$\mathrm{U}_{\gamma}$ : Elastic Surface Energy

$\mathrm{U}_{\mathrm{o}}$ : Initial Energy

$\mathrm{W}$ : Width of fracture toughness specimen

Histomorphometric Variables

CtAr: Cortical Area

\%CtAr: Percentage Cortical Area

Hn.Cn.Ar: Haversian Canal Area

MeAr: Medullary Area

OAr: Osteoid Area

OnAr: Osteon Area

OnD: Osteon Density

OnN: Osteon Number

OnPm: Osteon Perimeter

Po: Porosity

TtAr: Total Bone Area

V.Cn.Ar: Volksmann Canal Area

Po.Ar: Pore Area

Compositional Analysis

AW: Ashed Weight

DW: Dry Weight

$\mathrm{V}$ : Volume

WW: Wet Weight

\section{Measurements}

Å: Angstroms
${ }^{\circ} \mathrm{C}$ : Degrees Celsius
$\mathrm{cm}$ : Centimeter
$\mathrm{kg}:$ Kilogram
min: Minutes
$\mathrm{mm}$ : Millimeter
$\mu \mathrm{m}:$ Micrometer
$\mathrm{mg}:$ Milligram
$\mathrm{ml}$ : Milliliter
$\mu \mathrm{g}:$ Microgram
$\mathrm{N}:$ Newton
psi: Pounds per Square Inch
RPM: Revolutions Per Minute




\section{CHAPTER 1: INTRODUCTION}

\subsection{Project Overview}

Bone is in a constant state of change with the processes of remodeling and modeling, which is different from the growth process, since it is an overturning and renewal of a mature skeleton. As a bone models and/or remodels it becomes more porous, but may have an increase in overall bone mass. Due to this unique property, fracture toughness, a well known engineering measure of a predamaged material's resistance to fracture or crack propagation, is a good indicator of bone quality.

Bone mass is commonly used as an indicator of fracture risk, and Dempsey and Linsey (1993) have shown that bone loss causes an increased risk of fracture and fragility in general, but Avioli (1987) has reported that 50\% of people with osteoporotic vertebral compression fractures have the same bone mass as normal age matched controls. This would imply that bone mass is insufficient as an indicator of bone quality and ability to resist fracture.

The purpose of this project is to qualitatively assess the fragility of bone by use of histomorphometry and fracture toughness testing, as well as bone mineral density testing (DXA), to demonstrate the ability of bisphosphonates to decrease the fragility, or maintain the fragility at a pre-ovarectomized state.

\subsubsection{The Cost of Osteoporosis}

The National Institute of Health estimates that the annual cost of osteoporitic and associated fractures in the United States to be $\$ 17$ billion, or $\$ 47$ million per day $(\mathrm{NIH}$, 2003). The annual cost is approximately $0.2 \%$ of the United States Gross Domestic Product (GDP) for the year 2000, which is greater than the 2000 GDP of such countries as Costa Rica ( $\$ 14.7$ billion), El Salvador ( $\$ 11.0$ billion), and Oman ( $\$ 16.7$ billion) (EIA, 2002). The 
number of hip fractures, which is the second most common osteoporotic fracture, has been estimated to rise to 6 million per year by 2050 (Genant et al, 1999).

\subsubsection{Clinical Significance}

Osteoprosis is a major problem for approximately 44 million Americans, 68\% of whom are women. Half of woman with osteoporosis sustain some kind of osteoporitic fracture (Stevenson, 1990). One out of two women and one out of eight men over the age of fifty will have a fracture related to osteoporosis. The annual fracture total is approximately 1.5 million with : 300,000 hips, 700,000 vertebral fractures, 250,000 wrists, and 300,000 other fractures, such as ribs, shoulders, etc. The breakdown of these fractures can be seen in figure 1 (NIH, 2003).

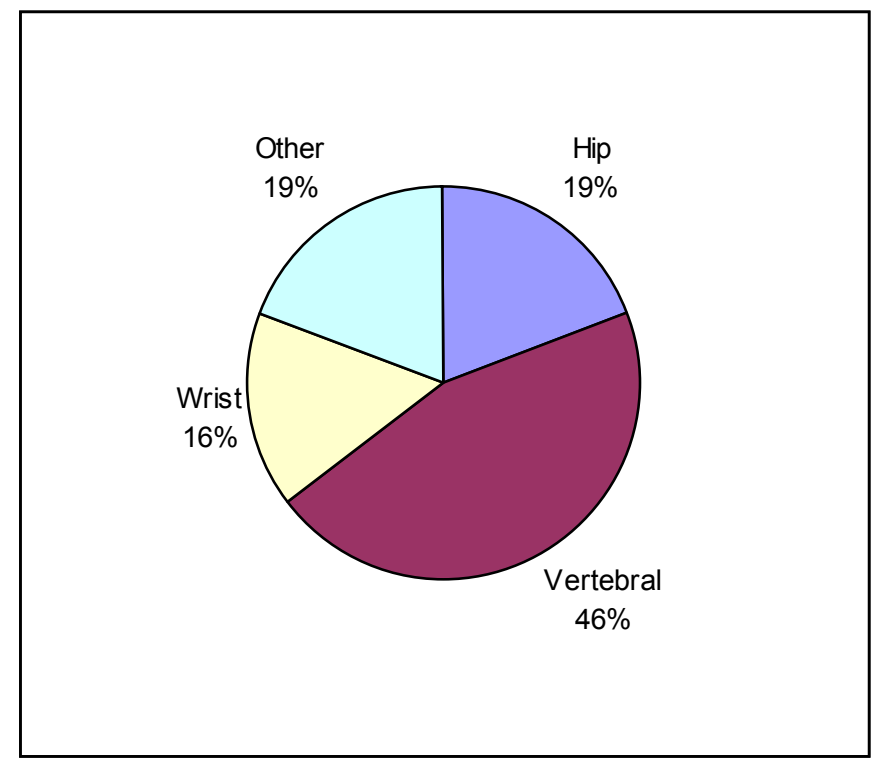

Figure 1.1.2-1: Fracture Types and Percentages Related to Osteoporosis (adapted from NIH ORBD data) (NIH, 2003)

Cortical bone fragility has been implicated in debilitating conditions such as osteoporitic fracture, fatigue fracture, stress fracture, and loosening of prosthesis, and 
the loss of cortical bone has been identified as a key feature contributing to femoral neck fracture.

Crabtree et al. (2001) concluded from a study of intracapsular hip fracture patients that generalized bone loss accounts for less than about $15 \%$ of fracture risk and that a loss of cortical bone thickness and increased intracortical porosity is the key feature to hip fracture risk.

\subsection{Objectives}

To better understand the effects of estrogen deficiency and various treatments for osteoporosis on the fracture toughness of bone, three objectives were set:

1. Perform histomorphometry to quantify bone parameters (porosisty, osteon density, osteon area, etc) for comparison.

2. Perform mechanical testing (fracture toughness and femoral neck fracture) on the bones to find strength and toughness values for comparison.

3. Compare and correlate the histomorphometric and mechanical data.

\subsection{Hypotheses}

The following hypotheses were made:

1. There is a significant difference in fracture toughness between all Ovarectomized (Ovx) and Normal specimens.

2. There is a significant difference in the fracture toughness between Ovx and Ovx with Residronate (Ovx - Ris) treatment specimens, with the Ovx-Ris specimens approaching but not reaching the fracture toughness of the Normal group. 
3. There is a significant difference in the structural properties of the femoral neck between the groups, with the values of the Ovx-Ris treatment group approaching that of the Normal group.

4. There is a significant difference in the dynamic and static histomorphometric that will correlate with the fracture toughness and femoral neck fracture values, with the Ris group approaching the values of the Normal group.

\subsection{Anatomical Background}

Bones are the main structural components of the body. They provide support for the weight of the body, resist dynamic loads caused by the movement of the body, protect the nervous system and organs, provide levers for the skeletal muscles, and are reserves for various substances necessary for bodily function, such as calcium. The skeleton does all of these things with a high level of adaptability, making the skeleton a machine of unparalleled complexity. From an engineering or design standpoint, it would be difficult to imagine creating a structure which satisfies these needs, and even more difficult to create such a structure.

Bone is a unique material. Unlike most engineering materials, it cannot be considered homogeneous, bone is often assumed to be transversely isotropic, which is similar to many composite materials. Unlike all engineering materials, it has the ability to repair damage and adapt to various loading situations, using a constant state of tearing down and renewal, through resorption and formation.

\subsubsection{Body Definitions}

It is beneficial to know some of the anatomical terms that will be used in this paper particularly in chapters 4 and 5. These terms are general directional, sectional, 
and location terms, and although they are not related to engineering, they are necessary in the study of anatomy and physiology.

Figure 1.4.1 shows the important planar definitions for the rabbit and most quadrupeds, which have some notable differences to bipeds, such as humans.

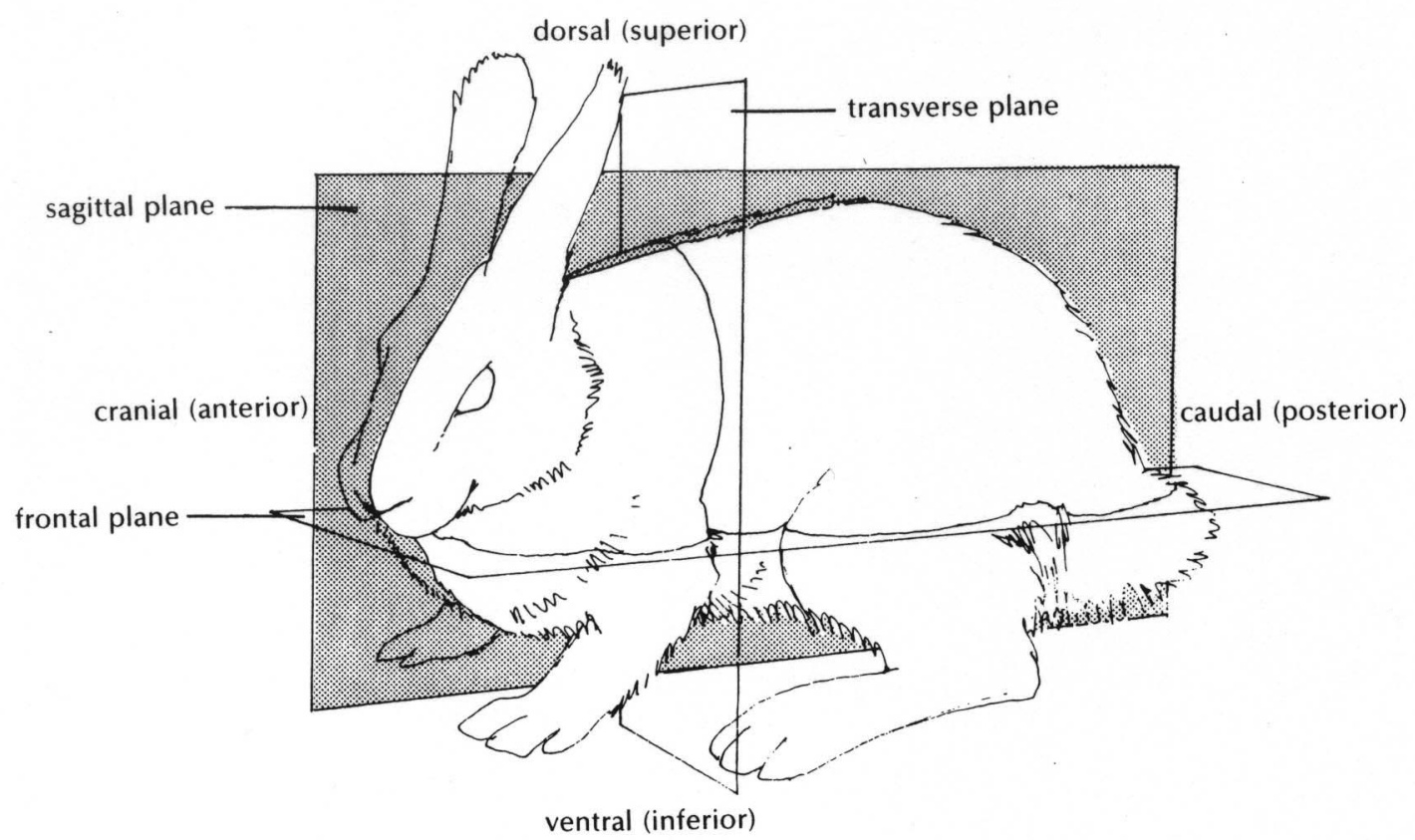

Figure 1.4.1 - 1: Schematic representation of anatomical terms for the rabbit (Wingerd, 1985).

The dorsal side is simply the back side. The reader may notice that the dorsal and superior sides are equivalent for a quadruped, but are not the same for a biped (ie humans); this may cause some confusion for those familiar with only human anatomy. The anterior (cranial), caudal (posterior), and ventral (inferior) sides may also cause confusion, because the terms are the same, as shown for a quadruped, but do not correspond for bipeds. The difficulty can be eliminated by thinking of the directions (superior, inferior, cranial, and caudal) separately from the planes (anterior, 
posterior, dorsal, and ventral). For example, dorsal means the plane of the back, and can be easily seen as the plane looking down on the top of the animal, if the animal is standing normally. The superior direction is simply that it is above another structure, this is not related to body structure, per se, and just means to be above something else. The other pairs of correlating planes and directions make sense as well, when thought of in this way.

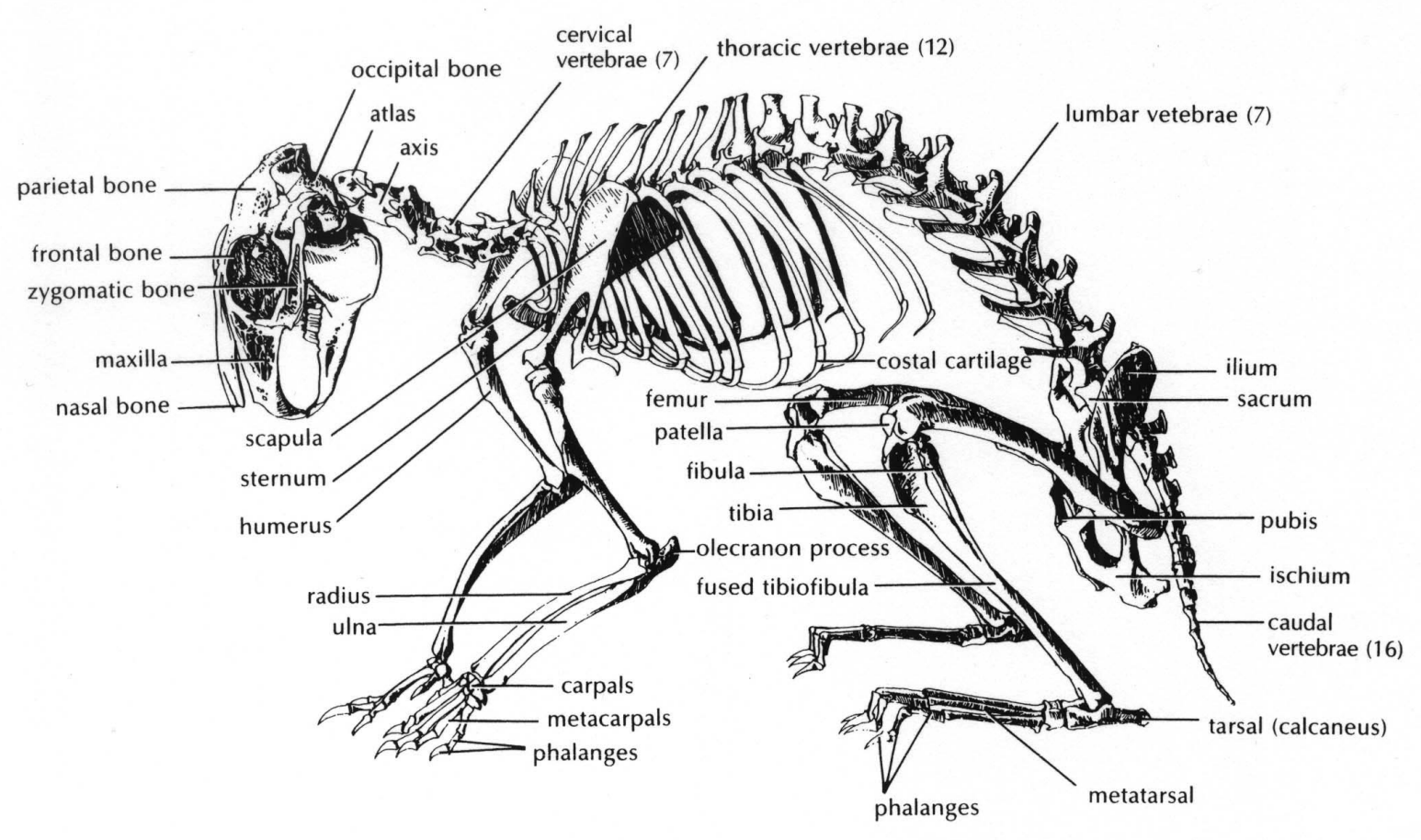

Figure 1.4.1-2: Diagram of the rabbit skeleton (Wingerd, 1985).

Figure 1.4.1-2 shows the rabbit skeleton. The bones used in this study were the tibia and femur, which are the two main long bones of the hind legs of the rabbit. The fibulas were also removed during the dissection, because unlike humans, they are fused to the tibias, but were eventually discarded during machining.

Bone anatomy necessitates the definition of more terms. This project uses the femur and tibia, so the effort of definition will focus on these. Proximal is a 
direction, relative to a particular point, going towards the midpoint of the body. By this definition, the proximal end of a long bone would be the end that is towards or closest to the midpoint, which for the femur would be the head and neck region, and for the tibia it would be the condyles that make up part of the knee. The midshaft of a long bone is the general area that is approximately halfway between the two end points of the long bone, which is often thought of as a shaft even though it does not usually have the uniform cylindrical shape associated with a shaft. The term definitions can be seen in figures 1.4.1-3 and 1.4.1-4, where the arrows are indicative of the directional definition from the midshaft.

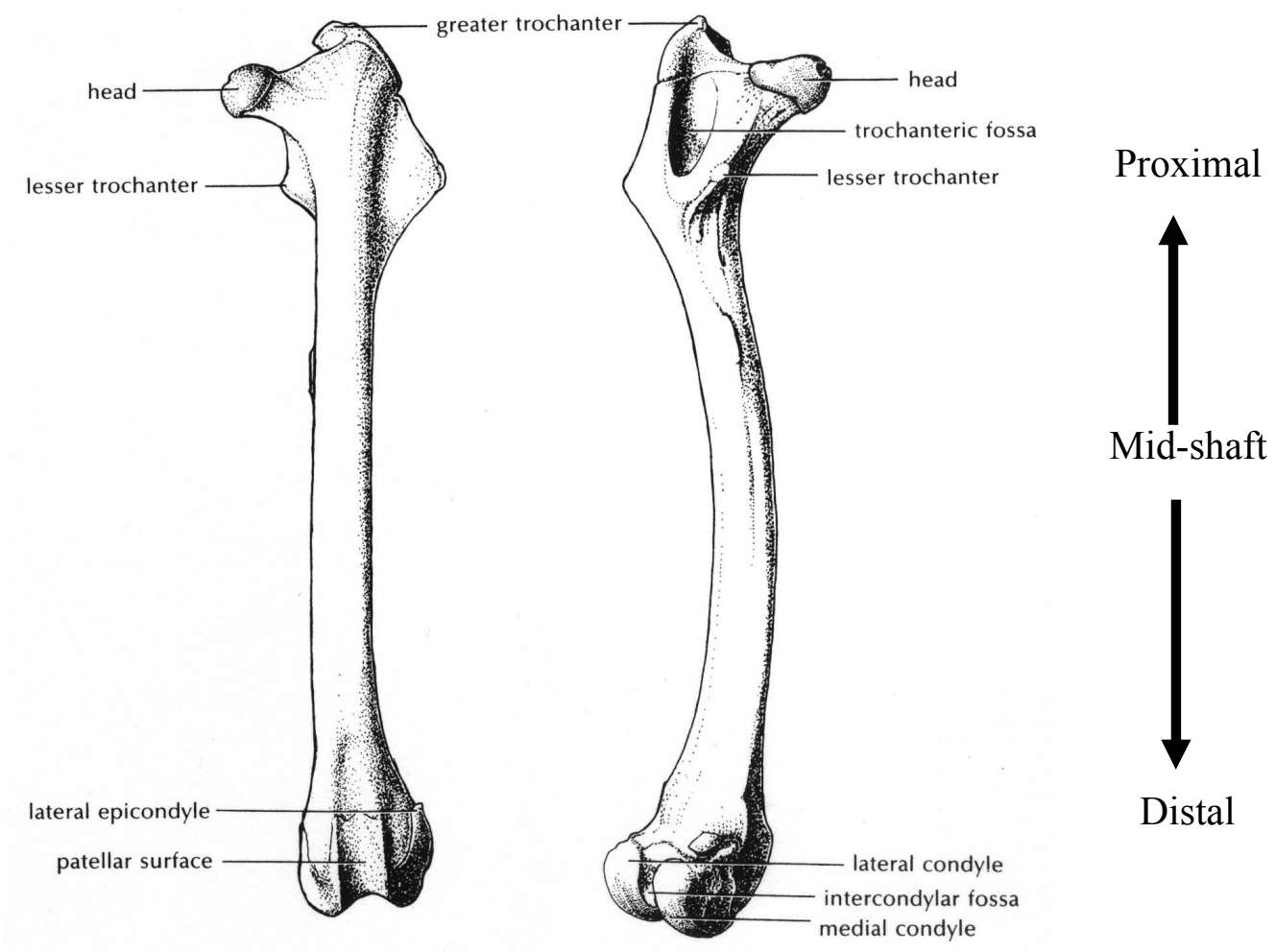

Figure 1.4.1-3: Definition of locations and Anatomy of the Femur (Wingerd, 1985) 
Figures 1.4.1-3 and 1.4.1-4 also show some of the important bony landmarks of the femur and tibia.

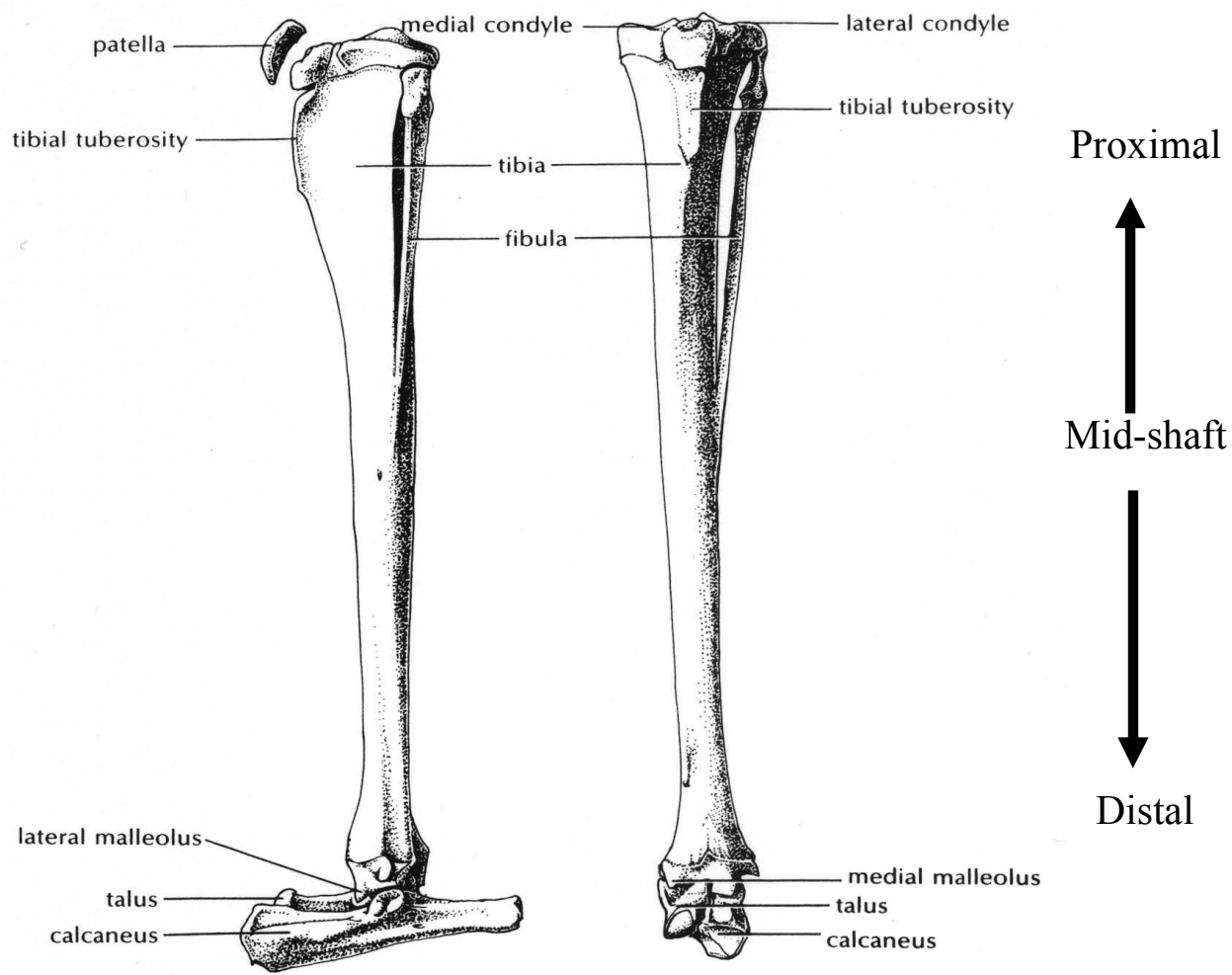

Figure 1.4.1-4: Direction and Anatomy Illustration of the tibia (Wingerd, 1985)

\subsubsection{Macrostructure of Bone}

Macroscopically bone is generally divided into two types: cortical and trabecular bone. Cortical bone is often referred to as compact bone, and trabecular bone is known as cancellous or spongy bone. The different types of structures can easily be seen in the figure 1.4.2-1, where cortical bone is the dense region and cancellous is the latticework region, that makes up most of the femoral head and neck, with a outer cortex of cortical bone, but the shaft is mainly cortical bone. 


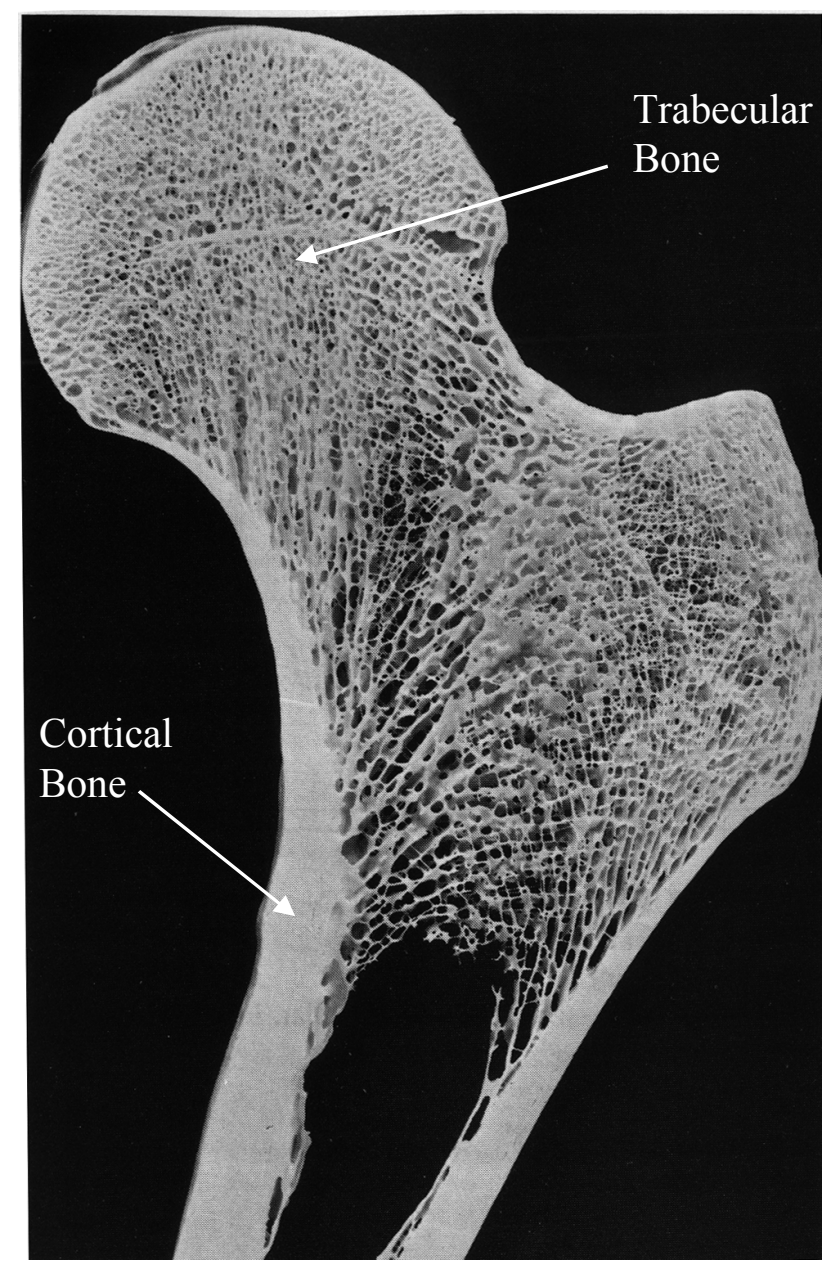

Figure 1.4.2-1: Cross-section of the Proximal Femur Showing Cortical and Cancellous Bone (Albright and Skinner, 1987, with labels added)

The structure of having a compact outer shell with an inner woven structure allowing for optimal mechanical function under loading is common in all bones. The structure of bone adapts to the loading that the bone is subjected.

\subsubsection{Microstructure of Bone}

Microscopically, two types of bone can be distinguished, woven and lamellar bone. Woven bone is characterized by an irregular array of loosely packed collagen fibrils resembling a crudely woven cloth. This type of bone is initially formed in the 
embryo and during child development, but is only found in small amounts in the adult skeleton, except under conditions of rapid bone formation, such as fracture healing and diseases such as Paget's disease. In the normal adult skeleton, both the cortical and trabecular bone is made of parallel collagen fibers, organized in a lamellar pattern.

Bone consists of two major components: the matrix of collagen fibers and four types of bone cells. The matrix is the main structural referent of the bone, which has a characteristic distribution. The outer part of the bone consists of a shell or cortex of cortical bone that generally forms the overall conformation of the bone and within this structure lays the trabecular bone.

The cortical bone is divided into three regions. The outer most region is known as periosteal bone. The middle and most dominant region is the Haversian bone, which is a region of bone containing the Haversian system, and the inner layer called subcortical bone.

Haversian bone consists of hollow cylinders made of concentric lamellae with a vascular canal in the center, which is called an osteon. The diameter of an osteon is approximately $200 \mu \mathrm{m}$ regardless of species, because the maximal transport distance for nutrients is approximately $100 \mu \mathrm{m}$.

\section{The Bone Matrix}

Bone matrix has four major molecular components: collagen, noncollagenous proteins, nonprotein organic material, and mineral crystals resembling hydroxyapatite, with the chemical structure $\mathrm{Ca}_{10}\left(\mathrm{PO}_{4}\right)_{6}(\mathrm{OH})_{2}$. 
Collagen is the most abundant organic protein making up $90 \%$ of the organic matrix. The collagen fibers are bundled into a complex three-dimensional structure similar to rope that form a lamellae with the collagen fibers running parallel, with the long axis being at right angles in adjacent lamellae. Collagen has a triple helix structure, which can be though of as like a rope, which gives bone its tensile strength.

\section{COMPOSITION OF SKELETAL CONNECTIVE TISSUES}
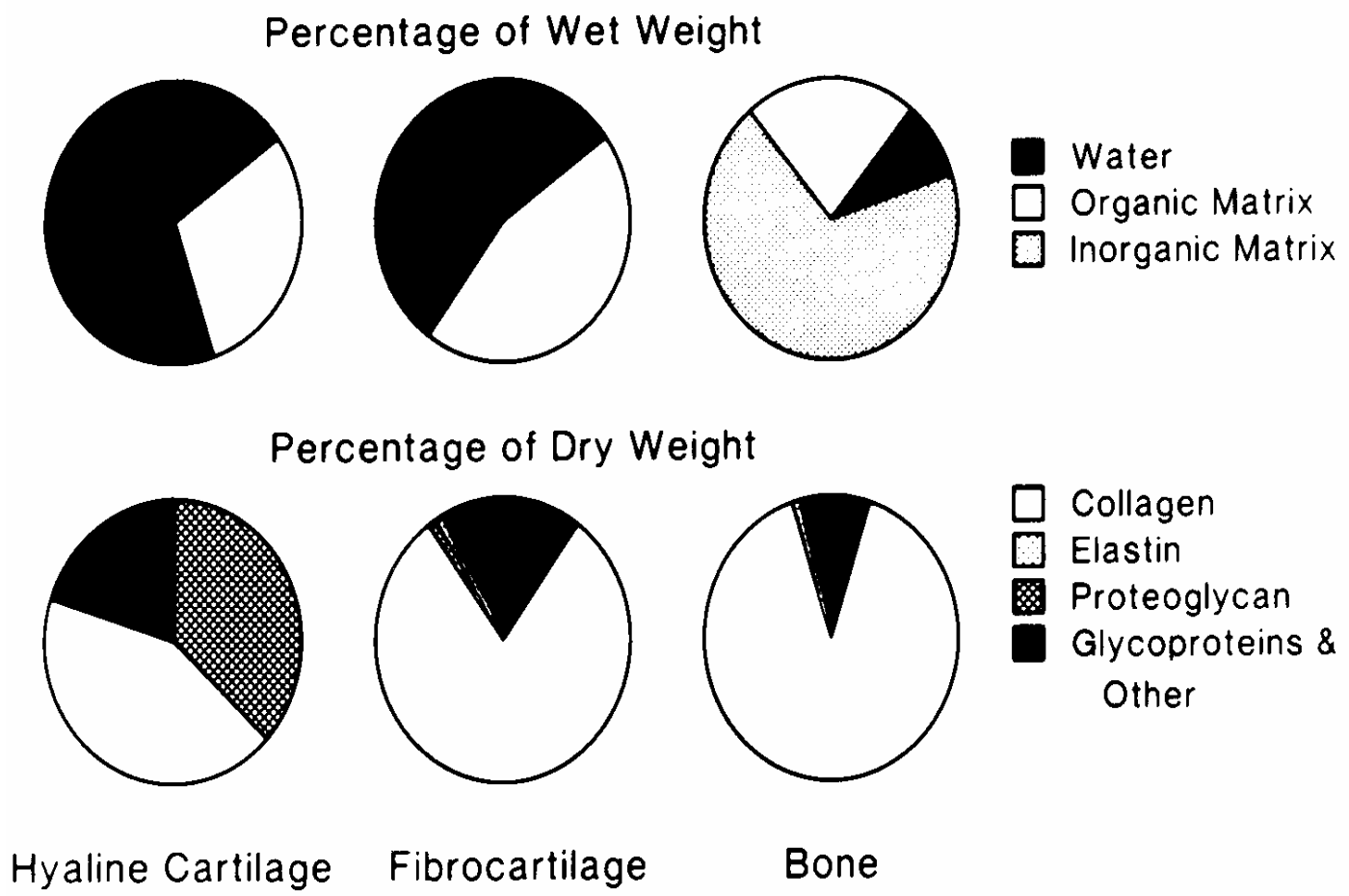

Figure 1.4.3-1: Composition of Cartilage, Fibrocartilage, and Bone (Albright, ).

The remainder of the organic matrix is closely associated with the collagen fibers and is dependent on the orientation of the collagen fibers. The noncollagenous proteins

Mineral makes up approximately $65 \%$ of the dry weight of bone, and is made of very small crystals of the dimensions $200-400$ x 35-75 x 10-40 Á in the shape of 
plates. These plates are located within and between the collagen fibers in such a way to give the bone its compressive strength and stiffness, which is similar to a chopped fiber composite.

The minerals are laid down during formation of new bone. Such substances as calcein, tetracycline, polyphosphates, and bisphosphonates have an affinity for calcium phosphate, and are laid down in areas of new bone formation. This property is what makes marking for dynamic histomorphometry possible, which will be explained in later chapters.

\section{Osteoclasts}

Osteoclasts are multinucleated cells and are known to be the primary cell responsible for bone resorption, or the breakdown of bone. The task of resorbing bone is accomplished within a closed microenvironment, which is between the cell and the bone surface, as can be seen in figure 1.4.3-2.

Osteoclasts have proton pumps on the side attached to the bone, which is called the ruffled border. The osteoclast can be thought of as an upside down cup on a saucer, which leaves a space between the bone and the cell. The proton pumps of the osteoclast pumps protons into this enclosed space, which causes an enclosed acidic region ( $\mathrm{pH}$ of approximately 4 ) that dissolves the bone matrix. The cell also pumps various enzymes into the enclosed space as well, such as cathespins, and possibly collegenase, which dissolves the collagen matrix.

There are three main ways of controlling bone resorption, which are: recruitment of new osteoclasts, lifespan of new osteoclasts, which is determined by 
apoptosis, and the regulation of the mature osteoclasts. All three of these processes seem to be influenced by cells of the osteoblastic lineage.

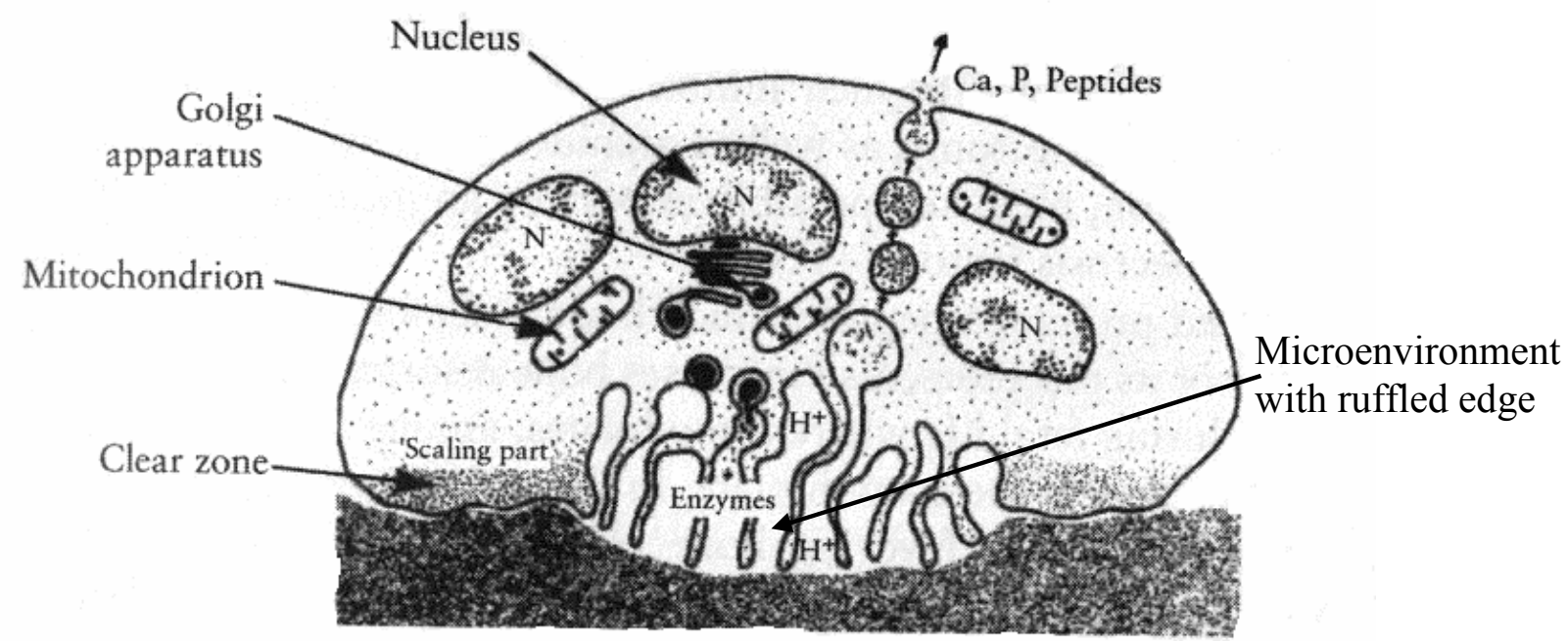

Figure 1.4.3-2: Diagram of an osteoclast (Fleisch, 2000, with additional label)

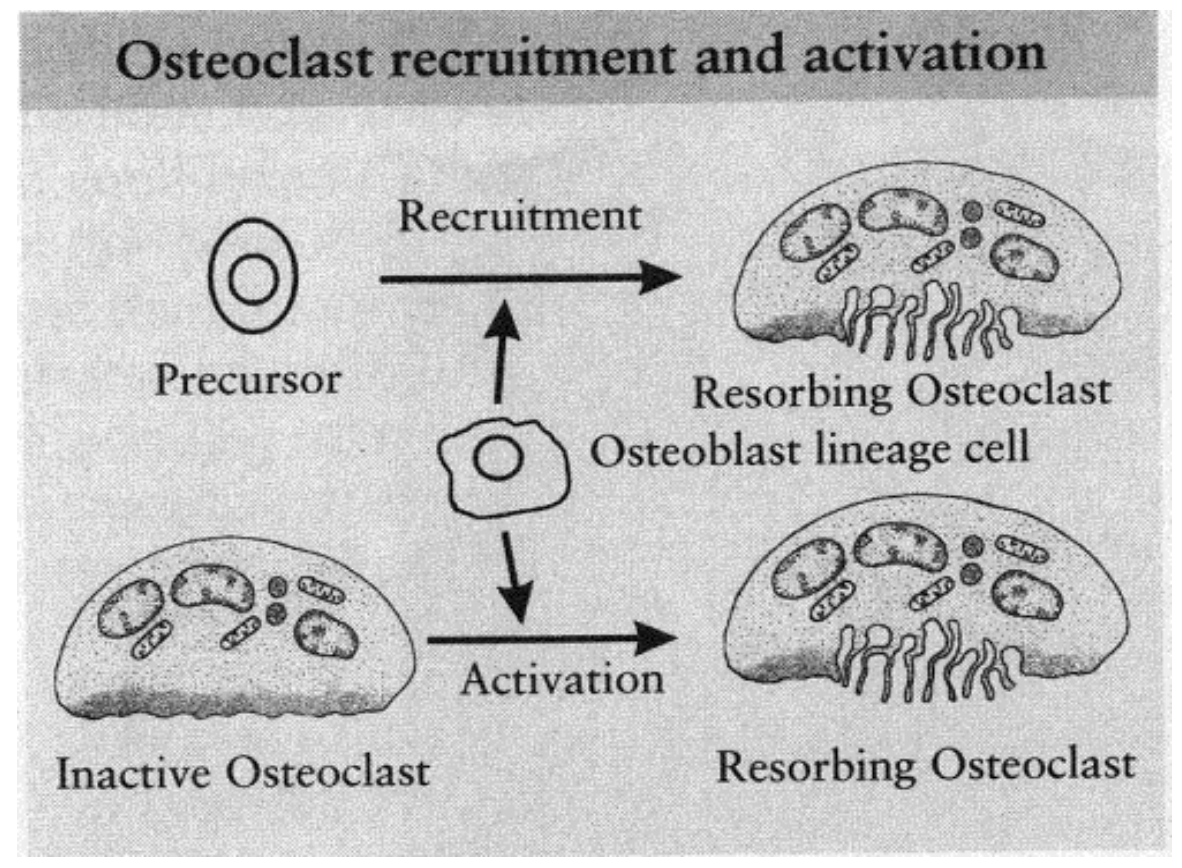

Figure 1.4.3-3: Role of Osteoblastic cells on Osteoclast's and therefore bone resorption (Fleisch, 2000). 
These cells are varied in size and are characteristically seen in lacunae of resorbed bone.

\section{Osteoblasts}

Osteoblast comes from the two Greek words osteon, which means bone, and blastos, which means germ. Osteoblasts are mononucleated cells and are primarily responsible for bone formation, or rather the synthesis of the organic components of the bone matrix (i.e. type I collagen, proteoglycans, and glycoproteins). Osteoblasts are derived from mesenchymal progenitors, and lay down the unidirectional organic matrix, which is later mineralized.

The time between the laying down and calcification steps means that there is a layer of uncalcified bone under the osteoblast. The uncalcified seam that is left by the osteoblast is thin when bone formation rate is decreased, and it is widest when mineralization is delayed.

The osteoblasts can be found on the bone surface and have the appearance of epithelium, which is why they are often classified as bone lining cells, when they are inactive.

\section{Bone Lining Cells}

Active osteoblasts and bone lining cells form a membrane on the bone surface. Bone lining cells are osteoblasts that are not actively forming bone. When the osteoblast is inactive, they are flat and found on the bone surface. The inactive osteoblasts are called bone lining cells because of the characteristic of osteoblasts appearing like epithelial cells, which are lining cells in the gastrointestinal track. 


\section{Osteocytes}

Osteocytes are the osteoblasts that have been completely embedded in the bone matrix. Osteocytes are the most abundant cell found in bone, but their exact purpose is still poorly understood. These cells are in the lacunae and are connected to each other and to osteoblasts. It is theorized that there is signaling between bone cells, and that osteocytes are the cells that sense the mechanical stimulation.

\subsection{Bone Modeling and Remodeling}

The skeleton serves many mechanical, metabolic, and protective functions. The most obvious functions are mechanical support and protection. Bones are often mistakenly thought of as dead or unchanging structures, but bone is a living, metabolically active, and highly organized tissue that is in a constant state of flux through processes of resorption and formation. The osteoblasts and osteoclasts are in opposition to each other in a cycle called the resorption/ formation cycle $(\mathrm{R} / \mathrm{F})$. The rate of these processes lends itself to this widely held misconception, because the processes are too slow, or too imbalance for them to be seen macroscopically, with the naked eye, except over a long period of time and/or some disease state.

Both cortical and cancellous bone undergoes remodeling, in which old bone is torn down or resorbed, and new bone is built of formed in its place. This process is very important in damage repair, and in keeping the skeleton strong. It is very important in the bones adaptation to loading, since the bones will reform in a new architectural formation to most optimally handle the loading environment, or the particular loading parameters present on the bone. 
In adults, bone remodeling accounts for more than $90 \%$ of normal bone turnover. In normal individuals, the remodeling space is approximately $6-8 \%$ of skeletal volume (Parfitt, 1980).

\subsubsection{R/F Balance Implications in Bone Fragility}

The resorption/ formation balance is significant in the net amount of bone mass and/or microstructructural changes, such as porosity.

Normal bone has a balance between the amount of bone being resorbed and the amount being formed, for a net change of approximately zero. As people age, the osteoclasts start to slightly outpace the osteoblasts, so skeletal mass decreases, thus fracture risk increases. Diseases such as osteoporosis are from an imbalance of this process. The $\mathrm{R} / \mathrm{F}$ balance is particularly skewed in women after menopause.

\subsubsection{Bone Mass and Bone Fragility}

Many studies have shown that bone, rather human or other animal, from disuse (paralysis, suspension, immobilization, etc.) and/or sex hormone deficiency (ovarectomy or oophorectormy) results in loss of bone mass (Smith 1989; Weinreb, 1989; Saville, 1969; Schoutens, 1984; Wronski, 1985; Okumra, 1986; Bain, 1990; Cao, 2001). Decreased bone mass in humans has been shown to be an indicator of increased fracture risk (Dempster, 1993), but Avioli (1987) has reported that 50\% of osteoporotic vertebral compression fractures have the same bone mass as normal age matched controls.

Bone mass is not the only change in bone during resorption and formation.

The architecture of the bone is also changed. Patients with osteoporotic fractures are 
found to have larger osteons with larger Haversian canals and a lower osteon density than patients without a fracture (Barth 1992). The change in structure at a microscopic level may not be seen in the current tests available for bone mineral density or bone mass testing, so a new technique is needed to test for fracture risk.

\subsection{Bisphosphonates}

Various drugs have been used for the treatment of osteoporosis. Two of the major categories of treatment are Parathyroid Hormone, Hormone Replacement Therapy, and Bisphosphonates. This project focuses on the use of bisphosphonates, because of their widespread use, FDA approval for osteoporosis prevention and treatment, and the proven safety and effectiveness in clinical trials.

The first report of the biological characteristics of bisphosphonates appeared in 1968, from earlier studies of inorganic pyrophosphates (Fleisch, 2000).

Bisphosphonates, which were formerly called diphosphates, are analogs of pyrophosphate, but has a carbon joining the two phosphors instead of an oxygen, as in the pyrophosphate. The carbon is bonded to two other groups to fill it octet and has the form shown in figure 1.6.3-1. The two side groups (R1 and R2) are what make each bisphosphonate unique; figure 1.6.3-2 shows the side groups of the FDA approved drugs, and their corresponding names and manufactures.

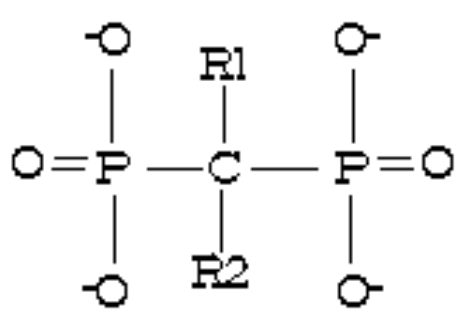

Figure 1.6.3-1 General Chemical Structure 
Table 1.6.3-1: FDA approved bisphosphonates for the treatment and prevention of osteoporosis in postmenopausal women and their chemical structure (Adapted from Fleisch, 2000).

\begin{tabular}{|c|c|c|c|}
\hline Name & $\begin{array}{l}\text { Brand } \\
\text { Name }\end{array}$ & Manufacture & Chemical Structure \\
\hline Alendronate & Fosamax & $\begin{array}{l}\text { Ambiogen; } \\
\text { Merck, } \\
\text { Sharp \& } \\
\text { Dohme }\end{array}$ & 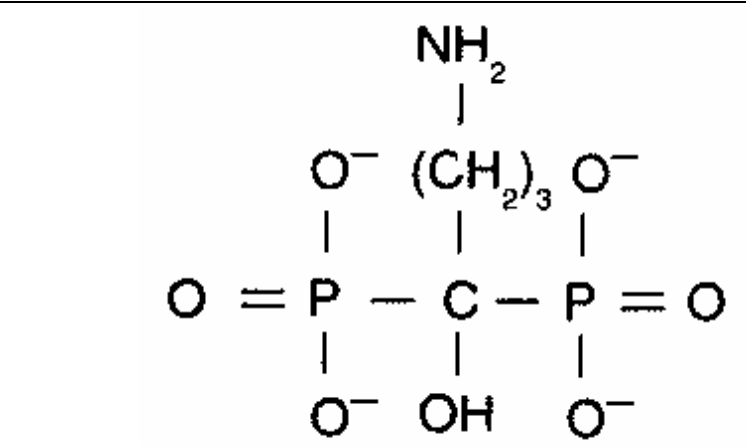 \\
\hline Residronate & Actenol & $\begin{array}{l}\text { Proctor \& } \\
\text { Gamble }\end{array}$ & 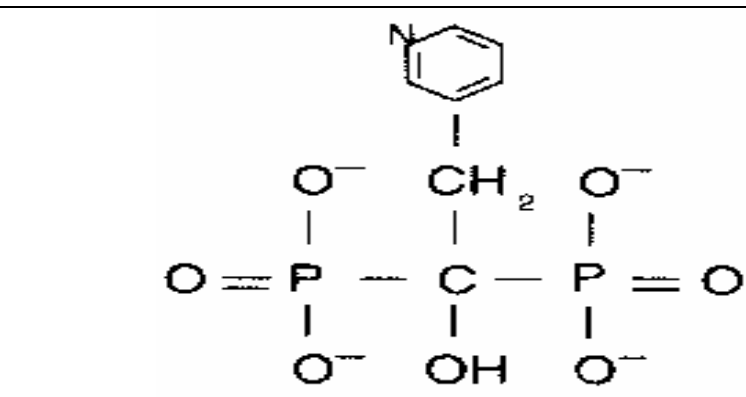 \\
\hline
\end{tabular}

Bisphosphonates are commonly used in the treatment of osteoporosis, glucocorticoid-induced osteoporosis, hypercalcemia of malignancy, Paget's disease, heterotopic ossification, and osteolytic bone metastases of breast cancer or multiple myeloma.

There are currently only two bisphosphonates that are FDA approved for the treatment of osteoporosis, which are Alendronate and Risedronate, there are four other bisphosphonates that are also commonly used in the treatment of bone loss, but are not FDA approved for osteoporosis treatment.

One drug that is FDA approved for the treatment and prevention of osteoporosis in postmenopausal women is risedronate, which is the type of 
bisphosphonates used in this study. Several studies have shown that residronate is effective in increasing bone mineral density (BMD), as shown in tables 1.6.3-2. Several studies have shown the effectiveness of Alendronate and are included in table 1.6.3-3 for the purpose of completeness.

Table 1.6.3-2: Effects of Risedronate Treatment on BMD (adapted from Cummins, et al, with additions)

\begin{tabular}{|c|c|c|c|}
\hline Author & $\mathrm{N}$ & \multicolumn{2}{|c|}{$\begin{array}{l}\text { Mean Increase (\%) in BMD in Treatment } \\
\text { Group vs. Placebo }\end{array}$} \\
\hline Harris, et al., 1999 & 2458 & $\begin{array}{l}\text { L-spine: } \\
\text { Femoral Neck: }\end{array}$ & $\begin{array}{l}4.4 \\
2.8\end{array}$ \\
\hline Reginster, et al, 2000 & 1226 & $\begin{array}{l}\text { L-spine: } \\
\text { Femoral Neck: }\end{array}$ & $\begin{array}{l}5.9 \\
3.1\end{array}$ \\
\hline Geusens, et al. 1999 & 9497 & $\begin{aligned} & \text { L-spine: }(2.5 \mathrm{mg} \text { dose }) \\
&(5.0 \mathrm{mg} \text { dose }) \\
& \text { Femoral Neck: }(2.5 \mathrm{mg} \text { dose }) \\
&(5.0 \mathrm{mg} \text { dose })\end{aligned}$ & $\begin{array}{l}5.37 \\
7.02 \\
2.11 \\
3.24\end{array}$ \\
\hline Fogelman, et al, 2000 & 543 & $\begin{aligned} & \text { L-spine: }(2.5 \mathrm{mg} \text { dose }) \\
&(5.0 \mathrm{mg} \text { dose }) \\
& \text { Femoral Neck: }(2.5 \mathrm{mg} \text { dose }) \\
&(5.0 \mathrm{mg} \text { dose })\end{aligned}$ & $\begin{array}{l}1.4 \\
4 \\
1.9 \\
2.3\end{array}$ \\
\hline Mortensen, et al, 1998 & 111 & $\begin{array}{c}\text { L-spine: (5 mg cyclic dose) } \\
\text { (5 mg daily dose) }\end{array}$ & $\begin{array}{l}2.7 \\
5.7\end{array}$ \\
\hline Fleisch, 2000 & large & L-spine: (5 mg daily dose) & $4.3-5.8$ \\
\hline
\end{tabular}


Table 1.6.3-3: Effects of Alendronate on BMD in Postmenopausal Woman (adapted from Cummins, et al, with additions)

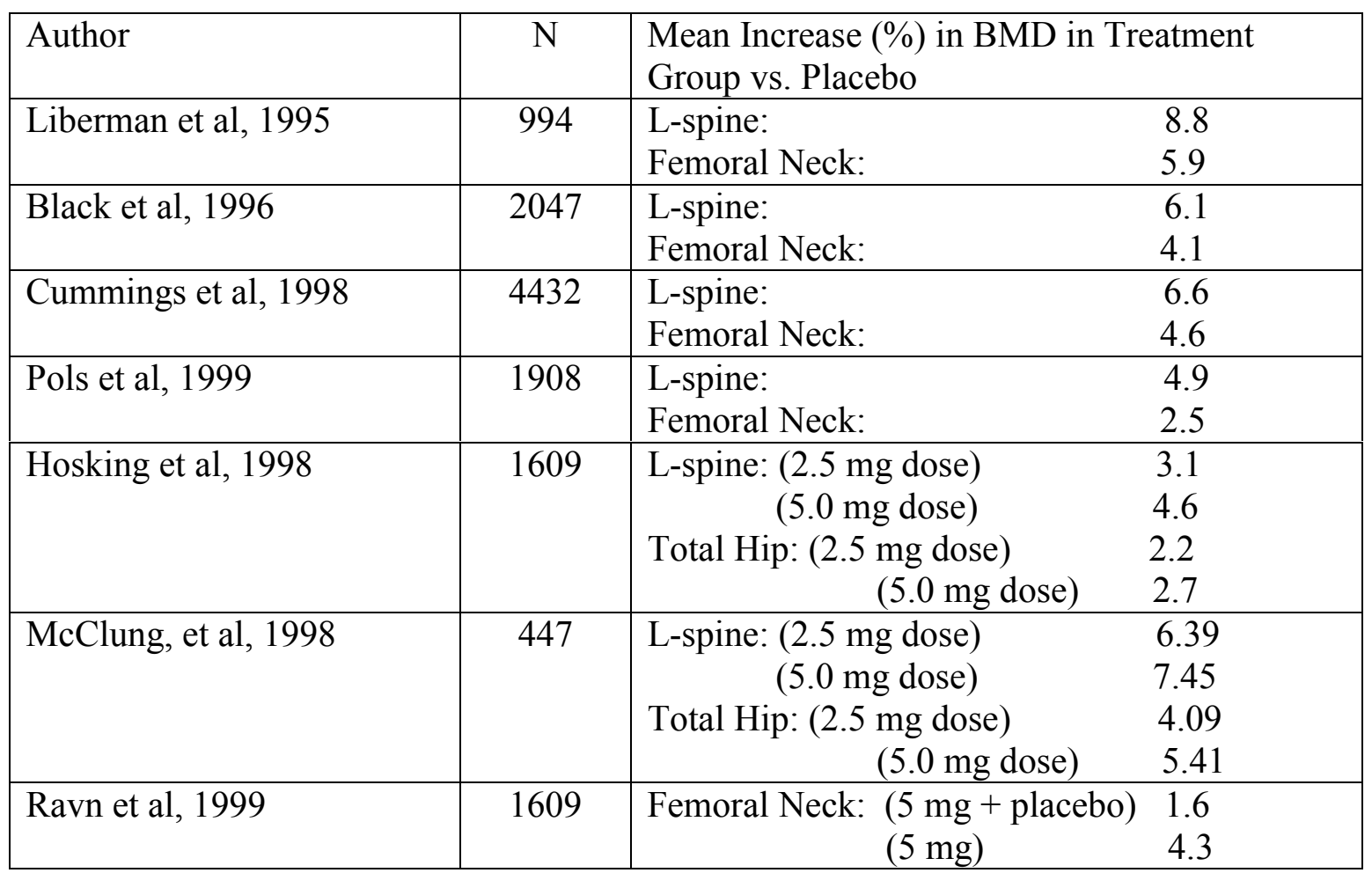

The action of Bisphosphonates on the process of bone resorption and formation is not well known, but there are theories of how the bisphosphonates effect the osteoclasts, which can be regulated by four ways: inhibition of recruitment, inhibition of osteoclast adhesion, shortening of the osteoclast lifespan, and/or inhibition of the osteoclast activity.

\subsection{Validity of the Animal Model}

\subsubsection{Introduction}

Animals are invaluable assets in medical research, since they allow for the study of medical and biological processes in a living system without harming humans. The use of animals allows for the study of things that are impossible, immoral, or unethical to study in humans. For example, chemical exposures are often studied using animals, which 
would be considered reprehensible to conducting on humans and would be similar to some of the crimes against humanity committed by the Nazis during World War II.

The type of study being undertaken often makes the use of animals necessary, but great care must be taken in the selection of the animal model and the interpretation of these models.

\subsubsection{Interpretation of Animal Model Results}

Animal models, no matter how well selected, are still just models. A model, by definition, is only an approximation of the phenomenon that is desired to be studied. Care and intelligence should be used in the interpretation and implementation of results derived from an animal model for applications to humans.

\subsubsection{Selection of an Animal Model}

Care must be taken in the selection of the model, because animal physiology is often different from that of humans, and the effect that is desired to be studied in humans may be very different in animals. A simple example of this would be the attempted use of a reptile model for the study of body temperature change in humans with cold exposure. A reptile does not have a steady internal body temperature, and has no regulation mechanism, but humans do, so the reptile model would be unable to model the human phenomenon, because the mechanism desired for study, does not exist in the model. To be able to select an effective animal model, knowledge of the phenomenon in humans and the similar phenomenon in animals must be known, or some knowledge of the mechanism must be known before the experiment can begin. 
Many studies (biochemical and radiodensiometric) have established that disuse (immobilaztion, paralysis, and weightlessness), and sex hormone deficiency causes loss in bone mass (Nestle, 2000; Li, 2001; Yang, 1997; Bain and Rubin, 1990; Smith and Gillian, 1989; Weinreb, et al., 1989; Wronski et al., 1985; Okumura, et al., 1986; Schoutens, et al, 1984; Saville, 1969; Muhlbaur, et al 1971).

This study used a sex hormone deficient rabbit model that has been shown to have the desired biological effects on bone that we wish to study, and the 140 day duration will allow for two full remodeling cycles, which should allow sufficient time for the observation of change in fragility, if any, with treatment (Mashiba et al., 2001). 


\section{CHAPTER 2: FRACTURE TOUGHNESS OF BONE}

\subsection{Bone as an Engineering Material}

Bone is an anisotropic material. The material properties depend on several factors, such as microstructure (Wagner and Weiner, 1992), density (Behiri and Bonfield, 1984) and orientation (Pope and Outwater, 1974). Correlations between strength and fracture toughness, one cannot be predicted from the other (Zioupos and Currey, 1998).

Bone is often thought of as a composite material. A composite is a material that has at least two distinct materials or phases (matrix and fiber), and bone is often thought of in this way, because of the nature of the collagen fibers and minerals.

\subsection{Introduction to Linear Elastic Fracture Mechanics (LEFM)}

Linear Elastic Fracture Mechanics (LEFM) is assumed valid when the plastic deformation around the crack tip is small compared to the crack length. When this condition is violated other methods of analysis such as Elastic Plastic Fracture Mechanics (EPFM). The test specimen must be designed such that this condition is met for the material being tested.

Fracture toughness is the measure of a damaged material to resist the propagation of the crack or damage. This is a good measure for bone, because bone is damaged by its very nature. This is because of the modeling and remodeling cycles that cause the lacunar structure, which would be called damage in an engineering structure. Fracture toughness analysis is conducted using an energy balance approach or a stress field analysis. 


\subsubsection{Energy Balance Approach}

The key idea to this approach is that a crack will only grow when there is sufficient potential energy in the material to overcome the resitance of the material. As the crack extends there is a decrease in elastic strain energy within the stressed specimen. The total energy, $\mathrm{U}$, can be described by the following equation:

$$
U=U_{o}+U_{a}+U_{\gamma}-F
$$

where $U_{o}$ is the elastic energy of the loaded uncracked plate, $U_{a}$ is the internal strain energy, $\mathrm{U}_{\gamma}$ is the elastic surface energy, and $\mathrm{F}$ is the work done by the external force.

\subsubsection{Stress Analysis Approach}

This technique, as the name implies, analysizes the stresses in the vicinity of the crack tip. The maximum stress intensity at the crack tip before crack extension is the critical stress intensity factor and is denoted by $\mathrm{K}_{\mathrm{c}}$. The stress ahead of the crack tip in linear elastic materials is described by:

$$
\sigma_{i j}=\frac{K}{\sqrt{2 \pi r}} f_{i j}(\theta)
$$

where $r$ is the radial distance from the crack tip and $\theta$ is the polar direction from the crack tip. As $r$ increases to $r>>$, the stress becomes zero.

For thicknesses smaller than $3 \mathrm{~mm}$ a linear relationship exists between $\mathrm{K}_{\mathrm{IC}}{ }^{2}$ and $\mathrm{G}_{\mathrm{IC}}$ (Wright and Hayes, 1977; Behiri and Bonfield, 1984). $\mathrm{K}_{\mathrm{IC}}$ and $\mathrm{G}_{\mathrm{IC}}$ are generally considered to be equivalent measures of fracture toughness, $\mathrm{K}_{\mathrm{IC}}$ reaches a constant value for certain thicknesses, but $\mathrm{G}_{\mathrm{IC}}$ continues to decrease with increasing thickness for the bovine tibia (Norman, et al 1995b). The lack of a shown constant value for $\mathrm{G}_{\mathrm{IC}}$ in cortical bone with thickness makes $\mathrm{K}_{\mathrm{IC}}$ an attractive test parameter; 
even though $\mathrm{G}_{\mathrm{IC}}$ has been predicted to be a better indicator of composite, such as bone, fracture toughness (Grootenboer and Weersink, 1982).

\subsection{Introduction to Fracture Toughness Testing (Stress Analysis Approach)}

Fracture toughness has become a very important field in engineering. This field analyzes materials and structures that are already built, and may not have the ideal material and structural properties that were present when the structure was first made. A classic example of fracture toughness analysis is the cracked bridge problem.

A mechanics of materials approach to the analysis of a flaw is to just model the material as if it were a perfect material, only weakened by some factor. This is often a good means of modeling, but a danger inherent in cracks is the potential for the crack to propagate suddenly and uncontrollably, particularly in brittle materials.

Bone by its very nature, from an engineering standpoint, fits the concept of being a "damaged" material, because the bone is under a constant state of crack growth and crack repair.

\subsubsection{Modes of Testing}

There are three modes of loading, which can be applied singly or in combination to a body, labeled as modes I, II, and III. Mode I is also known as the opening mode, in which the crack propagates perpendicular to the applied load. Mode II is the sliding of one of the crack faces with respect to the other, which is why it is also known as the shear mode. Mode III is also known as the tearing mode, since is it similar to the tearing of a piece of paper, and is valuable in the measure of resistance to out-of-plane shear. 
Mode I fracture toughness testing was the focus of this paper, so more detail will be given for this type.

There are several orientations that the fracture toughness specimen can be taken from the specimen. The various orientations are significant in bone, because of the linearly isotropic material properties of bone. Behiri and Bonfield (1989) using bovine bone, and Norman, et al (1996) using human bone showed that the crack will propagate in the longitudinal direction regardless of the loading direction, which would imply that bone is less tough in the longitudinal direction, which is consistent with the composite theory of bone and the orientation of the collagen fibers. The shear cracks has been observed to propagate between the lamellae, along the cement lines (Saha, 1977; Vashisth, 1997).

\subsubsection{Fracture Mechanics of Composite Materials}

Fracture in composite materials is different than in an isotropic material, where the crack will only grow in size. The fracture of composite materials depends on the properties of the phases and also the interface between the phases. The fracture can depend on any of these properties, or a combination of all of them.

\subsubsection{Specimen Dimensions}

The specimen dimensions are very important, since $\mathrm{K}$ is thickness dependent, with $\mathrm{K}$ increasing as the thickness increases, to a maximum and then begins to decrease with increasing thickness. The limiting value of $\mathrm{K}$ at plain strain is a property independent of size and geometry, which is known as $\mathrm{K}_{\mathrm{C}}$, also known as fracture toughness or stress intensity factor. $\mathrm{K}_{\mathrm{C}}$ uniquely characterizes the crack tip conditions, as long as the plastic zone is small. 
$\mathrm{K}_{\mathrm{IC}}$ has been shown to linearly increase with increasing width in compact tension specimens machined from bovine bone (Bonfield, et al 1985). $\mathrm{K}_{\mathrm{IC}}$ has also been found to be independent of thickness for $1.85 \mathrm{~mm}-3 \mathrm{~mm}$ (Wright and Hayes, 1977) and for $0.5 \mathrm{~mm}-2 \mathrm{~mm}$ (Behiri and Bonfield, 1984), which allows for some margin of error in machining of specimens. Although it $\mathrm{K}_{\mathrm{IC}}$ is independent of the specimen thickness at certain ranges, plain strain is achieved at the larger thicknesses, so bone fracture toughness values from the literature, and this paper, can not generally be represented by plain strain fracture toughness. Norman, et al in 1991 determined that the minimum thickness for a $17.5 \mathrm{~mm}$ x $16.8 \mathrm{~mm}$ CT specimen to achieve plane strain conditions for bovine bone was $7 \mathrm{~mm}$, which is difficult to achieve in most animals and in humans.

The compact tension specimen must meet some dimensional requirements to have a valid test. According to ASTM E 399 recommendations, the dimensions should meet the following:

$$
\begin{aligned}
& 0.45 \leq a / W \leq 0.55 \\
& B,(W-a) \geq 2.5\left(\frac{K_{Q}}{\sigma_{Y S}}\right)^{2}
\end{aligned}
$$

The CT specimens were machined using the same proportions as those described by Norman, et al. (1996), with B equal to $0.5 \mathrm{~mm}$ and $\mathrm{W}$ being approximately $5 \mathrm{~mm}$, and the crack length a is $2 \mathrm{~mm}$ long. 


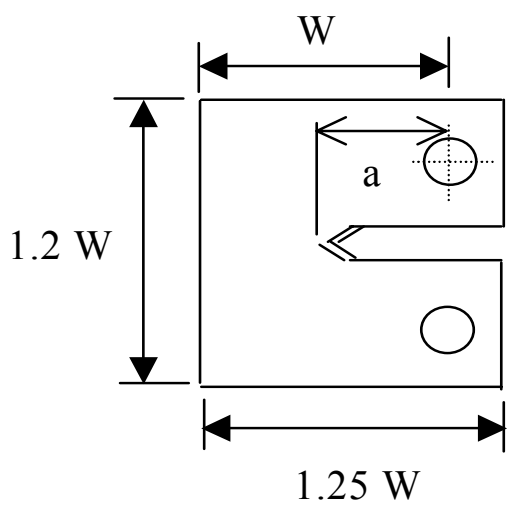

Figure 2.3.3-1: Schematic of the Compact Tension (CT) specimen.

Although fracture toughness testing for bone may not satisfy the reguirous requirements laid out above for plain strain fracture toughness, fracture toughness is still useful in comparisons within groups.

\subsubsection{Stress Analysis Calculations}

There are three modes of testing, therefore there are three stress intensity values that depend on the type of testing employed. These three stress intensity values are denoted in the literature as $\mathrm{K}_{\mathrm{k}}$, where $\mathrm{k}$ is a I, II, or III depending on the mode of testing used.

The stress intensity value, $\mathrm{K}$, is the fracture toughness parameter of the stresses around the crack tip. The testing used in this experiment was mode I and the mode I stress intensity factor can be calculated from equation 1.

$$
K_{I C}=\frac{P_{Q}}{B \sqrt{W}} f\left(\frac{a}{W}\right)
$$

Where a is the length of the chevron from the crack tip to a line connecting the two holes, $\mathrm{W}$ is the linear length from the holes to the end of the specimen past the tip, $\mathrm{B}$ 
is the thickness of the specimen, $\mathrm{f}(\mathrm{a} / \mathrm{W})$ is a dimensionless geometric property called the shape factor. The shape factor can be calculated using equation 2 .

$$
f\left(\frac{a}{W}\right)=29.6\left(\frac{a}{W}\right)^{0.5}-185.5\left(\frac{a}{W}\right)^{1.5}+655.7\left(\frac{a}{W}\right)^{2.5}-1017\left(\frac{a}{W}\right)^{3.5}+638.9\left(\frac{a}{W}\right)^{4.5}
$$

The load $\mathrm{P}_{\mathrm{Q}}$ is found from the analysis of the test results. The results are plotted on a graph of load versus displacement, as shown in figure 2.3.4-1.

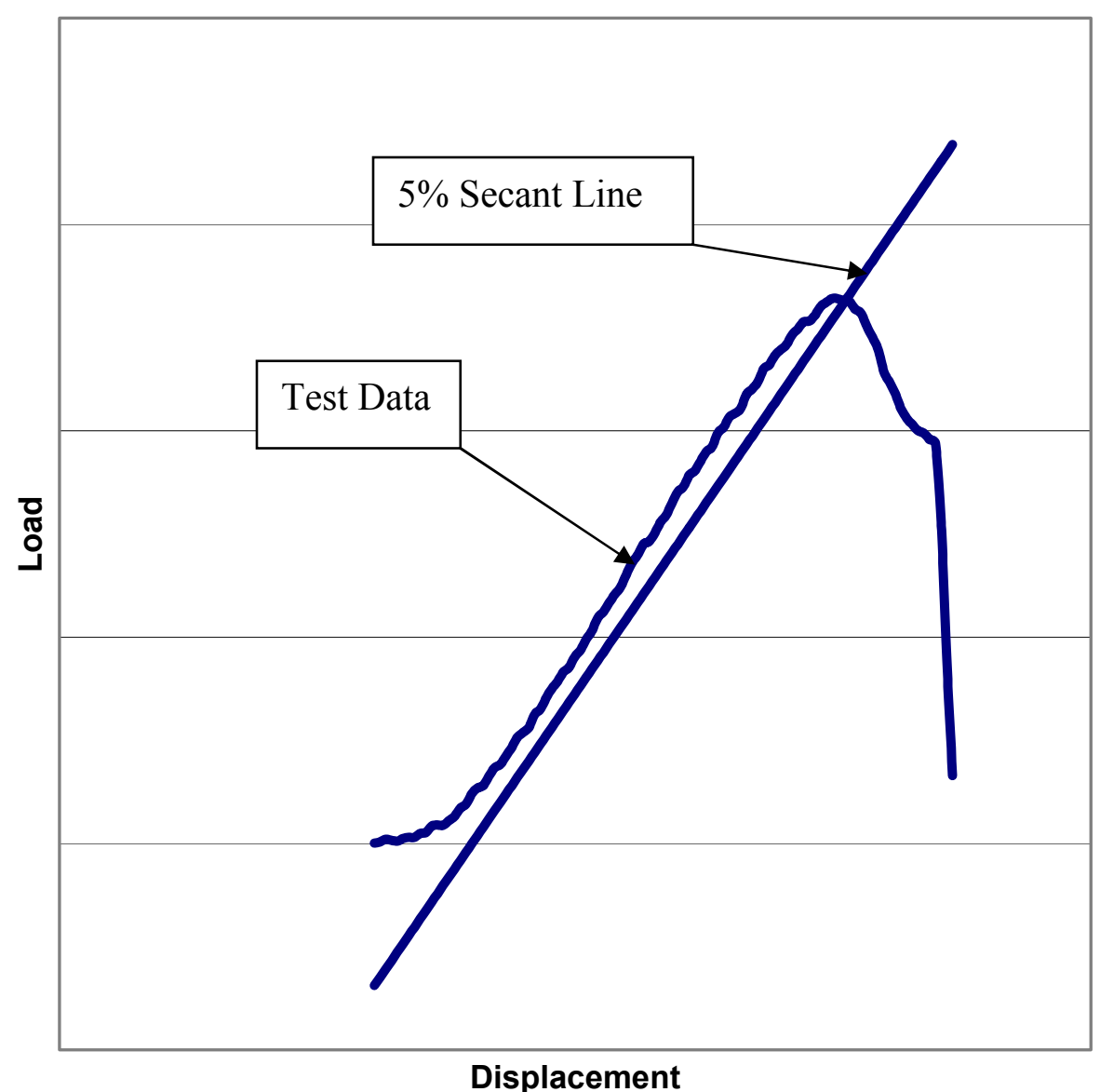

Figure 2.3.4-1: Fracture toughness test results plots with $5 \%$ secant line plotted.

The slope is found for the elastic portion, linear portion, of the graph. A 5\% secant line is drawn from the linear portion of the graph, to insure that the plane strain condition is maintained. After the line is drawn, the intersection between the line and 
the test results is the $\mathrm{P}_{5}$ value, which if it meets the following conditions is used as $\mathrm{P}_{\mathrm{Q}}$ in the equation above. $\mathrm{P}_{\mathrm{Q}}$ must meet the condition of:

$$
P_{\max } \leq 1.10 P_{Q}
$$

This condition can be seen in figure 2.3.4-2, when the 5\% secant line is plotted.

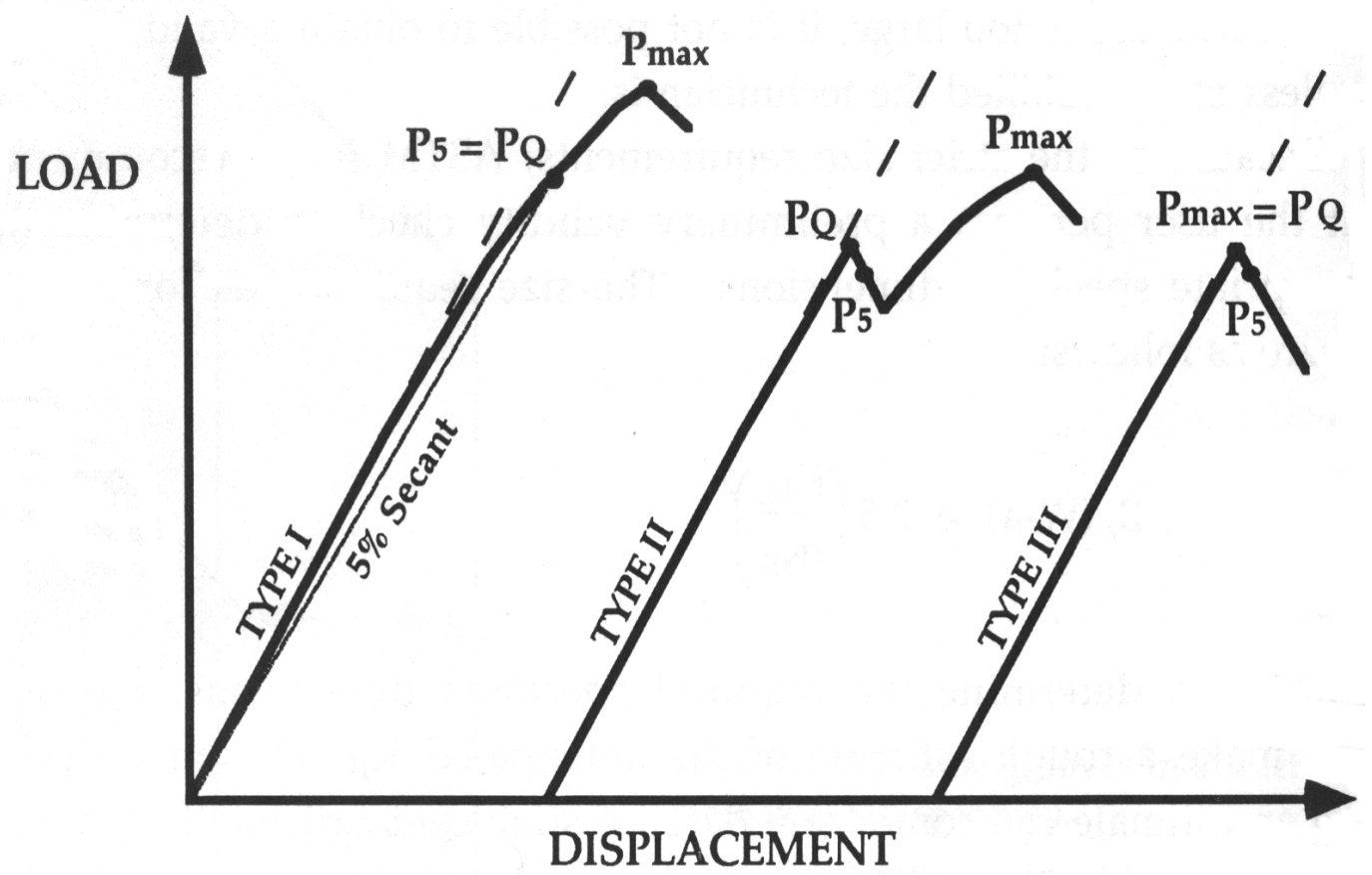

Figure 2.3.4-2: Fracture toughness test result analysis, showing the three possible outcomes of the $5 \%$ secant line being plotted on the graph (Anderson, 1991).

If $\mathrm{P}_{5}$ occurs after $\mathrm{P}_{\max }$, as in Type III in figure 2.3.4-2, $\mathrm{P}_{\max }$ is used to satisfy the condition of stress at the initiation of the crack, and using this $\mathrm{P}_{5}$ would underestimate the fracture toughness of the material. If the test data shows a pronounced spike, as in Type II in figure 2.3.4-2, and then a decrease before continued increase, the value as the top of this spike is used as the $\mathrm{P}_{\mathrm{Q}}$ value, since the equation is concerned with the initiation of the crack, which would has occurred around this point, and not at the 
point found by $\mathrm{P}_{\max }$ or the $5 \%$ secant line. If $\mathrm{P}_{5}$ occurs as shown in Type I in figure 2.3.4-2, than this value is used as $\mathrm{P}_{\mathrm{Q}}$

Another property of fracture toughness testing that is analyzed is the compliance, which is the inverse of the slope of the linear portion of the stress versus displacement graph of the test values.

\subsection{Specimen Orientation}

Bone properties are directional dependent, so the orientation must be given special consideration. ASTM defines the crack direction as shown in figure 2.4-1.

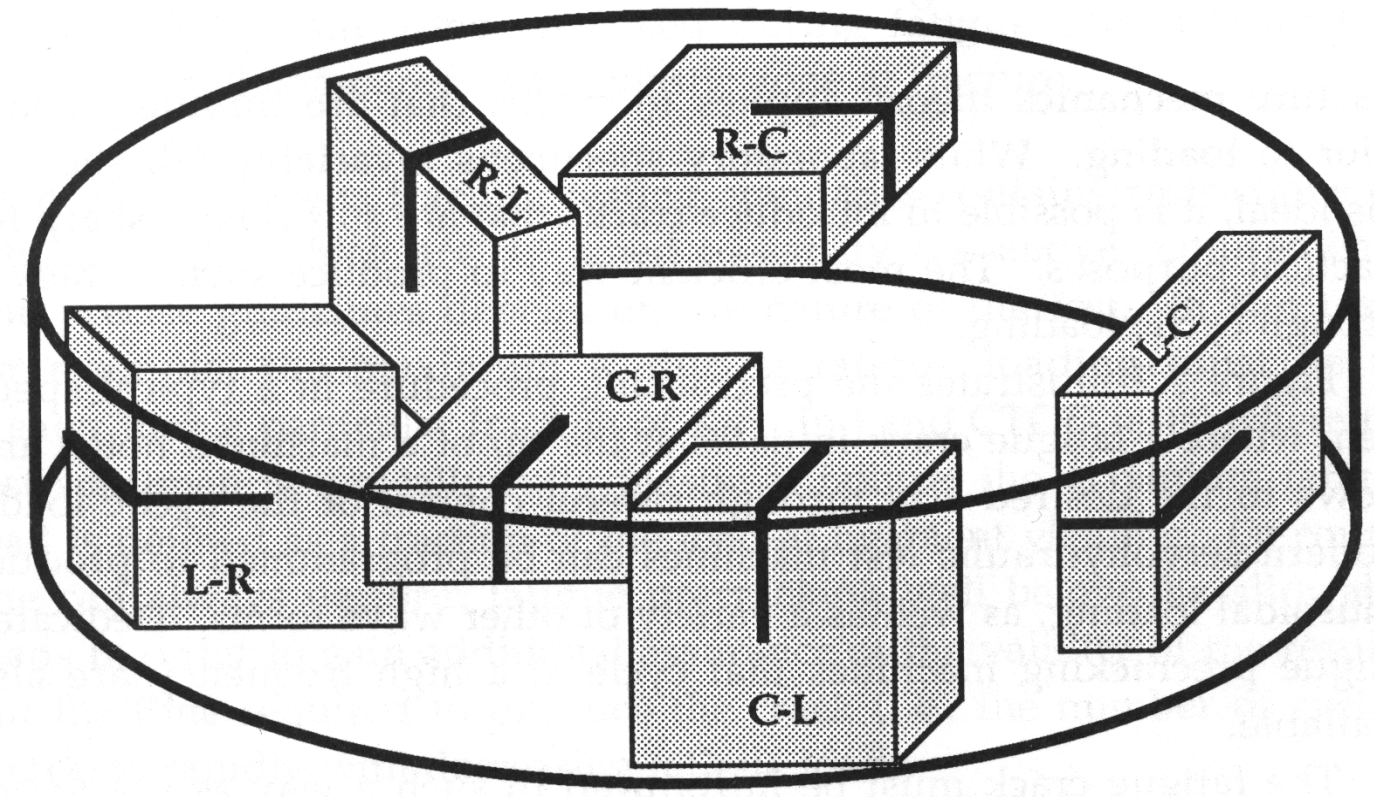

Figure 2.4-1: Crack direction definition for cylindrical geometries (ASTM, 1989; Anderson, 1991).

Some literature values do not define the directions as shown in figure 2.4-1, so care must be used in deciphering the type of test used. Using the above definition, the 
long axis would correspond to the longitudinal direction or $\mathrm{L}$ in the above figure. Fracture toughness specimens in this study were from a C-L orientation.

Cracks in ungrooved specimens tend to propogate in the longitudinal direction reguarless of the loading direction (Behiri and Bonfield, 1989), which would imply that bone is less tough in this direction. To overcome the tendency for the crack to propagate in the longitudinal direction, grooved speciemens were introduced to direct the crack. Experiments using grooved bovine tensile speciemens showed that KIC was the greatest transverse to the bone's long axis followed by cracks $15 \mathrm{o}$ to the long axis with $\mathrm{KIC}$ for the longitudinal $\left(0^{\circ}\right.$ from the long axis) being the lowest (Behiri and Bonfield, 1989).

\subsection{Tibial Fracture Toughness Values from the Literature}

The fracture toughness of bone has been studied by several researchers (Table 2.4-1), but the particular effects of treatment on the fracture toughness are not known, which is the purpose of this study. 
Table 2.4-1: Stress Concentration Factors for the Literature for the Tibia (Adapted from Yeni, 1998)

\begin{tabular}{|c|c|c|c|c|c|}
\hline Author(s) & Species & Experiment & Measurement & Direction & Loading Rate \\
\hline $\begin{array}{c}\text { Bonfield \& Datta } \\
(1974)\end{array}$ & Bovine & Center Notched Shock Tube & $\mathrm{Kc}=0.23$ & Longitudinal & $\sim 7 \mathrm{~s}^{\wedge}-1$ \\
\hline $\begin{array}{c}\text { Bonfield \& Datta } \\
(1976)\end{array}$ & Bovine & Single-edge Notched & $\mathrm{Kc}=2.2-4.6$ & Transverse & $3 e-3 s^{\wedge}-1$ \\
\hline $\begin{array}{c}\text { Behiri \& Bonfield } \\
(1980)\end{array}$ & Bovine & CT & $\mathrm{Kc}=4.46-5.38$ & Longitudinal & $\begin{array}{c}0.0102-1.02 \\
\mathrm{~mm} / \mathrm{min}\end{array}$ \\
\hline $\begin{array}{c}\text { Behiri \& Bonfield } \\
(1982)\end{array}$ & Bovine & CT & $\mathrm{Kc}=3.3-5.7$ & Longitudinal & \\
\hline $\begin{array}{l}\text { Behiri \& Bonfield } \\
(1984)\end{array}$ & Bovine & CT & $\mathrm{Kc}=2.8-6.3$ & Longitudinal & $\begin{array}{l}0.01-50 \\
\mathrm{~mm} / \mathrm{min}\end{array}$ \\
\hline \multirow{2}{*}{$\begin{array}{l}\text { Bonfield et al. } \\
\text { (1985) }\end{array}$} & Human & $\mathrm{CT}$ & $\mathrm{Kc}=2.1-4.7$ & Longitudinal & $\begin{array}{l}0.504 \mathrm{e}-3 \\
\mathrm{~mm} / \mathrm{min}\end{array}$ \\
\hline & Canine & CT & $\mathrm{Kc}=3.2-6.5$ & Longitudinal & $\begin{array}{c}0.0102 \\
\mathrm{~mm} / \mathrm{min}\end{array}$ \\
\hline $\begin{array}{l}\text { Moyle \& Gavens } \\
\text { (1986) }\end{array}$ & Bovine & Single-edge Notched & $\mathrm{Kc}=11.2$ & Transverse & $0.45 \mathrm{~mm} / \mathrm{min}$ \\
\hline $\begin{array}{c}\text { Behiri \& Bonfield } \\
(1989)\end{array}$ & Bovine & CT (grooved) & $\mathrm{Kc}=3.2$ & Longitudinal & $\begin{array}{c}0.0198 \\
\mathrm{~mm} / \mathrm{min}\end{array}$ \\
\hline $\begin{array}{c}\text { Norman et al } \\
(1991)\end{array}$ & Human & $\mathrm{CT}$ & $\mathrm{Kc}=4.48$ & Longitudinal & $0.5 \mathrm{~mm} / \mathrm{min}$ \\
\hline $\begin{array}{c}\text { Norman et al } \\
(1991)\end{array}$ & Human & $\begin{array}{c}\text { CT (corrected for } 7 \mathrm{~mm} \\
\text { thickness) }\end{array}$ & $\mathrm{Kc}=3.68$ & Longitudinal & $0.5 \mathrm{~mm} / \mathrm{min}$ \\
\hline $\begin{array}{l}\text { Norman et al } \\
\quad(1992)\end{array}$ & Bovine & CT & $\mathrm{Kc}=5.3-9.4$ & Longitudinal & $0.5 \mathrm{~mm} / \mathrm{min}$ \\
\hline $\begin{array}{c}\text { Norman et al } \\
(1992)\end{array}$ & Bovine & CT (grooved) & $\mathrm{Kc}=5.2-9.3$ & Longitudinal & $0.5 \mathrm{~mm} / \mathrm{min}$ \\
\hline $\begin{array}{c}\text { Valishth et al } \\
\text { (1994) }\end{array}$ & Bovine & CT & $\mathrm{Kc}=4-7.6$ & Longitudinal & $0.5 \mathrm{~mm} / \mathrm{min}$ \\
\hline $\begin{array}{c}\text { Valishth et al } \\
\text { (1994) }\end{array}$ & Human & CT & $\mathrm{Kc}=1.6-2.5$ & Longitudinal & $0.5 \mathrm{~mm} / \mathrm{min}$ \\
\hline $\begin{array}{c}\text { Norman et al } \\
\text { (1995) }\end{array}$ & Bovine & CT & $\mathrm{Kc}=4.68-6.73$ & Longitudinal & $2.6 \mathrm{~mm} / \mathrm{min}$ \\
\hline $\begin{array}{c}\text { Norman et al } \\
(1995 b)\end{array}$ & Human & CT & $\mathrm{Kc}=4.05-4.32$ & Longitudinal & $2.6 \mathrm{~mm} / \mathrm{min}$ \\
\hline $\begin{array}{c}\text { Feng \& Salzmann } \\
(199)\end{array}$ & Bovine & CT & $\mathrm{Kc}=2.55$ & Longitudinal & $0.2 \mathrm{~mm} / \mathrm{min}$ \\
\hline $\begin{array}{l}\text { Norman et al } \\
(1996)\end{array}$ & Human & CT & $\mathrm{Kc}=2.12$ & Longitudinal & $0.2 \mathrm{~mm} / \mathrm{min}$ \\
\hline
\end{tabular}




\section{CHAPTER 3: FEMORAL NECK TESTING}

\subsection{Introduction to Femoral Neck Testing}

As it has been mentioned earlier, femoral neck fractures are a common type of osteoporotic fracture. Femoral neck testing is a test of the femoral head and neck structure, namely the femoral neck's ability carry load. This testing was done to find the ultimate strength of the femoral neck structure, and to see if the treatment had an effect on the load carrying ability of the femoral neck, which would ultimately relate to the femoral neck's ability to resist fracture.

The geometry of the femoral neck of rabbits differs from the human femoral neck that these test are often performed, but the rational of being able to test a structure is the same, even if the structure is different.

\subsection{Rational for Testing}

The tests were performed to gain insight into structural changes of the bone and its ability to carry load, which gives another area to correlate the fracture toughness data. The femur is a heavily loaded region and is commonly involved in osteoporotic fractures, and is second in prevalence after vertebral compression fractures.

The femoral neck is a common area for fracture in humans because of the relatively small size, low mass, and heavy loads received under normal activities. The rabbit femur is unique in the large femoral neck region that goes lower on the shaft relative to size than the human counterpart, which makes the fracture behavior unique. The unique fracture properties do not make the femur untestable, since this 
characteristic is shared by all of the test specimens, and a difference can be found between treatment groups. 


\section{CHAPTER 4 HISTOMORPHOMETRY OF BONE}

\subsection{Introduction to Histomorphometry}

Histomorphometry is the term used to describe the measurement and quantification of microscopic specimens.

\subsubsection{Example of use of the Lexicon}

The abbreviations are used in the order of the words in the measurement description, such as single pore area, which would be abbreviated as s.Po.Ar. The use of abbreviations was standardized, but was not overly suggested by Parfitt (1987) with the purpose of standardizing abbreviations when used to report data. The abbreviations will be used in this paper to report measurements, because of their compact size and the ease to which they lend themselves to the potential writing of data analysis computer programs for post processing of the data.

\subsubsection{Example of Measures}

There are different types of histomorphometric measures. These measures can be divided in a few categories namely: static and dynamic, and primary and secondary (calculated) measures. 
Table 4.1.1: Abbreviations and Symbols of Terms Used in Bone Histomorphometry (Parfitt, 1987)

\begin{tabular}{|c|c|c|c|}
\hline A & Apposition(al) & $\mathrm{m}$ & Maturation \\
\hline $\mathrm{Ab}$ & Absolute & $\mathrm{N}$ & Number of profiles or structures \\
\hline Ac & Activation & $\mathrm{n}$ & Number of sampling units \\
\hline $\mathrm{Aj}$ & Adjusted & $\mathrm{O}$ & Osteoid \\
\hline $\mathrm{Ar}$ & Area (2D) & $\mathrm{Ob}$ & Osteoblast(ic) \\
\hline $\mathrm{a}$ & $\operatorname{Activ}(e)(i t y)$ & Oc & Osteoclast(ic) \\
\hline B & Bone & On & Osteon(al) \\
\hline BMU & Basic Multicellular Unit & Ot & Osteocyt(e)(ic) \\
\hline $\mathrm{Ca}$ & Canal(icula)(r) & $\mathrm{P}$ & Period \\
\hline $\mathrm{Cd}$ & Corrected & $\mathrm{Pm}$ & Perimeter (2D) \\
\hline $\mathrm{Cn}$ & Cancellous & Po & Por(e)(ous)(osity) \\
\hline $\mathrm{Ct}$ & Cortical & Ps & Periost(eal)(eum) \\
\hline d & Double & $\mathrm{Pt}$ & Point \\
\hline $\mathrm{E}$ & Ero(ded)(sion) & Q & Quiescent \\
\hline EX & External & $\mathrm{R}$ & Rate \\
\hline $\mathrm{F}$ & Formation & $\mathrm{Rd}$ & Radi(al)(us) \\
\hline $\mathrm{Fb}$ & Fibro(sis)(us) & Rf & $\operatorname{Referen}(\mathrm{ce})(\mathrm{t})$ \\
\hline $\mathrm{Fr}$ & Front & $\mathrm{Rm}$ & Remodeling \\
\hline $\mathrm{f}$ & Frequency & Rs & Resorption \\
\hline G & Grow(th)(ing) & $\mathrm{S}$ & Surface (3D) \\
\hline $\mathrm{H}$ & Haversian & $\mathrm{Sa}$ & Sample \\
\hline $\mathrm{Hp}$ & Hypertrophic & $\mathrm{Se}$ & Section \\
\hline $\mathrm{Ht}$ & Height & $\mathrm{Sn}$ & Spongiosa \\
\hline $\mathrm{Hz}$ & Horizontal & $\mathrm{St}$ & Structur(e)(al) \\
\hline I & Interface (3D) & $\mathrm{s}$ & Single \\
\hline Ic & Intercept & $\mathrm{Tb}$ & Trabecula(r) \\
\hline Il & Initial & $\mathrm{Th}$ & Thickness (3D) \\
\hline In & Internal & $\mathrm{Tt}$ & Total \\
\hline Ir & Inter & $\mathrm{t}$ & Time \\
\hline $\mathrm{i}$ & Intersection & $\mathrm{U}$ & Unit \\
\hline $\mathrm{L}$ & Label(led) & V & Volume (3D) \\
\hline Lc & Lacuna(r) & $\mathrm{Vd}$ & Void \\
\hline Le & Length & $\mathrm{Vk}$ & Volkmanns \\
\hline $\mathrm{Lm}$ & Lamella(r) & $\mathrm{Vt}$ & Vertical \\
\hline $\mathrm{Ln}$ & Line & W & Wall \\
\hline Lo & Longitudinal & $\mathrm{Wi}$ & Width \\
\hline 1 & lag & Wo & Woven \\
\hline M & Mineral(iz)(ing)(ation) & $\mathrm{Z}$ & Zone \\
\hline $\mathrm{Me}$ & Medullary & & \\
\hline Ml & Modeling & & \\
\hline
\end{tabular}




\subsection{Static Histomorphometry}

Static histomorphometry is the microscopic measure of surfaces and structures. The measures are called static, because the structures and surfaces of bone, are no longer living, embedded in plastic, and are unchanging.

Most measures are in terms of percent of the total area, which is done for a few reasons. Measures of length, when dealing with such small sizes, are difficult. The surfaces and areas of interest are irregular in shape, so the use of linear measures to then extrapolate an area is difficult. Image analysis software that easily allows the measure of the percent of the total area occupied by a unique region.

\section{Total Area (TtAr)}

The total area is exactly that, the total area of the image. When a picture is analyzed, the measures are usually in terms of percentage of a larger area, and this is the most basic one.

Medullary Area

The medullary area is the area enclosed by the cortical bone. For illustrative purpose, a long bone (i.e. femur, or tibia) can be thought of as hollow pipes. The medullary area would then be the area found from internal diameter (ID). The medullary area is often thought of as a percentage of the total area from the equation:

$$
\operatorname{MeAr}(\%)=\operatorname{MeAr} / \operatorname{TtAr}
$$

\section{Cortical Bone Area (CtAr)}

The cortical bone area is defined as the area that is composed of cortical bone, and is usually expressed as a percentage of the total bone area by the equation.

$$
\mathrm{CtAr}=\mathrm{TtAr}-\mathrm{MeAr}-\text { Other Area }
$$


Other Area is all the area that may lie on the outside of the cortical bone that is not part of the medullary area, and is not bone area, such as any area in the field that lies outside of the cortex.

The cortical bone area though is often reported as a percentage of the total area, from the equation:

$$
\operatorname{CtAr}(\%)=\mathrm{CtAr} / \mathrm{TtAr}=1-\operatorname{MeAr} / \operatorname{TtAr}=1-\operatorname{MeAr}(\%)
$$

\section{Osteon Area (OnAr)}

The osteon area is expressed as the percentage of the total area that is composed of osteons, or more precisely the percentage of the bone area that is enclosed within cement lines, which are the boundaries of the osteon. The area of each osteon is summed and then divided by the total cortical bone area (CtAr), or from the equation:

$$
\mathrm{OnAr}=\mathrm{TOnAr} / \mathrm{CtAr}
$$

Porosity (Po)

The porosity of the bone or the percentage of the total bone that is porous is found by finding the areas of the haversian, and volkmann canals, any other spaces that are present in the cortical bone, and the total area of the cortical bone. The porosity $(\mathrm{Po})$ can then be found by the equation:

$$
P o=\frac{H n \cdot C n \cdot A r+V \cdot C n \cdot A r+\operatorname{Pr} \cdot V \cdot A r}{T t \cdot A r}
$$

Osteon Number (OnN)

The osteon number is simply the number of osteons present in the bone specimen, which is measured by using analysis software to count the number of osteons identified by the user. This parameter gives an idea as to the 
resorption/formation activity present in the bone, but does not give areas of any sort.

If two osteons and haversian canals are merged together, as shown in figure 4.3-1, they are counted as two osteons, because they are two independent osteons.

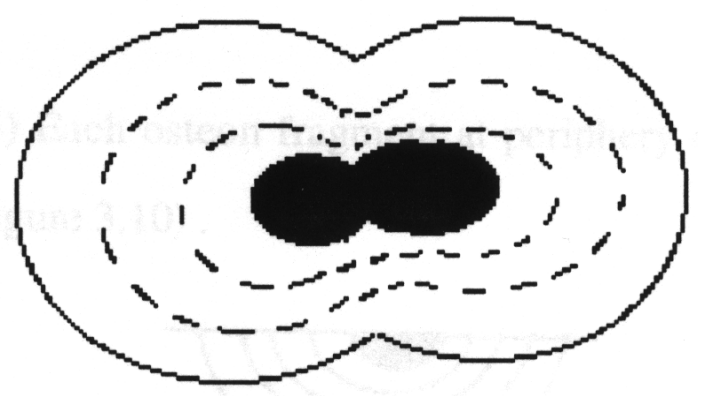

Figure 4.3-1: Merged osteons (Wang, 1995).

If two osteons are merged by a Volkmann's canal, these are also counted as two, because they are independent osteons.

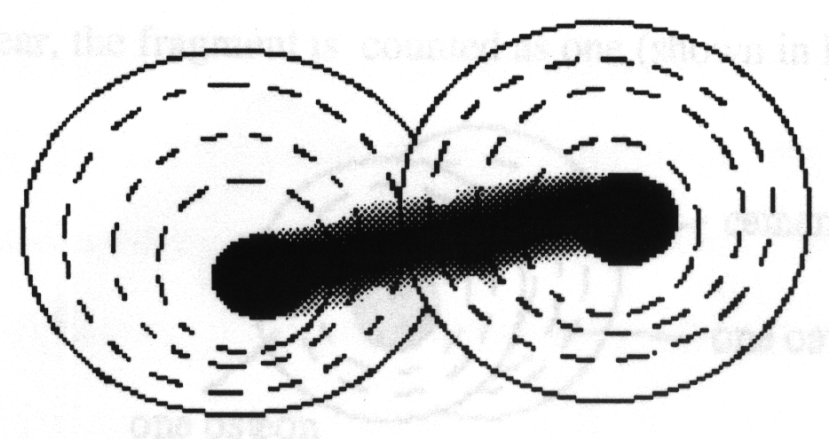

Figure 4.3-2: Osteons connected by a Volkmann's canal (Wang, 1995).

If the Haversian canals are separate, but the osteons are merged together, each osteon is counted, because each is still an independent system. 


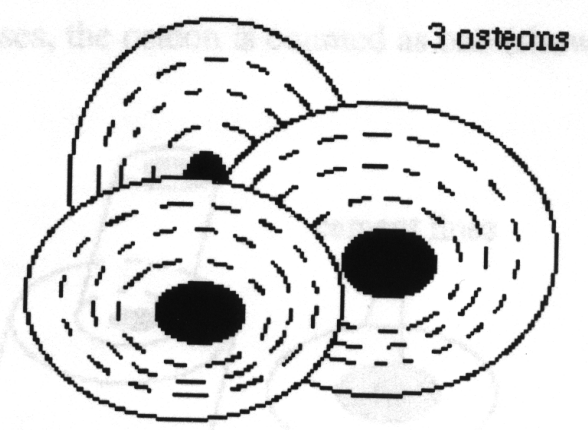

Figure 4.3-3: Merged osteons with independent Haversian canals (Wang, 1995).

When images are made, some osteons may only be partially in the field as shown in figure 4.3-4. The partial osteons are counted as well.

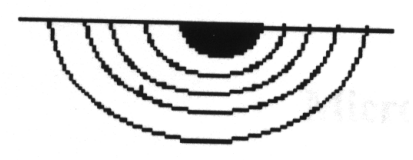

Figure 4.3-4: Osteon fragment cut by edge of the field (Wang, 1995).

If an osteon fragment does not have a clear haversian canal (figure 4.3-5), but does have a clear cement line, the fragment is also counted, because it has important mechanical properties similar to those of osteons with Haversian canals.

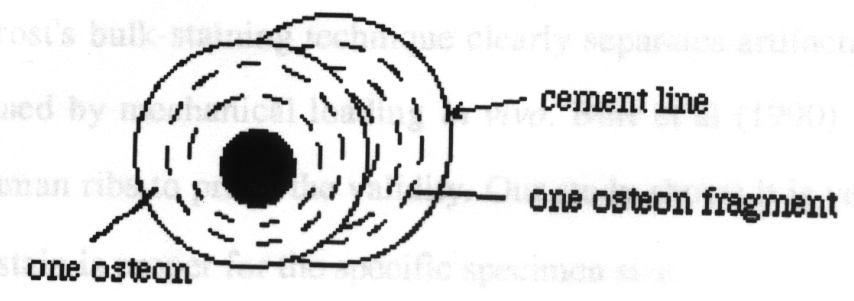

Figure 4.3-5: Osteon fragment with a clear cement line (Wang, 1995).

Occassionally an osteon will appear to have a double cement line, which could be caused by the specimen being sectioned oblique to the face or to a small remodeling 
event. The osteon, similar to the schematic in figure 4.3-6, is counted as one, and the outer cement line is used for measurement purposes.

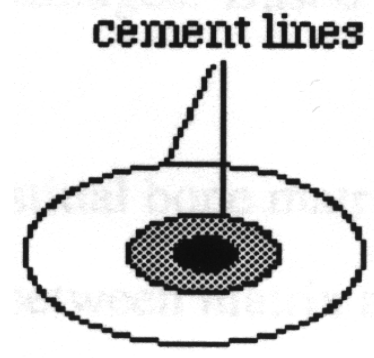

Figure 4.3-6: Osteon, which appears to have two cement lines (Wang, 1995).

Osteon Density (OnD)

Osteon density is an index of the number of osteons per unit area, which can be found from the equation.

$$
\mathrm{OnD}=\mathrm{OnN} / \mathrm{CtAr}
$$

Osteoid Area (OAr)

The osteoid area is the area of the bone occupied by osteoids, but this quantity like most bone quantities is given as a percentage of the cortical bone area from the equation.

$$
\mathrm{OAr}=\mathrm{OAr} / \mathrm{CtAr}
$$

\subsection{Compositional Analysis (R Cain et al, 2003)}

The mineral and organic content of bone can be found from a drying procedure as follows:

1. The dimensions of the specimen were measured using calipers, and the volume (V) of the cylinder was calculated. 
2. The specimens were hydrated overnight in water, lightly blotted dry, and then the wet weight (WW) was found.

3. The specimen was then defatted by soaking in acetone in a vacuum oven $\left(20 \mathrm{psi} ; 60^{\circ} \mathrm{C}\right)$ for 24 hours.

4. The specimen was brought back to room temparature in a dessicator (1 hour). The specimen was then weighed. This was repeated until a constant mass was found, which is the dry weight (DW).

5. The specimens were then placed in a crucible in a muffle oven at 600 ${ }^{\circ} \mathrm{C}$ for 24 hours. The specimen's ash weight (AW) was then found.

6. The following parameters were then calculated:

$$
\begin{gathered}
\text { Weight Density }=\mathrm{WW} / \mathrm{V} \\
\text { Dry Density }=\mathrm{DW} / \mathrm{V} \\
\% \text { Mineral, \%Min }=\mathrm{AW} / \mathrm{DW} * 100 \\
\% \text { Organic }(\mathrm{dry})=(\mathrm{DW}-\mathrm{AW}) / \mathrm{DW} * 100 \\
\% \mathrm{ASH}=\mathrm{AW} / \mathrm{DW} * 100 \\
\% \text { Organic }(\text { wet })=(\mathrm{DW}-\mathrm{AW}) / \mathrm{WW} * 100 \\
\% \text { Water }=(\mathrm{WW}-\mathrm{DW}) / \mathrm{WW} * 100
\end{gathered}
$$

The \%Ash can be thought of as the apparent mineral content, and the $\%$ Mineral is the material mineral content and is independent of porosity. The $\%$ Organic (dry) is the organic content and is independent of porosity, and the $\%$ Organic (wet) is the apparent organic content of the bone. 


\section{CHAPTER 5 ANIMAL CARE AND EXPERIMENTAL PROCEDURE}

\subsection{Introduction}

The experiment used a total of twenty-eight New Zealand White (NZW) rabbits (Covance, Denver, PA), which were divided into three trial groups and four treatment groups.

Group $I(N=6)$

Group I consisted of eight rabbits. Four of these rabbits were ovarectomized and four of them were sexually normal. The purpose of this group was to illustrate the difference between the overectomized and normal groups, and add validity to the rabbit Ovx model.

Group II $(N=8)$

Group II consisted of eight rabbits, all of which had received ovarectomies. Four of the animals received risidronate injections of $5 \mu \mathrm{g} / \mathrm{ml} / \mathrm{kg}$ three days per week $(\mathrm{M}, \mathrm{W}$, and F), meaning animals in this group that received Residronate (Actonel, Proctor and Gamble) received an injection of a solution of a concentration of $5 \mu \mathrm{g} / \mathrm{ml}$ and then given a dose of one $\mathrm{ml}$ per $\mathrm{kg}$ of body weight. The remaining four rabbits received saline injections equal to $1 \mathrm{ml} / \mathrm{kg}$.

Group III $(N=16)$

This group consisted of all four treatment methods (Normal, Ovx-NaCl, OvxRis, Ovx), as described previously with four animals per treatment method.

A more visually pleasing representation of the division of specimens can be seen in table 5.1-1. 
Table 5.1-1: Animal Treatment and Group Distribution Table

\begin{tabular}{|l|l|}
\hline \multicolumn{1}{|c|}{ Normal (No Injection) } & \multicolumn{1}{c|}{ Ovx (No Injection) } \\
Group I: $\mathrm{n}=5$ & Group I: $\mathrm{n}=4$ \\
Group III: $\mathrm{n}=4$ & Group III: $\mathrm{n}=4$ \\
\hline \multicolumn{1}{|c|}{ Ovx (Residronate Injection) } & \multicolumn{1}{c|}{ Ovx (Saline Injection) } \\
Group II: $\mathrm{n}=4$ & Group II: $\mathrm{n}=4$ \\
Group III: $\mathrm{n}=4$ & Group III: $\mathrm{n}=4$ \\
\hline
\end{tabular}

\section{2: Animal Care Introduction}

Animals deserve a level of respect and consideration when an experiment is designed. There are many moral and legal issues that must be addressed before the use of animals should be considered.

Animals should not be used in experiments unless the data is simply unavailable from any other model. If the data can also be derived by a computer model, even if the accuracy is lower than an in vivo model, it should be strongly considered.

From a legal point-of-view, the use of animals is strongly regulated by the United States Government under the authority of the Department of Human Services.

All of the animals in the study were housed by the West Virginia University Office of Laboratory Animal Research at the Robert C. Byrd Health Sciences Center Morgantown, WV. The animal quarters officials took care of feeding, watering, and cleaning duties necessitated by the use of animals.

The experimental procedure received Animal Care and Use Committee (ACUC) approval (\# 01-1102). 


\section{3: Animal Injection Procedure}

All injections were given subcutaneous on the dorsal side of the animal. The animal was placed on a flat surface outside of its cage, and the skin of the posterior dorsal region was pinched up. The needle was then inserted into the skin horizontally along the length of the pinch. The plunger was then slowly pressed forward, to allow for the maximum comfort of the animal, since a relatively large volume of fluid is being introduced to the animal. The area was then examined by lightly rubbing the hand over the dorsal area in a petting motion. The petting has a two pronged purpose: it allows for the checking of dosing, since if the injection is not fully successful, the liquid will be stuck in the fur and will not be readily visible, and the stroking of the animal helps to comfort and sooth the animal, that is stressed by the injection procedure.

\section{4: Animal Sacrifice Procedure}

The animals were brought from the animal housing area to the operating room, in which the dissections were to take place. The animal is anesthetized using an injection of Ketamine (Ketajet, 100mg/ml, Phoenix Scientific, St. Lois, MO) and Xylene (Xylajet, $20 \mathrm{mg} / \mathrm{ml}$, Phoenix Scientific, St. Lois, MO) in a $30 \mathrm{ml}$ to $10 \mathrm{ml}$ mixture. Once the animal is asleep, an injection $30 \mathrm{ml}$ of Sleep Away (Fort Dodge Laboratories, Fort Dodge, IA) is injected directly into the cardiac muscle, which leads to almost instantaneous cardiac arrest.

\section{5: Animal Dissection}


Once the animal is confirmed dead, the hind limbs are dissected and the femurs and tibias are removed and cleaned. The bones were wrapped in saline soaked gauze and placed in labeled bags. The specimens were then placed in a freezer $\left(-20{ }^{\circ} \mathrm{C}\right)$, until the specimens were used in mechanical testing. 


\section{CHAPTER 6: SPECIMEN PREPARATION, MACHINING, AND ANALYSIS}

\subsection{Bone Selection and Bone Availability}

The tibia was selected for the preparation of the fracture toughness specimens, because of the relatively flat aspects of the bone on the proximal end, which allows for the machining of the compact fracture toughness specimens.

\subsection{Specimen Preparation and Storage}

When machining was going to be performed on the bones, only the number expected to be machined that day were removed from the freezer in the morning to defrost at room temperature. Hydration was maintained as well as possible during the machining process using normal saline to avoid drying out of the specimens.

After the machining process, the specimens were wrapped in saline soaked gauze and then placed in a labeled plastic bag; after which, the bones were placed in the refrigerator $\left(4^{\circ} \mathrm{C}\right)$ for no more than a few days until testing took place.

Before mechanical tests were performed, the bone specimens were removed from the refrigerator and allowed to return to room temperature, before testing was to begin. Hydration was maintained throughout the testing process using normal saline.

\subsection{Fracture Toughness Machining}

All specimens were removed from a flat lateral aspect of the proximal tibia adjacent to the fibula as shown in figure 6.3-2. This area provided the flattest and thickest area of cortical bone from which to extract a fracture toughness specimen.

The proximal end was removed by cutting it off perpendicular to the axis of the bone using a band saw at a location low enough on the shaft of the bone, such that 
there was sufficient cortical bone for the machining of the specimens. Using a jeweler's saw with a fine cutting blade, a slab was then removed along the selected flat aspect down the shaft of the bone, care was taken to ensure that a minimum amount of the other faces were removed, while still allowing the removal of the entire aspect down to approximately the midpoint of the shaft.

The slab once removed was ground flat using wet 180\# sandpaper, and then placed on a specially designed fixture designed by Vincent Kish and myself (figure 6.3.1) and secured using the set screws.

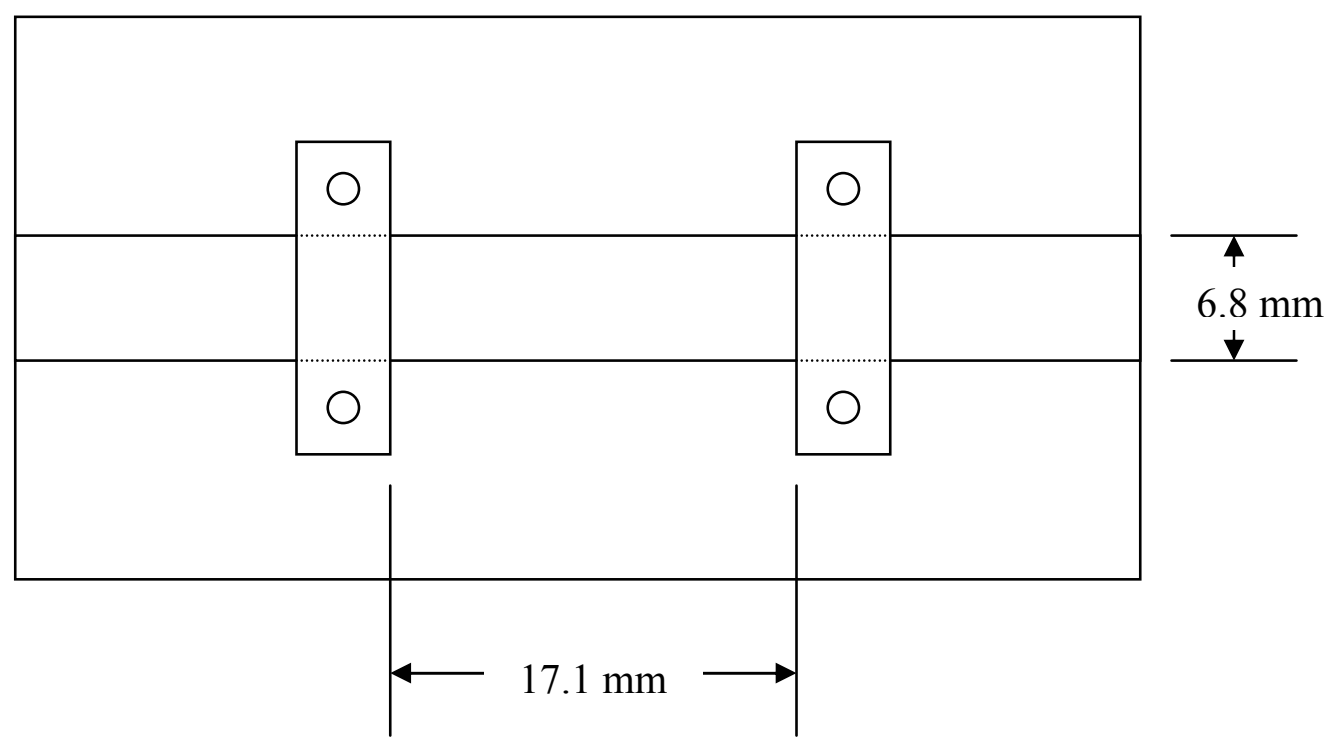

Figure 6.3.1: Machining Fixture for Milling and Drilling Processes 


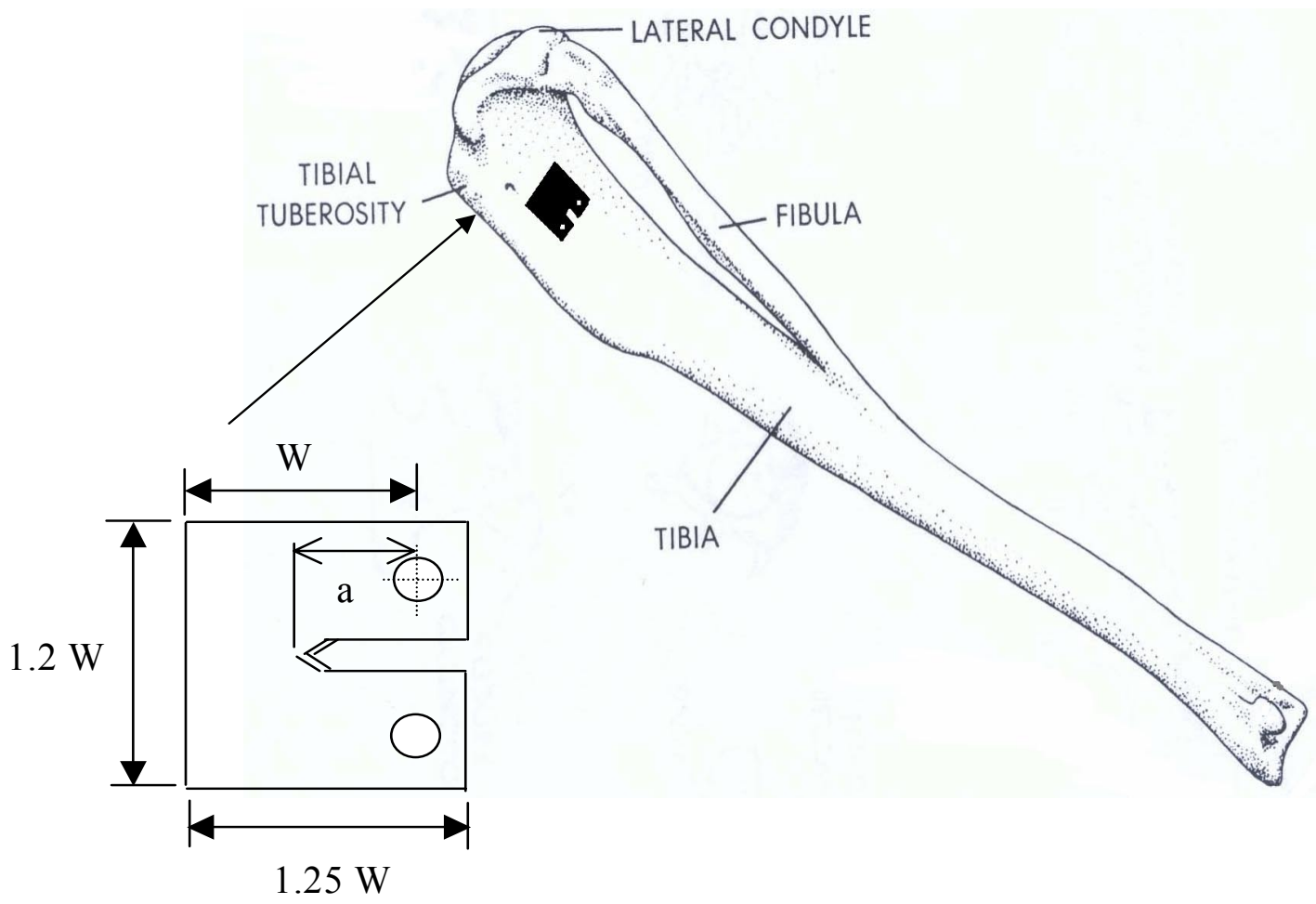

Figure 6.3-2: Fracture Toughness Specimen Location and Dimensions (Adapted from Wingerd, 1985 with CT specimen added)

The slab once secure in the fixture (Figure 5.3-1) was placed in the clamp in the vertical milling machine, and the center portion between the two clamps was milled to the desired thickness of $0.5 \mathrm{~mm}$ using a 3/16" milling bit running at 2300 RPM.

Once the center portion was milled to the correct thickness $(0.5 \mathrm{~mm})$, the holes for the fracture toughness specimen were drilled by putting a $1 \mathrm{~mm}$ diameter bit into the head of the milling machine and using as a press at 270 RPM. The hole placement was found by using a Mill Mate (Bridgeport, Bridgeport, CT) digital device that is connected to the bed of the mill/press and reads distance change on the horizontal plane. 
Once the holes were drilled into the specimen, it was removed from the fixture, and the measurements for the dimensions were made using the center of the holes as a reference point.

Once the measurements were transferred in pencil to the specimen, it was removed and cut to the proper length using a Buhler Low Speed Saw.

Once the specimen was the proper length, the crack was cut into the specimen on the Low Speed Saw (Buehler, Evanston, IL) using a blade of $10.2 \mathrm{~cm}$ diameter and a thickness of $0.3 \mathrm{~mm}$.

Prior to testing, the precrack was made at the end of the crack using a new flat razor blade.

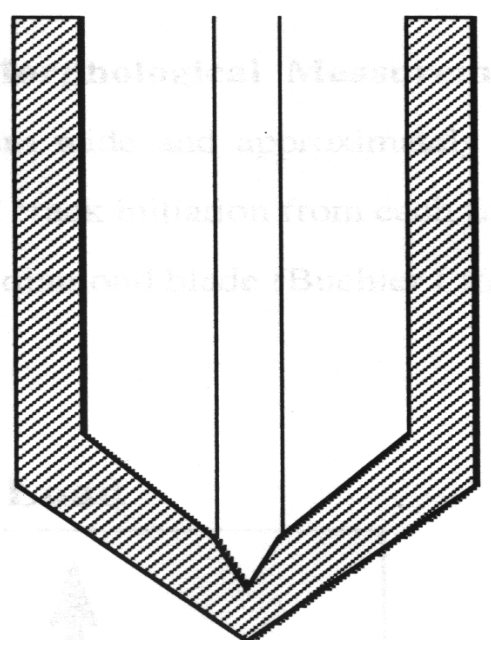

Figure 6.3-3: Making of the precrack (Yeni, 1998).

\subsection{Histomorphometric Preparation}

Complete cross sections were cut from the tibial shaft below the area used for the fracture toughness machining. A bulk section was cut from the middle of the shaft. The bulk section was embedded in plastic. After the embedding process, at least two $80 \mathrm{~mm}$ sections were cut using a diamond wire saw (Delaware Diamond 
Knives, Wilmington, DE). At least one section was stained using H\&E (Appendix A); the section after staining was mounted on a microscope slide with Permount (Fisher Scientific, Fairlawn, NJ) and a cover slip was applied. At least one other section was mounted on a slide unstained using Fleoromount-G (Southern Biotechnology Associates Inc., Birmingham, AL) for dynamic histomorphometry.

\subsection{Femoral Neck Fracture Testing}

The femoral neck was tested by cutting the femur perpendicular to the axis at the mid-shaft, taking care to insure that it was below the obvious neck structure. The bones were then "potted" or fixed in a metal tube using Duz-All Self Cure Acrylic Dental Cement from Coralite Dental Products (Skokie, IL). The structure of the femoral neck was then tested on the MTS (MTS Corp., Minneapolis, MN).

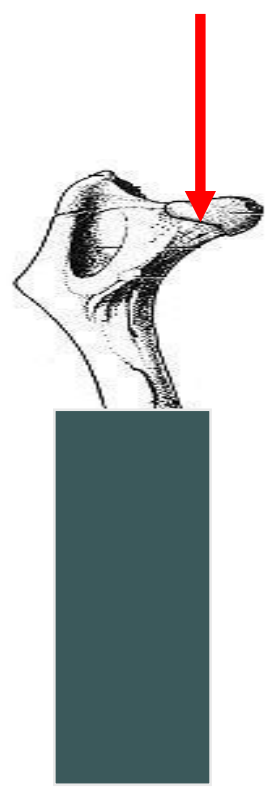

Figure 6.5-1: Femoral neck testing configuration with the arrow indicating the load. 


\subsection{Bone Mineral Density Testing}

The bone mineral density of the femurs for group II were tested at the Ohio State Musculoskeletal Research Center by Dr. John Landell. The bones were shipped to the OSU lab by FedEx in a Styrofoam box with dry ice. The bones upon receipt at OSU were kept frozen and then tested using DXA. After the analysis the bones were shipped back to Morgantown, WV, using the same box with dry ice.

\subsection{Histomorphometric Analysis}

Four fields were selected at random and an image was captured using the 20x

objective on the microscope (Olympus BH-2, Japan). The images were then analyzed using Scion Image version Beta 4.02 (Scion Corporation) and the results were exported as a text file. The text file was then opened in Microsoft Excel version 9.0.2720 for analysis. After the analysis, statistical analysis was performed using JMP (version 3.2.1, SAS Institute, Inc).

\subsection{Statistical Methods}

Statistical comparisons between groups and line fitting for the data was performed in JMP (version 3.2.1, SAS Institute, Inc). Significance was tested using ANOVA, student t-test, and Tukey-Kramer HSD. The confidence interval was set at $95 \%(\mathrm{p}<0.05)$. 


\section{CHAPTER 7: RESULTS}

\subsection{Introduction}

The data in this investigation was for determining the bone quality of bone, and the effects of estrogen deficiency and bisphosphonate treatment on the quality of bone. To get a clearer picture as to the effects of the drug treatment and estrogen deficiency on the mechanical properties a variety of tests were employed. The most important for our study was fracture toughness, and the other tests and measures were done to explain the difference or lack of differences found from this test.

\subsection{Fracture Toughness Results (Stress Intensity Factor)}

Fracture toughness testing was performed for all three groups. The stress intensity factors were calculated as described earlier, and the results in each group were compared, within the same experimental group and all groups.

\section{Group I:}

The fracture toughness of Group I was performed using a different machining technique than that employed in groups II and III. During this test many of the specimens broke during the machining process, particularly the Ovx bones, which were seemingly too brittle to go through the machining process without breakage. The difference between the treatment groups was significant, but the Ovx only had one specimen in the test. The results for the group can be seen in table 7.2-1 and figure 7.2-1. 
Table 7.2-1: Fracture Toughness Test Data for Group I.

\begin{tabular}{|c|c|c|c|c|c|c|c|c|}
\hline Specimen & $\begin{array}{c}\mathrm{W} \\
(\mathrm{mm})\end{array}$ & $\mathrm{a}(\mathrm{mm})$ & $\mathrm{F}_{\mathrm{c}}(\mathrm{N})$ & $\mathrm{B}(\mathrm{mm})$ & $\mathrm{a} / \mathrm{W}$ & $\mathrm{f}(\mathrm{a} / \mathrm{W})$ & $\begin{array}{c}\mathrm{K}_{\mathrm{c}} \\
\left(\mathrm{N} / \mathrm{mm}^{\wedge} 3 / 2\right)\end{array}$ & Treatment \\
\hline 977 & 6.80 & 2.40 & 5.76 & 0.60 & 0.35 & 6.59 & 24.27 & Ovx \\
\hline & & & & & & & & \\
\hline $981 \mathrm{a}$ & 6.33 & 2.00 & 12.84 & 0.81 & 0.32 & 6.08 & 38.32 & Norm \\
\hline $981 \mathrm{~b}$ & 6.50 & 2.20 & 11.98 & 0.80 & 0.34 & 6.38 & 37.47 & Norm \\
\hline 982 & 5.58 & 2.40 & 9.25 & 0.63 & 0.43 & 7.96 & 49.47 & Norm \\
\hline 983 & 5.80 & 2.50 & 4.57 & 0.50 & 0.43 & 7.98 & 30.32 & Norm \\
\hline Normal Avg. & 6.05 & 2.28 & 9.66 & 0.69 & 0.38 & 7.10 & 38.90 & \\
\hline Normal SD & 0.43 & 0.22 & 3.72 & 0.15 & 0.06 & 1.01 & 7.91 & \\
\hline
\end{tabular}

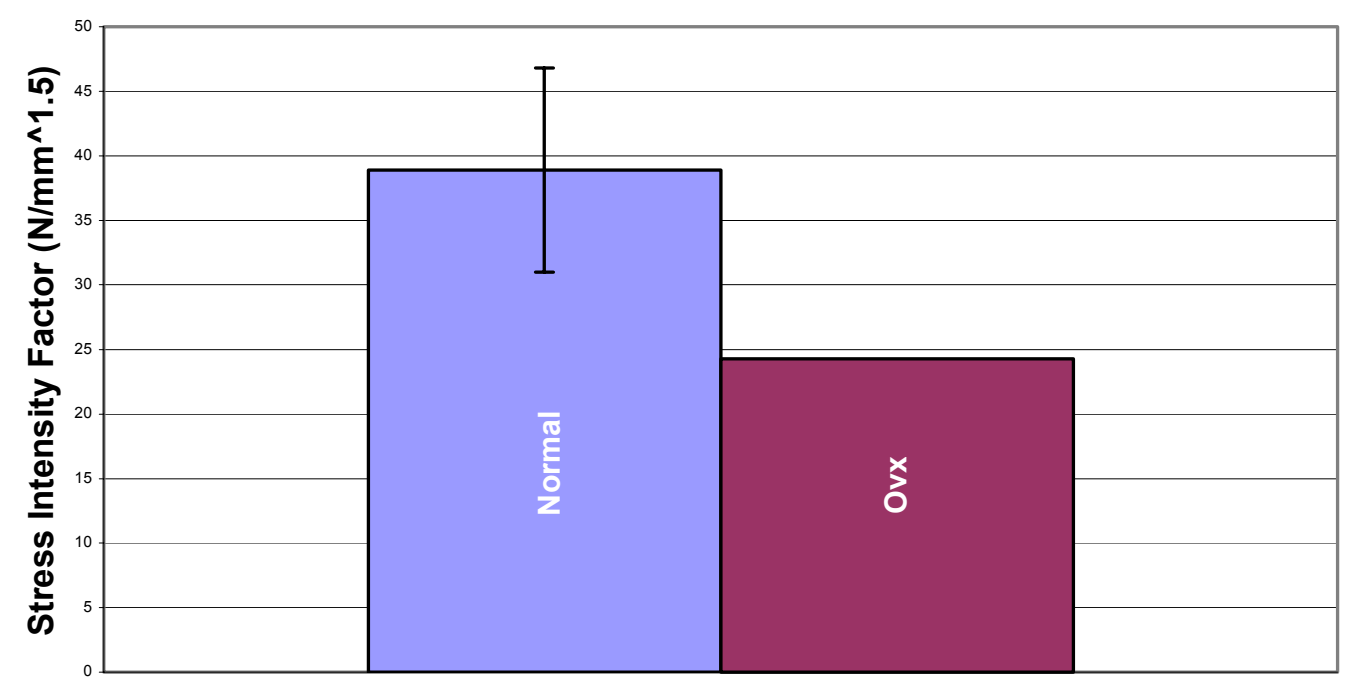

Figure 7.2-1: Stress intensity factor results for Group I (The average value for Normal is $38.9 \pm 7.91$ and the only value for Ovx was 24.27).

\section{Group II:}

In Group II, the stress intensity factors were not significantly different between Ovx and Ovx-Ris groups, which can be see in table 7.2-2 and figure 7.2-2. 
Table 7.2-2: Fracture toughness test values for Group II

\begin{tabular}{|c|c|c|c|c|c|c|c|c|c|}
\hline Treatment & Number & $\begin{array}{c}\text { Mass } \\
(\mathrm{kg})\end{array}$ & $\mathrm{F}_{\mathrm{c}}(\mathrm{N})$ & $\begin{array}{c}\mathrm{a} \\
(\mathrm{mm})\end{array}$ & $\begin{array}{c}\mathrm{W} \\
(\mathrm{mm})\end{array}$ & $\mathrm{T}(\mathrm{mm})$ & $\mathrm{a} / \mathrm{W}$ & $\mathrm{f}(\mathrm{a} / \mathrm{W})$ & $\begin{array}{c}\mathrm{K}_{\mathrm{c}} \\
\left(\mathrm{N} / \mathrm{mm}^{\wedge} 3 / 2\right)\end{array}$ \\
\hline $\mathrm{NaCl}$ & 20.00 & 4.40 & 11.68 & 1.37 & 6.85 & 0.77 & 0.20 & 5.23 & 30.30 \\
\hline $\mathrm{NaCl}$ & 22.00 & 5.10 & 14.34 & 1.24 & 6.07 & 0.61 & 0.20 & 5.24 & 49.99 \\
\hline $\mathrm{NaCl}$ & 23.00 & 4.80 & 13.67 & 1.21 & 6.84 & 0.53 & 0.18 & 5.21 & 51.34 \\
\hline & Average & 4.77 & 13.23 & 1.27 & 6.59 & 0.64 & 0.19 & 5.23 & 43.88 \\
\cline { 2 - 9 } & $\mathrm{SD}$ & 0.35 & 1.39 & 0.09 & 0.45 & 0.12 & 0.01 & 0.02 & 11.78 \\
\hline
\end{tabular}

\begin{tabular}{|l|c|c|c|c|c|c|c|c|c|} 
Ris & 21.00 & 4.80 & 18.44 & 1.18 & 7.06 & 0.53 & 0.17 & 5.21 & 68.22 \\
\hline Ris & 24.00 & 6.00 & 8.80 & 1.40 & 6.58 & 0.49 & 0.21 & 5.26 & 36.83 \\
\hline Ris & 25.00 & 4.30 & 10.92 & 1.18 & 6.71 & 0.33 & 0.18 & 5.21 & 66.51 \\
\hline Ris & 26.00 & 3.50 & 12.15 & 1.44 & 6.49 & 0.56 & 0.22 & 5.30 & 45.10 \\
\cline { 2 - 10 } & Average & 4.65 & 12.58 & 1.30 & 6.71 & 0.48 & 0.19 & 5.24 & 54.16 \\
\cline { 2 - 10 } & SD & 1.05 & 4.15 & 0.14 & 0.25 & 0.10 & 0.03 & 0.04 & 15.63 \\
\cline { 2 - 9 }
\end{tabular}

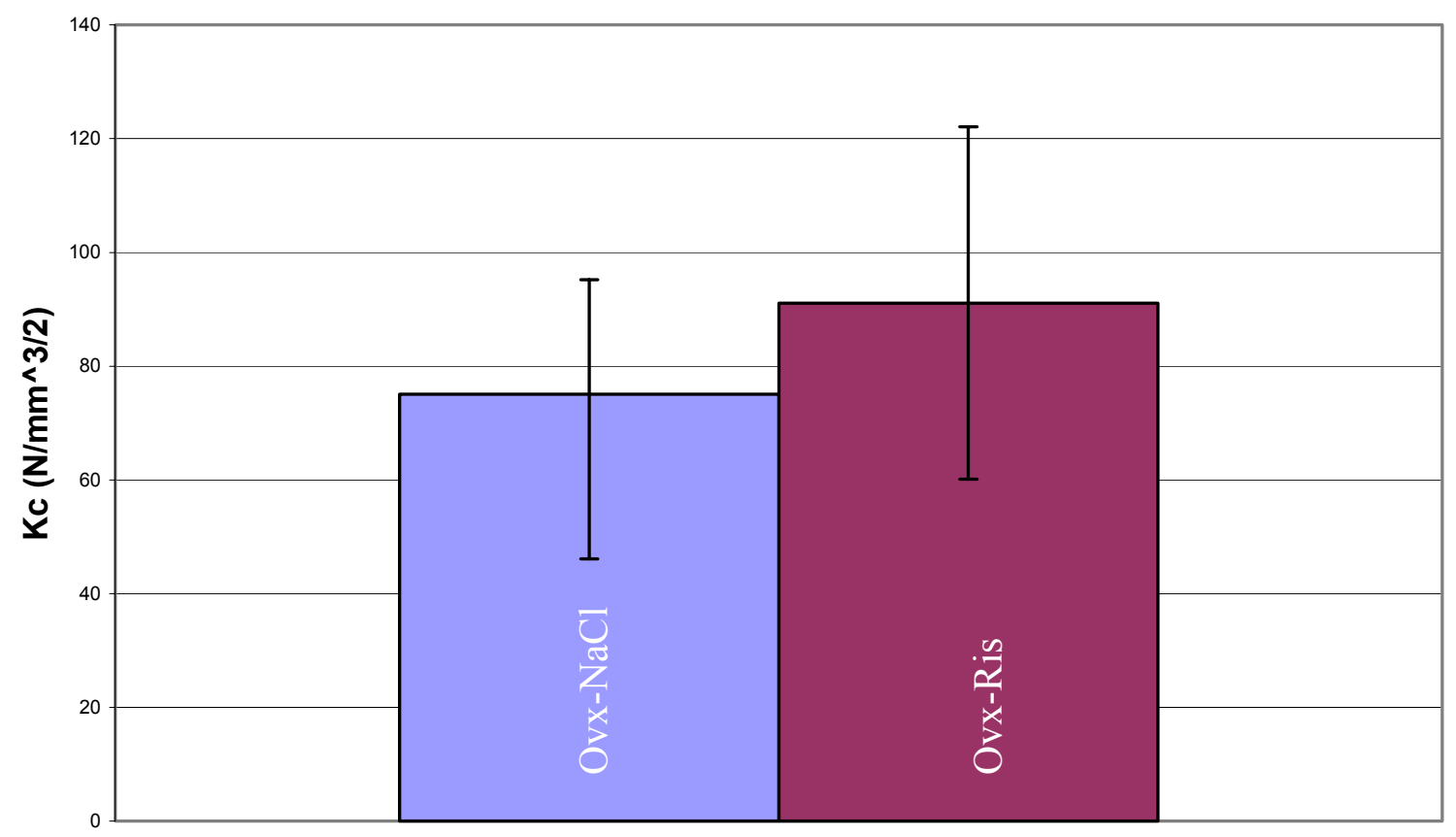

Figure 7.2-2: Stress intensity factor results for Group II (The average values are $43.88 \pm 11.78 \mathrm{~N} / \mathrm{mm}^{\wedge} 1.5$ for Ovx- $\mathrm{NaCl}$ and $54.16 \pm 15.63 \mathrm{~N} / \mathrm{mm}^{\wedge} 1.5$ for the Ovx-Ris group)

\section{Group III:}


The stress intensity factors for all of the treatment in Group III were

calculated, but none of the groups was significantly different, as can be seen in figure

7.2-3 and table 7.2-3.

Table 7.2-3: Fracture toughness test data for Group III

\begin{tabular}{|c|c|c|c|c|c|c|c|c|c|}
\hline Treatment & Number & $\begin{array}{c}\text { Mass } \\
(\mathrm{kg})\end{array}$ & $\mathrm{F}_{\mathrm{c}}(\mathrm{N})$ & $\mathrm{a}(\mathrm{mm})$ & $\mathrm{W}(\mathrm{mm})$ & $\mathrm{B}(\mathrm{mm})$ & $\mathrm{a} / \mathrm{W}$ & $\mathrm{f}(\mathrm{a} / \mathrm{W})$ & $\begin{array}{c}\mathrm{K}_{\mathrm{c}} \\
\left(\mathrm{N} / \mathrm{mm}^{\wedge} 3 / 2\right)\end{array}$ \\
\hline Normal & 127 & 4.91 & 13.2085 & 1.28 & 4.74 & 0.55 & 0.27 & 5.60 & 61.75 \\
\hline Normal & 128 & 2.90 & 7.0593 & 0.86 & 4.64 & 0.63 & 0.19 & 5.21 & 27.10 \\
\hline Normal & 129 & 5.02 & 9.9543 & 1.03 & 3.93 & 0.66 & 0.26 & 5.53 & 42.10 \\
\hline Normal & 130 & 4.85 & & 1.30 & 3.60 & 0.52 & 0.36 & 6.71 & 0.00 \\
\hline Normal & Average & 4.28 & 10.07 & 1.06 & 4.44 & 0.61 & 0.24 & 5.45 & 43.65 \\
\hline Norma & SD & 1.19 & 3.08 & 0.21 & 0.44 & 0.06 & 0.05 & 0.21 & 17.38 \\
\hline
\end{tabular}

\begin{tabular}{|c|c|c|c|c|c|c|c|c|c|}
\hline $\mathrm{NaCl}$ & 138 & 5.67 & 13.2714 & 1.40 & 4.67 & 0.56 & 0.30 & 5.89 & 64.60 \\
\hline $\mathrm{NaCl}$ & 139 & 4.71 & 12.3344 & 1.17 & 4.32 & 0.79 & 0.27 & 5.61 & 42.10 \\
\hline $\mathrm{NaCl}$ & 141 & 4.55 & 6.9785 & 1.38 & 4.47 & 0.64 & 0.31 & 5.99 & 30.91 \\
\hline $\mathrm{NaCl}$ & 142 & 4.31 & 16.0137 & 1.3 & 5.6 & 0.88 & 0.23 & 5.34 & 41.07 \\
\hline $\mathrm{NaCl}$ & Average & 4.81 & 12.15 & 1.31 & 4.77 & 0.72 & 0.28 & 5.71 & 44.67 \\
\hline $\mathrm{NaCl}$ & SD & 0.60 & 3.78 & 0.10 & 0.57 & 0.14 & 0.03 & 0.29 & 14.21 \\
\hline
\end{tabular}

\begin{tabular}{|c|c|c|c|c|c|c|c|c|c|}
\hline Ris & 131 & 4.61 & 12.0799 & 1.15 & 4.62 & 0.5 & 0.25 & 5.44 & 61.13 \\
\hline Ris & 132 & 4.9 & 15.7682 & 1.06 & 4.9 & 0.67 & 0.22 & 5.27 & 56.08 \\
\hline Ris & 133 & 5.45 & 9.7627 & 1.06 & 4.11 & 0.52 & 0.26 & 5.50 & 50.95 \\
\hline Ris & 136 & 4.76 & 17.8788 & 1.13 & 4.75 & 0.57 & 0.24 & 5.37 & 77.31 \\
\hline Ris & Average & 4.93 & 13.87 & 1.10 & 4.60 & 0.57 & 0.24 & 5.40 & 61.37 \\
\hline Ris & SD & 0.37 & 3.64 & 0.05 & 0.34 & 0.08 & 0.02 & 0.10 & 11.41 \\
\hline
\end{tabular}

\begin{tabular}{|c|c|c|c|c|c|c|c|c|c|}
\hline Ovx & 134 & 4.71 & 14.2085 & 1.02 & 4.94 & 0.66 & 0.21 & 5.24 & 50.80 \\
\hline Ovx & 135 & 4.83 & 11.7027 & 1.29 & 4.73 & 0.57 & 0.27 & 5.62 & 53.07 \\
\hline Ovx & 137 & 4.6 & 13.0379 & 1.2 & 4.5 & 0.67 & 0.27 & 5.57 & 51.10 \\
\hline Ovx & 140 & 4.88 & 16.5915 & 1.46 & 4.64 & 0.68 & 0.31 & 6.06 & 68.69 \\
\hline Ovx & Average & 4.76 & 13.89 & 1.24 & 4.70 & 0.65 & 0.27 & 5.63 & 55.91 \\
\hline Ovx & SD & 0.126 & 2.07 & 0.18 & 0.184 & 0.051 & 0.045 & 0.34 & 8.58 \\
\hline
\end{tabular}




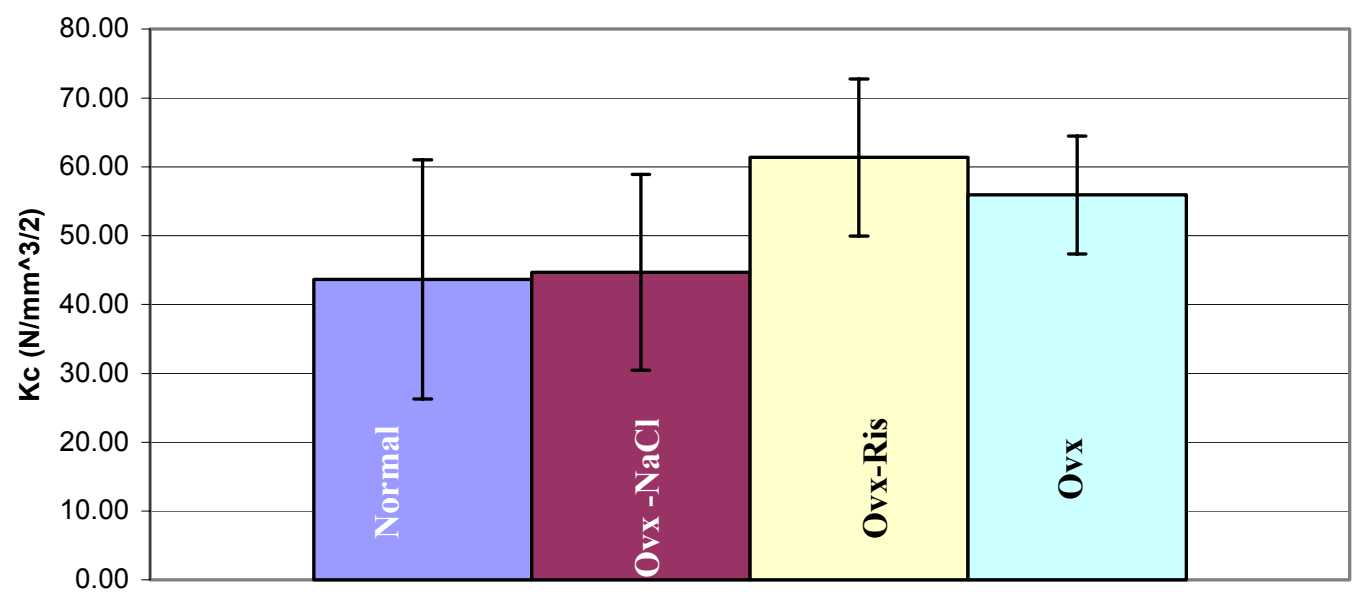

Figure 7.2-3: Stress intensity factor results for Group III (The average values were $43.65 \pm 17.38 \mathrm{~N} / \mathrm{mm}^{\wedge} 1.5$ for Normal, $44.67 \pm 14.21 \mathrm{~N} / \mathrm{mm}^{\wedge} 1.5$ for Ovx-NaCl, 61.37 $\pm 11.41 \mathrm{~N} / \mathrm{mm}^{\wedge} 1.5$ for Ovx-Ris , and $55.91 \pm 8.58 \mathrm{~N} / \mathrm{mm}^{\wedge} 1.5$ for Ovx.)

\section{All Groups}

When all of the stress intensity factors from all three groups were put together, the Ovx-Ris group was found to be significantly different the Normal group, but there was no other significant difference, as shown in figure 7.2-4, using data from tables 7.2-1, 7.2-2, and 7.2-3. 


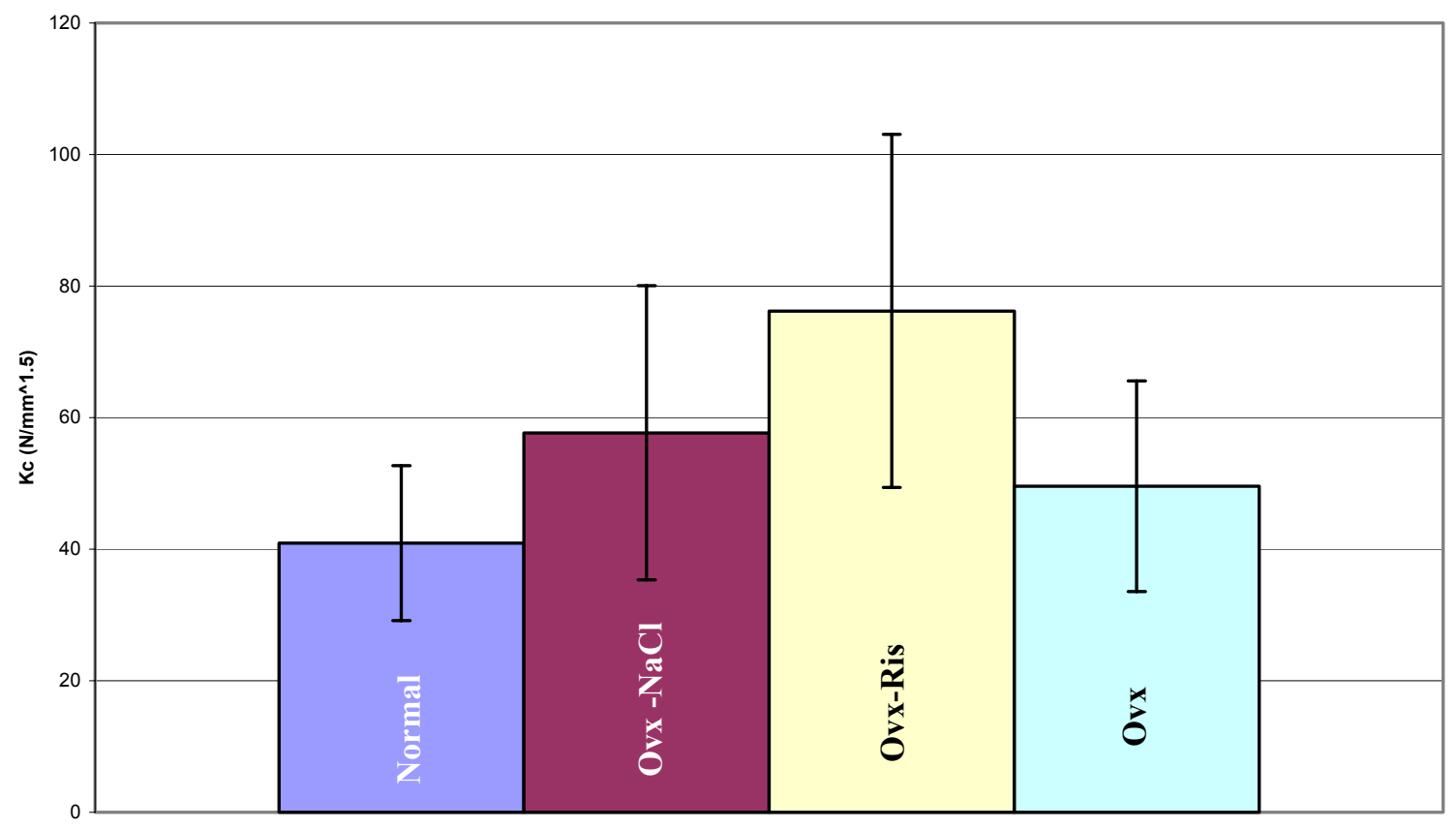

Figure 7.2-4: Stress intensity factor results for Groups I, II, and III (The average values were $40.93 \pm 11.77 \mathrm{~N} / \mathrm{mm}^{\wedge} 1.5$ for Normal, $57.71 \pm 22.36 \mathrm{~N} / \mathrm{mm}^{\wedge} 1.5$ for Ovx$\mathrm{NaCl}, 76.23 \pm 26.83 \mathrm{~N} / \mathrm{mm}^{\wedge} 1.5$ for Ovx-Ris , and $49.58 \pm 15.98 \mathrm{~N} / \mathrm{mm}^{\wedge} 1.5$ for Ovx.) 


\subsection{Femoral Neck Testing}

Femoral neck testing was performed for all three groups.

\section{Group I:}

In Group I, the Ovx group had a significantly higher amount of displacement from start of loading to fracture (figure 7.3-1 and table 7.3-1), but the load at fracture was not significantly different (figure 7.3-2 and table 7.3-1).

Table 7.3-1: Femoral Neck Test Results for Group I

\begin{tabular}{|c|c|c|c|}
\hline Specimen & Load $(\mathrm{N})$ & $\begin{array}{c}\text { Displacement } \\
(\mathrm{mm})\end{array}$ & Treatme \\
\hline 982 & -1339.68 & -2.4173 & ormal \\
\hline 983 & -858.275 & -2.4785 & \\
\hline Average & -1098.98 & -2.4479 & \\
\hline SD & 340.4025 & 0.043275 & \\
\hline 977 & -1183.48 & -3.2246 & Ovx \\
\hline 979 & -1037.7 & -3.4234 & Ovx \\
\hline Average & -1110.59 & -3.324 & \\
\hline SD & 103.0761 & 0.140573 & \\
\hline
\end{tabular}

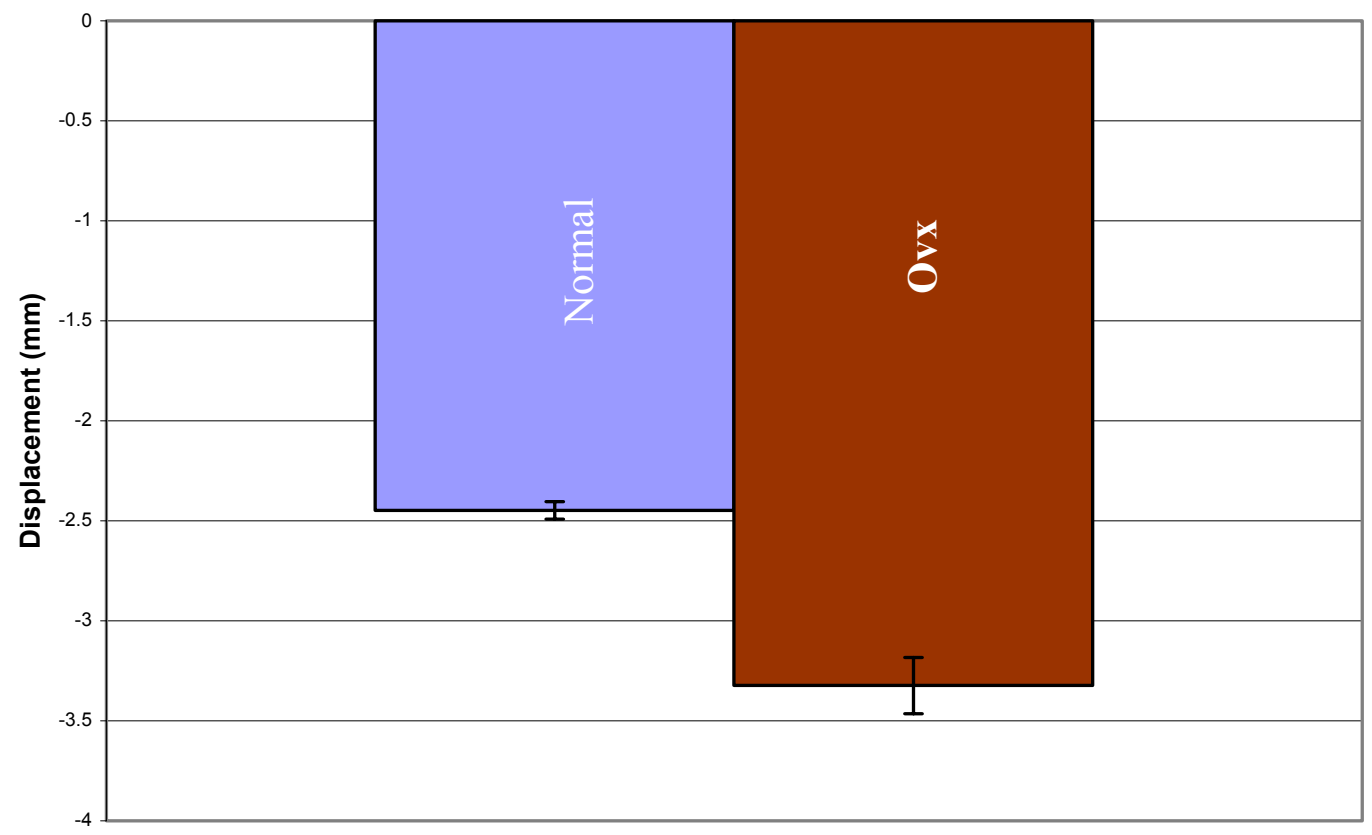


Figure 7.3-1: Comparison of Displacement at Fracture for Group I (Averages are for Normal $-2.45 \pm 0.04 \mathrm{~mm}$ and for Ovx $-3.32 \pm 0.14 \mathrm{~mm}$ ).

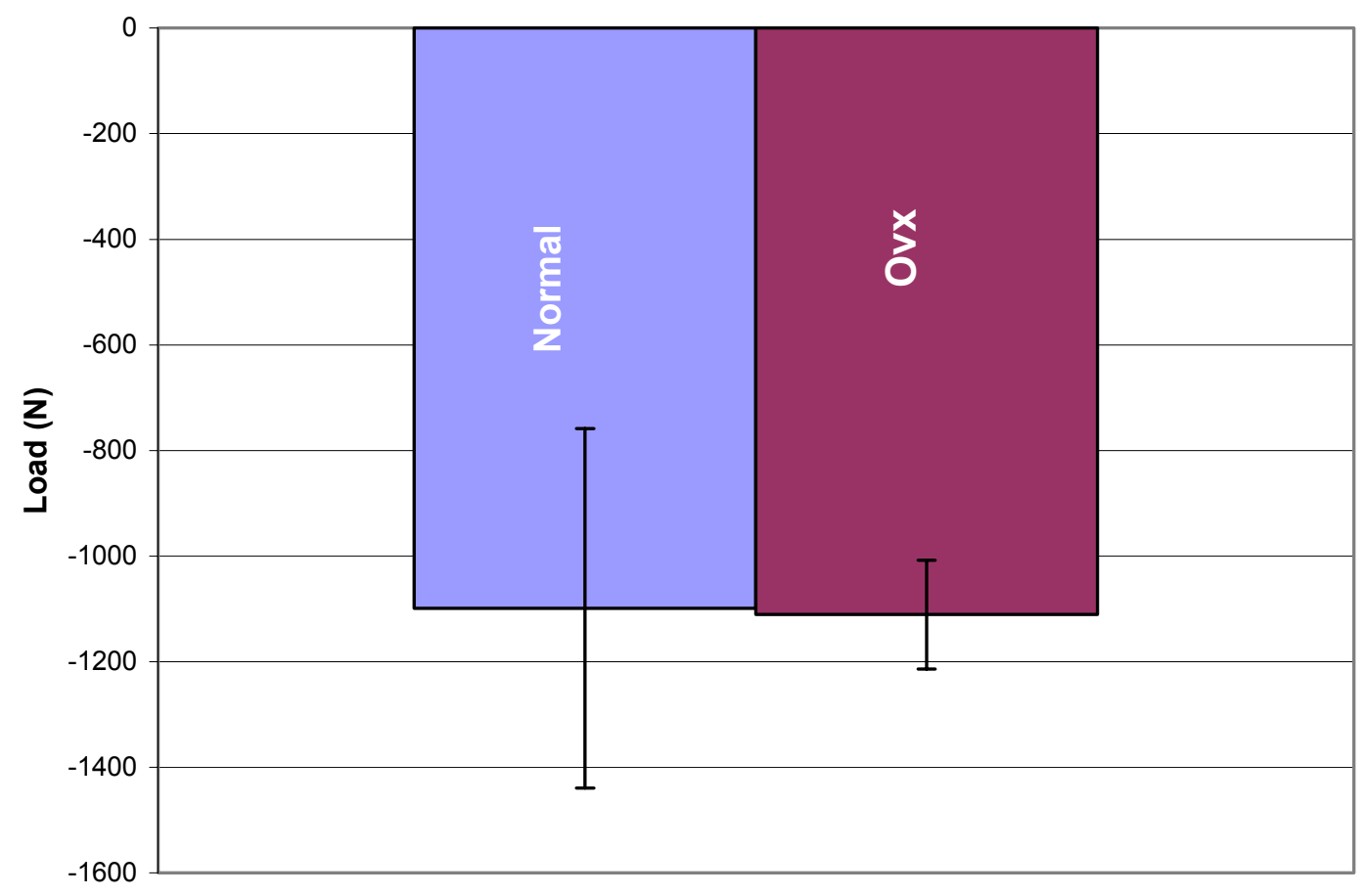

Figure 7.3-2: Graph of Force at Fracture for Group I (Averages are for Normal $-1099 \pm 340 \mathrm{~N}$ and for Ovx $-1111 \pm 103 \mathrm{~N}$ ).

\section{Group II:}

The displacement from beginning of load until fracture (figure 7.3-3 and table 7.3-2) and the ultimate load (figure 7.3-4 and table 7.3-2) were not significantly different for the Ovx- $\mathrm{NaCl}$ and Ovx-Ris groups. 
Table 7.3-2: Femoral Neck Test Results for Group II

\begin{tabular}{|c|c|c|c|}
\hline Specimen & $\begin{array}{c}\text { Force } \\
(\mathrm{N})\end{array}$ & $\begin{array}{c}\text { Displacement } \\
(\mathrm{mm})\end{array}$ & Treatment \\
\hline 19 & -1288.24 & -2.2057 & $\mathrm{NaCl}$ \\
\hline 20 & -932.227 & -2.1805 & $\mathrm{NaCl}$ \\
\hline 22 & -1063.78 & -2.7091 & $\mathrm{NaCl}$ \\
\hline 23 & -1483.79 & -2.4239 & $\mathrm{NaCl}$ \\
\hline Average & -1192.01 & -2.3798 & \multirow{2}{*}{} \\
\cline { 1 - 3 } SD & 243.8075 & 0.245230912 & \multirow{2}{|c}{} \\
\cline { 1 - 2 } & \multicolumn{3}{|c|}{}
\end{tabular}

\begin{tabular}{|c|c|c|c|}
\hline 21 & -1655.16 & -3.5199 & Ris \\
\hline 24 & -1176.6 & -1.9057 & Ris \\
\hline 25 & -949.53 & -1.7817 & Ris \\
\hline 26 & -718.903 & -1.7472 & Ris \\
\hline 27 & -1200.78 & -2.3099 & Ris \\
\hline Average & -1140.19 & -2.25288 & \multicolumn{1}{|}{} \\
\cline { 1 - 3 } SD & 347.8593 & 0.742773143 & \multicolumn{1}{|c}{} \\
\cline { 1 - 2 } & \multicolumn{2}{|c|}{}
\end{tabular}

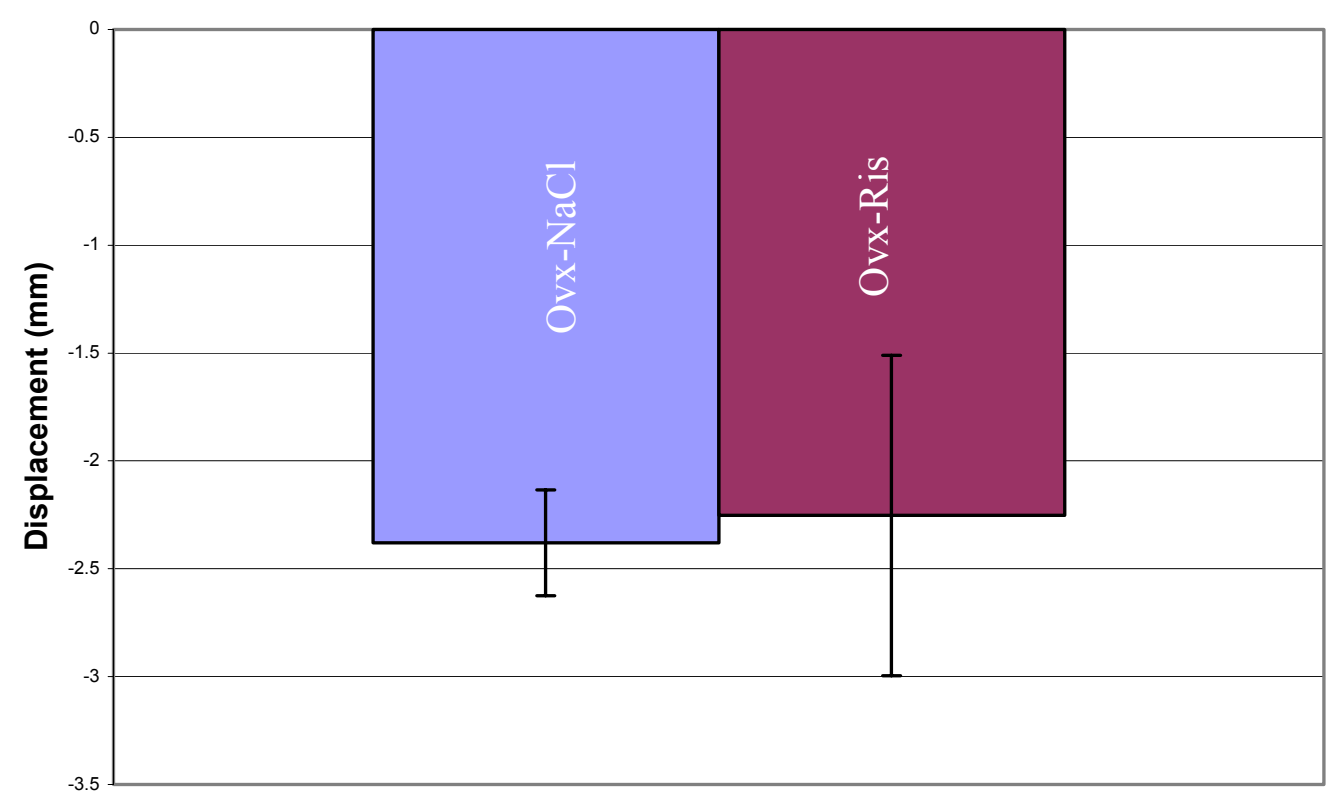

Figure 7.3-3: Femoral Head Displacement at Fracture for Group II (The average values were $-2.38 \pm 0.25 \mathrm{~mm}$ for $\mathrm{Ovx}-\mathrm{NaCl}$ and $-2.25 \pm 0.74 \mathrm{~mm}$.) 


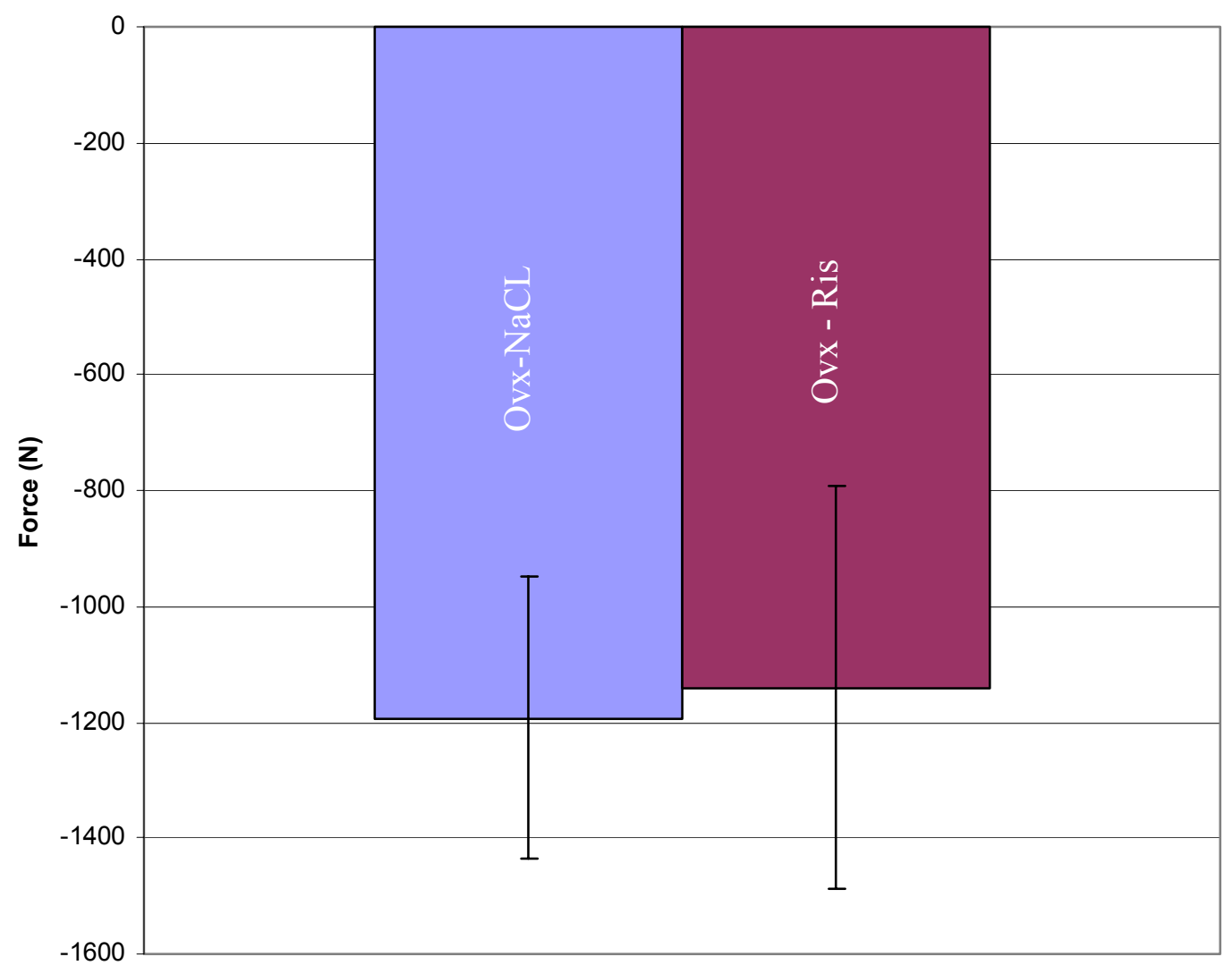

Figure 7.3-4: Femoral Head Force at Fracture for Group II (The average values were $1192.01 \pm 243.8 \mathrm{~N}$ for Ovx-NaCl and $-1140 \pm 347.9 \mathrm{~N}$.)

\section{Group III:}

The Ovx group had no significant differences in load (figure 7.3-5) or displacement (figure 7.3-6), this is also shown in table 7.3-3. 
Table 7.3-3: Femoral neck test data for Group III

\begin{tabular}{|c|c|c|c|}
\hline Specimen & Load $(\mathrm{N})$ & \begin{tabular}{|c|}
$\begin{array}{c}\text { Displacement } \\
(\mathrm{mm})\end{array}$ \\
\end{tabular} & Treatment \\
\hline 127 & 1082.5 & -2.89 & Normal \\
\hline 128 & 792.9 & -4.09 & Normal \\
\hline 129 & 1345.83 & -3.01 & Normal \\
\hline 130 & 942.7 & -2.84 & Normal \\
\hline Average & 1041.0 & -3.21 & \\
\hline SD & 235.2 & 0.59 & \\
\hline 131 & 1080.132 & -3.24 & Ris \\
\hline 132 & 1116.16 & -1.59 & Ris \\
\hline 133 & 1262.88 & -2.72 & Ris \\
\hline 136 & 890.5103 & -3.27 & Ris \\
\hline Average & 1087.421 & -2.71 & \\
\hline SD & 153.2304 & 0.78 & \\
\hline 134 & 1084.635 & -3.23 & Ovx \\
\hline 135 & 1638.568 & -3.04 & Ovx \\
\hline 137 & 1289.901 & -2.48 & Ovx \\
\hline 140 & 1120.427 & -3.07 & Ovx \\
\hline Average & 1283.383 & -2.95 & \\
\hline SD & 253.1495 & 0.33 & \\
\hline 138 & 1214.3 & -2.46 & $\mathrm{NaCl}$ \\
\hline 139 & 1030.8 & -2.59 & $\mathrm{NaCl}$ \\
\hline 141 & 937.7 & -3.14 & $\mathrm{NaCl}$ \\
\hline 142 & 1155.5 & -3.12 & $\mathrm{NaCl}$ \\
\hline Average & 1084.6 & -2.83 & \\
\hline SD & 124. 3 & 0.36 & \\
\hline
\end{tabular}




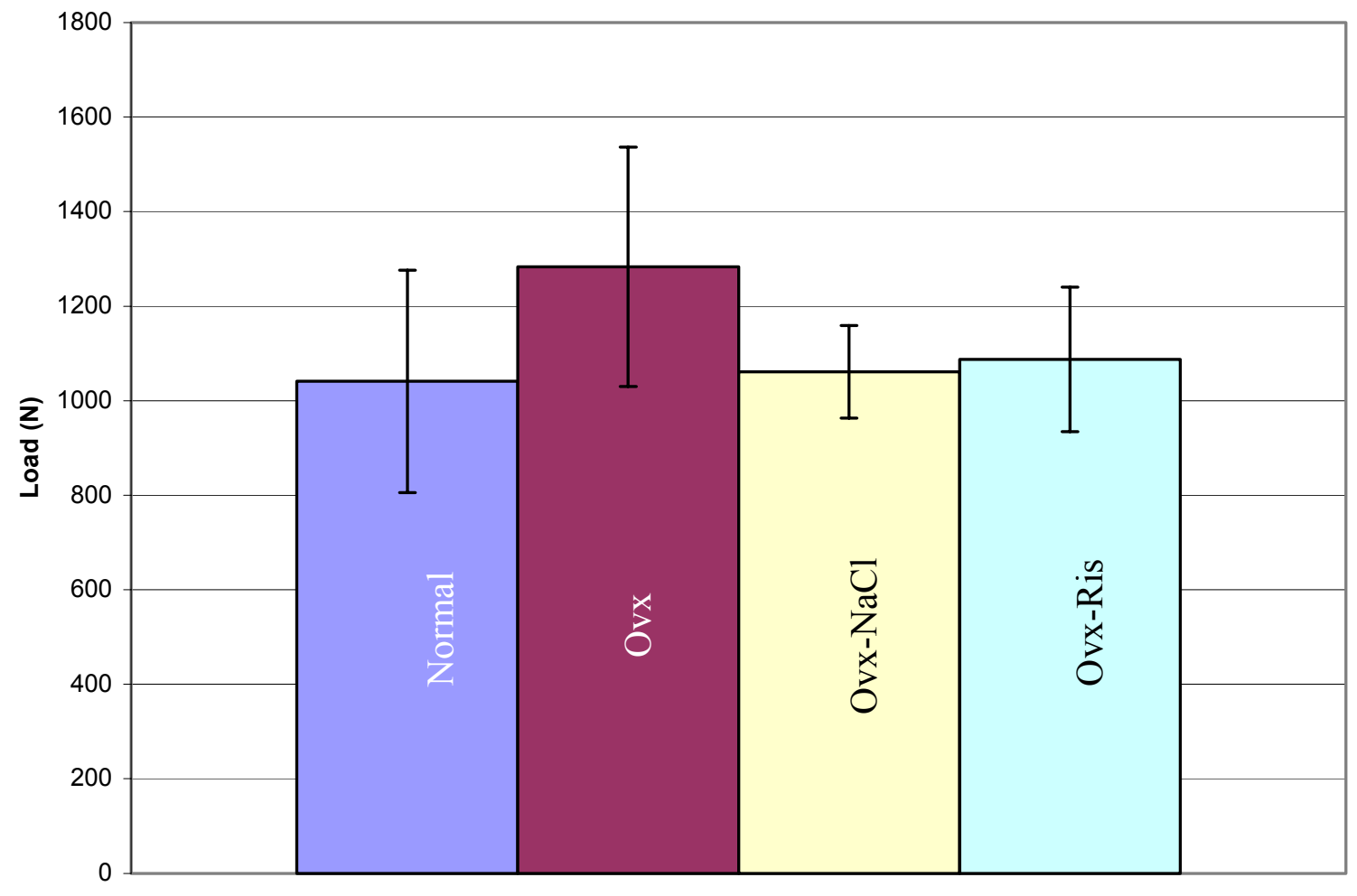

Figure 7.3-5: Load at Fracture of Femoral Neck for Group III (The average values were $1041.0 \pm 235.2 \mathrm{~N}$ for Normal, $1283.4 \pm 253.1 \mathrm{~N}$ for Ovx, 1084.6 $\pm 124.3 \mathrm{~N}$ Ovx-NaCl, and $1087.4 \pm 153.2 \mathrm{~N}$ for Ovx-Ris.) 


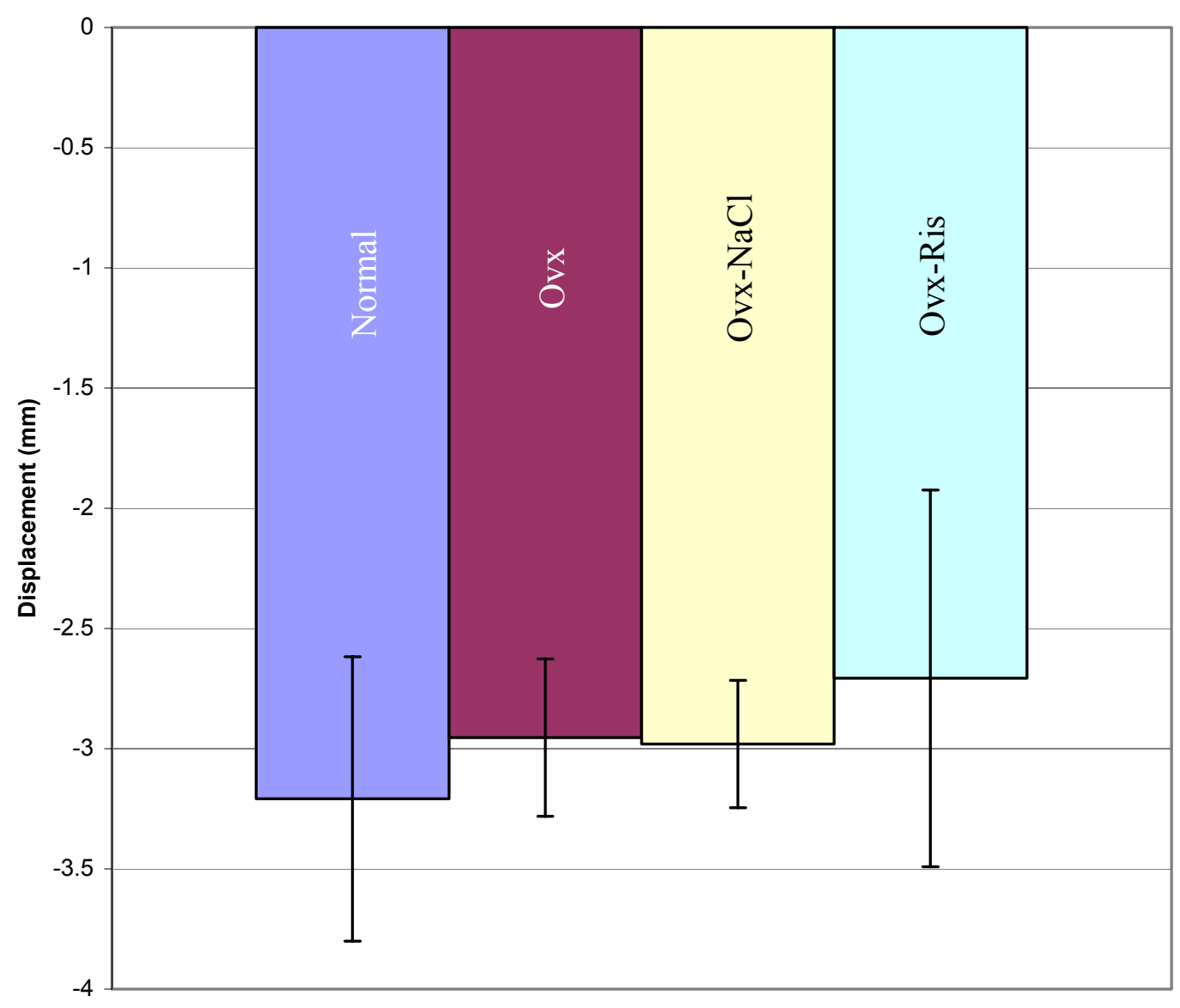

Figure 7.3-6: Femoral head displacement at fracture for Group III (The average values were $-3.21 \pm 0.59 \mathrm{~mm}$ for Normal, $-2.95 \pm 0.33 \mathrm{~mm}$ for Ovx, $-2.83 \pm 0.36 \mathrm{~mm}$ Ovx- $\mathrm{NaCl}$, and $-2.71 \pm 0.78 \mathrm{~mm}$ for Ovx-Ris.)

\section{All Three Test Groups:}

Data from all three test groups were compiled (tables 7.3-1, 7.3-2, and 7.3-3), and the results were compared, but there were no significant differences, as shown in figures $7.3-7$ and 7.3-8. 


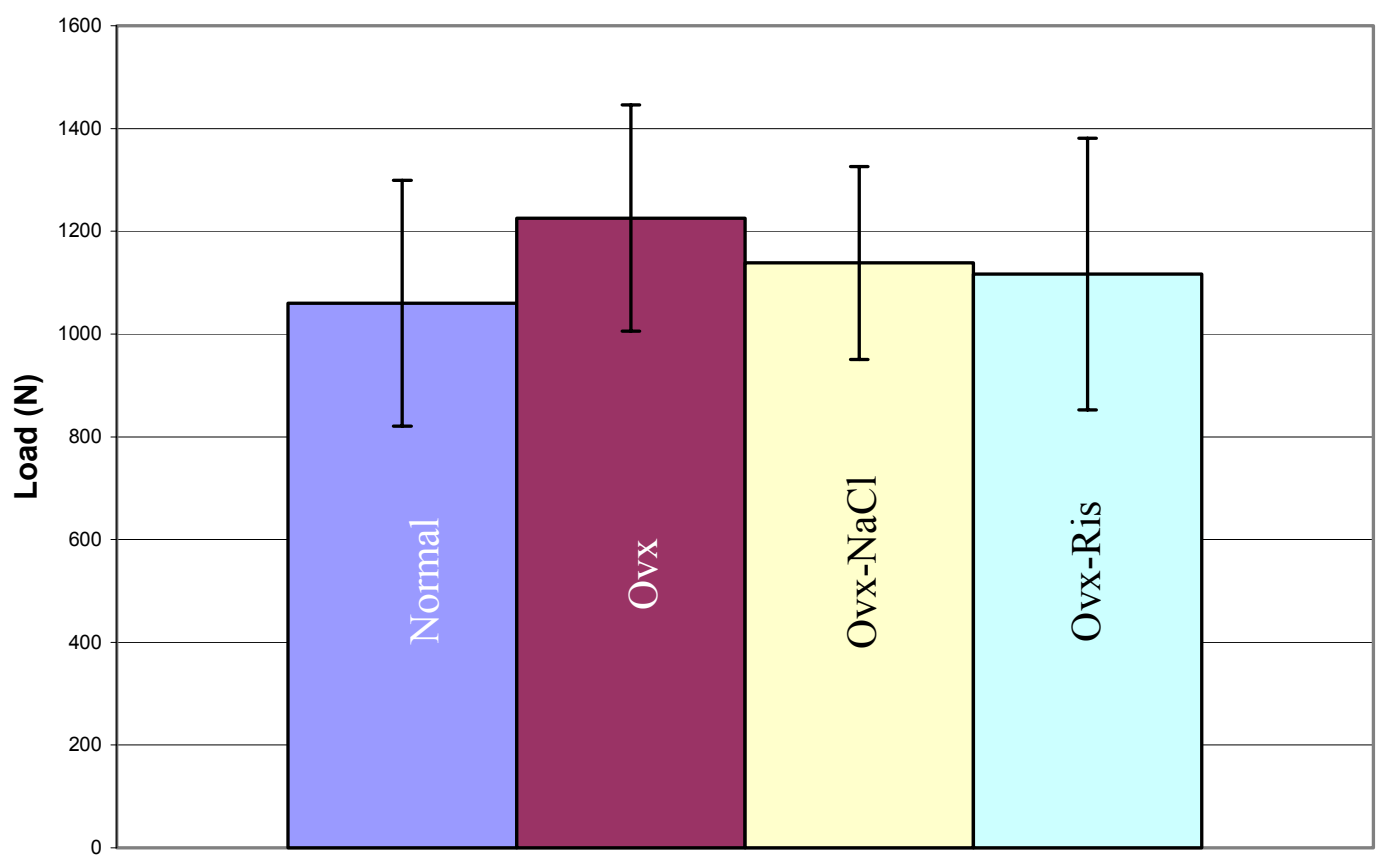

Figure 7.3-7: Femoral neck ultimate strength for all three groups (The average values were $1060 \pm 239.3 \mathrm{~N}$ for Normal, $1225.8 \pm 220.3 \mathrm{~N}$ for Ovx, 1138.3 $\pm 188.1 \mathrm{~N}$ for Ovx- $\mathrm{NaCl}$, and $1116.7 \pm 264.7 \mathrm{~N}$ for Ovx-Ris.)

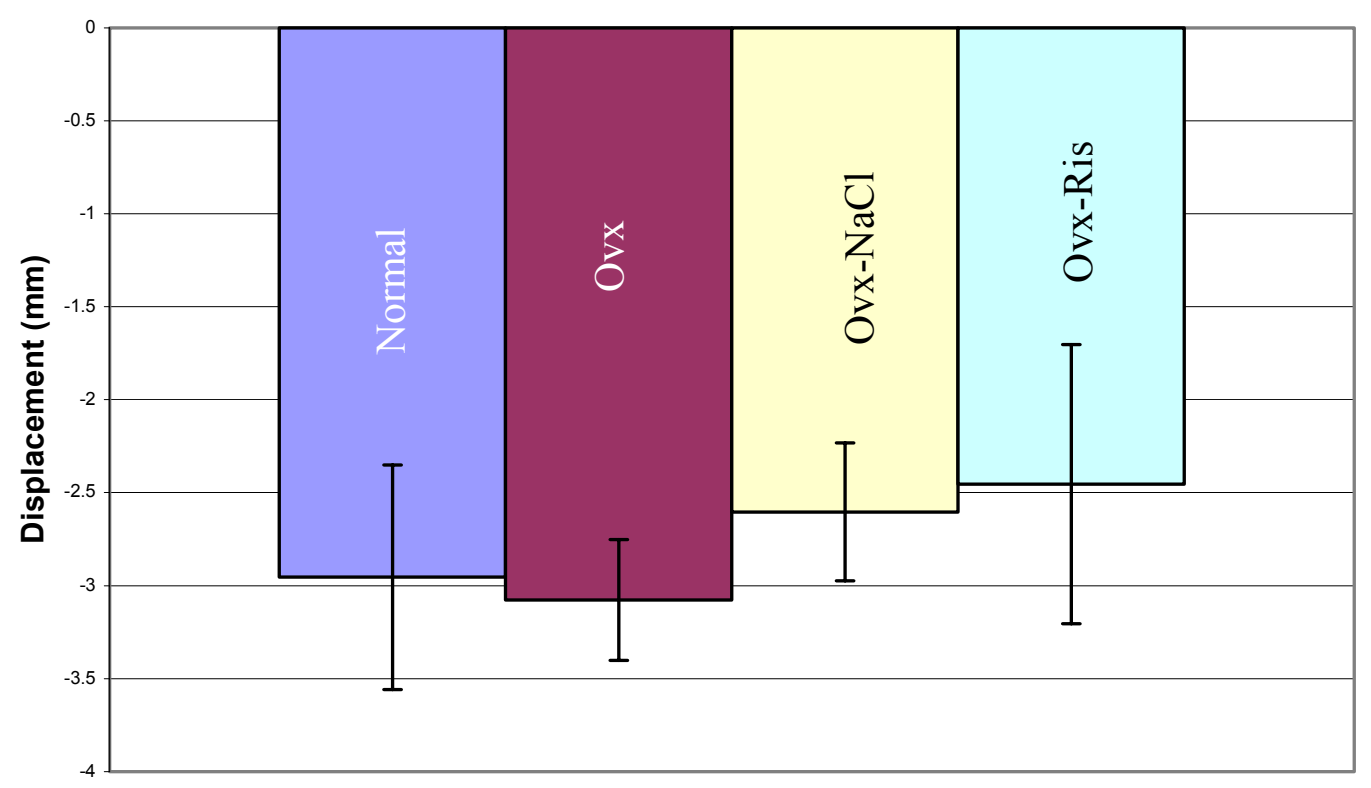

Figure 7.3-8: Femoral head displacement at time of fracture for all three groups (The average values were $-2.96 \pm 0.60 \mathrm{~mm}$ for Normal, $-3.08 \pm 0.32 \mathrm{~mm}$ for Ovx,$-2.60 \pm$ $0.37 \mathrm{~mm}$ for $\mathrm{Ovx}-\mathrm{NaCl}$, and $-2.45 \pm 0.75 \mathrm{~N}$ for Ovx-Ris.) 


\subsection{Histomorphometric Results}

The porosity was measured for Groups I and II, but there was no significant difference between treatment groups as shown in figures 7.4-1 and 7.4-2.

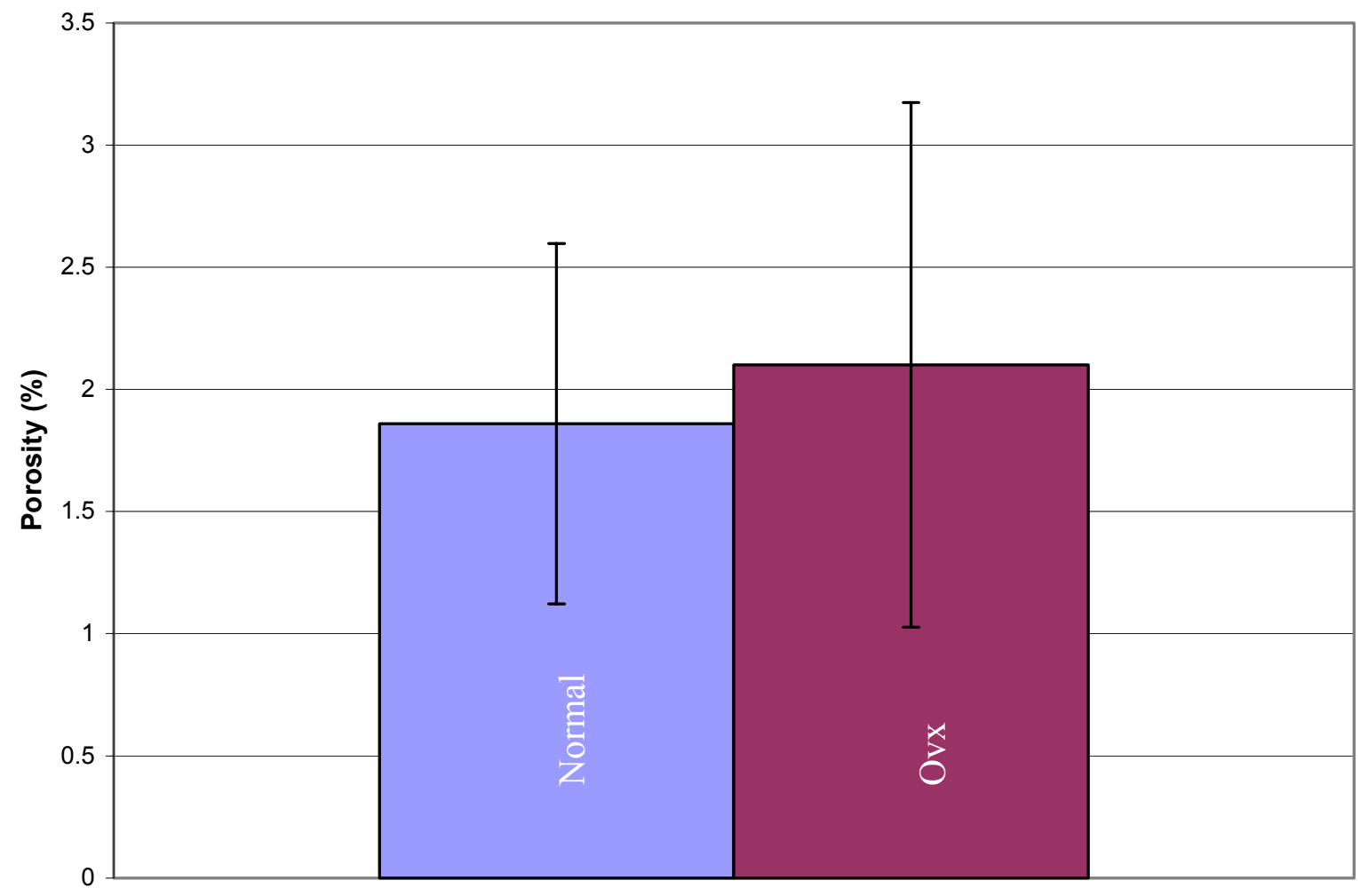

Figure 7.4-1: Porosity Percentage (Po) for Group I (The average values were $1.86 \pm 0.74$ for Normal, and $2.10 \pm 1.07$ for Ovx.) 


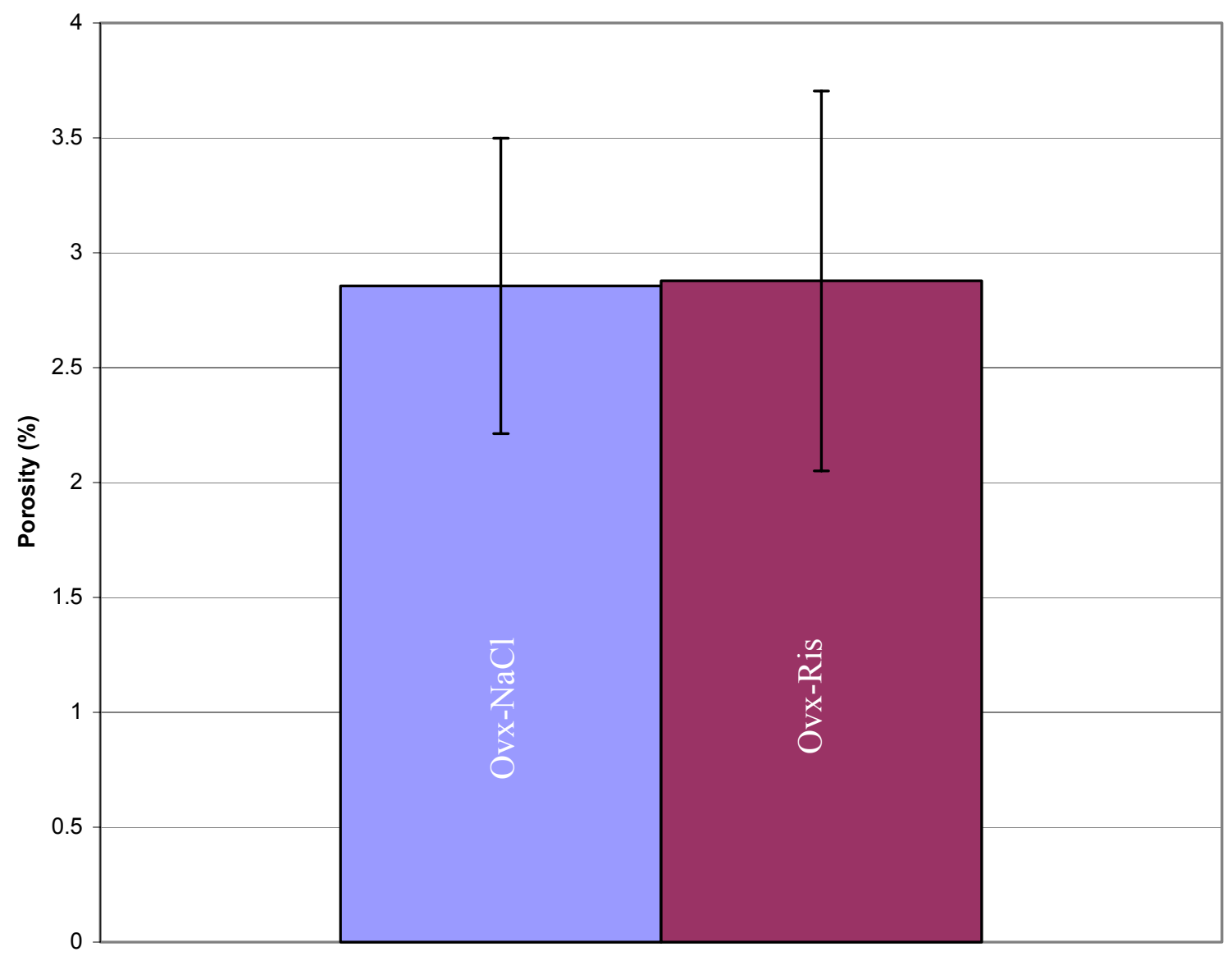

Figure 7.4-2: Porosity Percentage (Po) for Group II (The average values were $2.86 \pm 0.64$ for $\mathrm{Ovx}-\mathrm{NaCl}$, and $2.88 \pm 0.82$ for Ovx-Ris.) 


\subsection{DEXA Scan Results}

Table 7.5-1: DEXA Scan results from OSU and Analysis

\begin{tabular}{|c|c|c|c|c|c|c|c|c|}
\hline & \multicolumn{4}{|c|}{ Total } & \multicolumn{3}{|c|}{ Proximal $1 / 3$} & \multirow[b]{2}{*}{ Treatment } \\
\hline Number & Weight & BMD & BMC & Area & BMD & BMC & Area & \\
\hline & $\mathrm{kg}$ & $\mathrm{g} / \mathrm{cm}^{2}$ & g & $\mathrm{cm}^{2}$ & $\mathrm{~g} / \mathrm{cm}^{2}$ & $g$ & $\mathrm{~cm}^{2}$ & \\
\hline 19 & 4.9 & 0.458 & 5.694 & 12.443 & 0.381 & 1.974 & 5.185 & $\mathrm{NaCl}$ \\
\hline 20 & 4.4 & 0.427 & 5.257 & 12.307 & 0.358 & 1.882 & 5.251 & $\mathrm{NaCl}$ \\
\hline 22 & 5.1 & 0.382 & 4.269 & 11.186 & 0.321 & 1.473 & 4.593 & $\mathrm{NaCl}$ \\
\hline 23 & 4.8 & 0.469 & 5.046 & 10.751 & 0.405 & 1.768 & 4.37 & $\mathrm{NaCl}$ \\
\hline Avg & 4.8 & 0.434 & 5.0665 & 11.67175 & 0.36625 & 1.77425 & 4.84975 & \\
\hline Avg/kg & & 0.090417 & 1.055521 & 2.431615 & 0.076302 & 0.369635 & 1.010365 & \\
\hline 21 & 4.8 & 0.46 & 5.045 & 10.975 & 0.389 & 1.744 & 4.484 & Ris \\
\hline 24 & 6 & 0.439 & 5.161 & 11.762 & 0.37 & 1.813 & 4.905 & Ris \\
\hline 25 & 4.3 & 0.364 & 0.3766 & 10.348 & 0.284 & 1.248 & 4.395 & Ris \\
\hline 26 & 3.5 & 0.438 & 4.816 & 10.986 & 0.369 & 1.634 & 4.42 & Ris \\
\hline 27 & 3.7 & 0.371 & 4.213 & 11.347 & 0.319 & 1.509 & 4.738 & Ris \\
\hline Avg & 4.46 & 0.4144 & 3.92232 & 11.0836 & 0.3462 & 1.5896 & 4.5884 & \\
\hline Avg $/ \mathrm{kg}$ & & 0.092915 & 0.879444 & 2.485112 & 0.077623 & 0.356413 & 1.028789 & \\
\hline \multirow{2}{*}{$\begin{array}{l}\text { Difference } \\
\text { (NaCl-Ris) }\end{array}$} & 0.34 & 0.0196 & 1.14418 & 0.58815 & 0.02005 & 0.18465 & 0.26135 & \\
\hline & Normalized & -0.0025 & 0.176077 & -0.0535 & -0.00132 & 0.013223 & -0.01842 & \\
\hline \multirow{2}{*}{$\begin{array}{c}\text { \%Diff } \\
((\mathrm{NaCl}- \\
\left.\text { Ris }) / \mathrm{Ris}^{*} 100\right)\end{array}$} & 762331839 & 4.72973 & 29171 & 5306489 & 579145 & 1161613 & 5695885 & \\
\hline & Normalized & -2.68863 & 20.02139 & -2.15272 & -1.70211 & 3.709987 & -1.79091 & \\
\hline
\end{tabular}

The BMD of the Ris group is lower than that of the Saline control group, but when it is normalized on a per $\mathrm{kg}$ of body weight basis, the BMD of the Ris specimens are $2.7 \%$ greater than the saline control rabbits. The BMD for the proximal third of the bone is greater in the Ris group, but only by $1.8 \%$ (normalized for body weight). There were no significant differences between treatment groups regardless of parameter. The DEXA results when plotted against body mass shows a slight trend, as shown in figure 7.5-1 


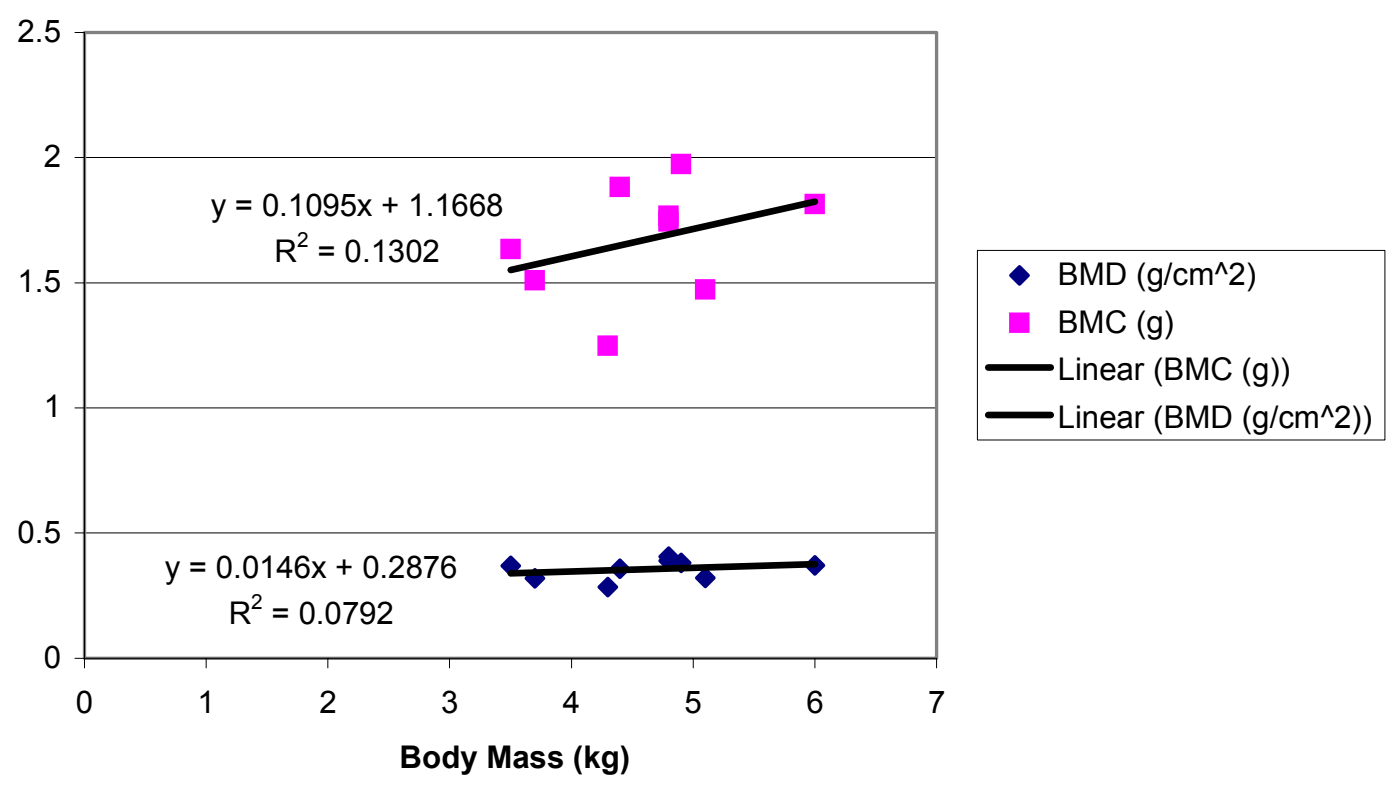

Figure 7.5-1: DEXA scan results versus body mass.

\subsection{Weight Measurements}

The weights of the animals were monitored in the injection groups because the dose volume was determined by the weight of the animal. The weights of the other two treatment groups were monitored for comparison purposes.

The average weight at dissection was not significantly different between any of the groups. The change in weight from the first day of the 140 day treatment until sacrifice was not significantly different. The percent change from the beginning weight was, also, not significantly different for the Normal group compared to all of the Ovx groups, and there is no significant difference for the percent change of any of the Ovx groups, but there is the beginnings of a trend towards an increased percentage change in mass for the Ovx groups. The relationships in mass can be seen 
in figure 7.6-1 and table 7.6-1, Group I was not included, because weekly mass data is not available for this group.

Table 7.6-1: Mass Results for Groups II and III

\begin{tabular}{|c|c|c|c|c|}
\hline Specimen & Treatment & Mass $(\mathrm{kg})$ & Change $(\mathrm{kg})$ & \%Change \\
\hline 127 & Normal & 4.10 & 0.81 & 19.76 \\
\hline 128 & Normal & 3.00 & -0.10 & -3.33 \\
\hline 129 & Normal & 4.00 & 1.02 & 25.50 \\
\hline \multirow[t]{3}{*}{130} & Normal & 4.50 & 0.35 & 7.78 \\
\hline & Average & 3.90 & 0.52 & 12.43 \\
\hline & SD & 0.64 & 0.50 & 12.84 \\
\hline 134 & Ovx & 3.70 & 1.01 & 27.30 \\
\hline 135 & Ovx & 4.00 & 0.83 & 20.75 \\
\hline 137 & Ovx & 3.80 & 0.80 & 21.05 \\
\hline \multirow[t]{3}{*}{140} & Ovx & 4.10 & 0.78 & 19.02 \\
\hline & Average & 3.90 & 0.86 & 22.03 \\
\hline & SD & 0.18 & 0.11 & 3.62 \\
\hline 19 & $\mathrm{NaCl}$ & 4.60 & 0.30 & 6.52 \\
\hline 20 & $\mathrm{NaCl}$ & 3.60 & 0.80 & 22.22 \\
\hline 22 & $\mathrm{NaCl}$ & 3.90 & 1.20 & 30.77 \\
\hline 23 & $\mathrm{NaCl}$ & 4.10 & 0.70 & 17.07 \\
\hline 138 & $\mathrm{NaCl}$ & 4.20 & 1.47 & 35.00 \\
\hline 139 & $\mathrm{NaCl}$ & 3.97 & 0.74 & 18.64 \\
\hline 141 & $\mathrm{NaCl}$ & 4.08 & 0.47 & 11.52 \\
\hline \multirow[t]{3}{*}{142} & $\mathrm{NaCl}$ & 3.79 & 0.52 & 13.72 \\
\hline & Average & 4.03 & 0.78 & 19.43 \\
\hline & SD & 0.30 & 0.39 & 9.61 \\
\hline 21 & Ris & 4.20 & 0.60 & 14.29 \\
\hline 24 & Ris & 4.70 & 1.30 & 27.66 \\
\hline 25 & Ris & 3.80 & 0.50 & 13.16 \\
\hline 26 & Ris & 3.50 & 0.00 & 0.00 \\
\hline 27 & Ris & 3.50 & 0.20 & 5.71 \\
\hline 131 & Ris & 3.93 & 0.68 & 17.30 \\
\hline 132 & Ris & 3.88 & 1.02 & 26.29 \\
\hline 133 & Ris & 4.35 & 1.15 & 26.44 \\
\hline \multirow[t]{3}{*}{136} & Ris & 3.64 & 1.12 & 30.77 \\
\hline & Average & 3.94 & 0.73 & 17.96 \\
\hline & SD & 0.41 & 0.45 & 10.66 \\
\hline
\end{tabular}




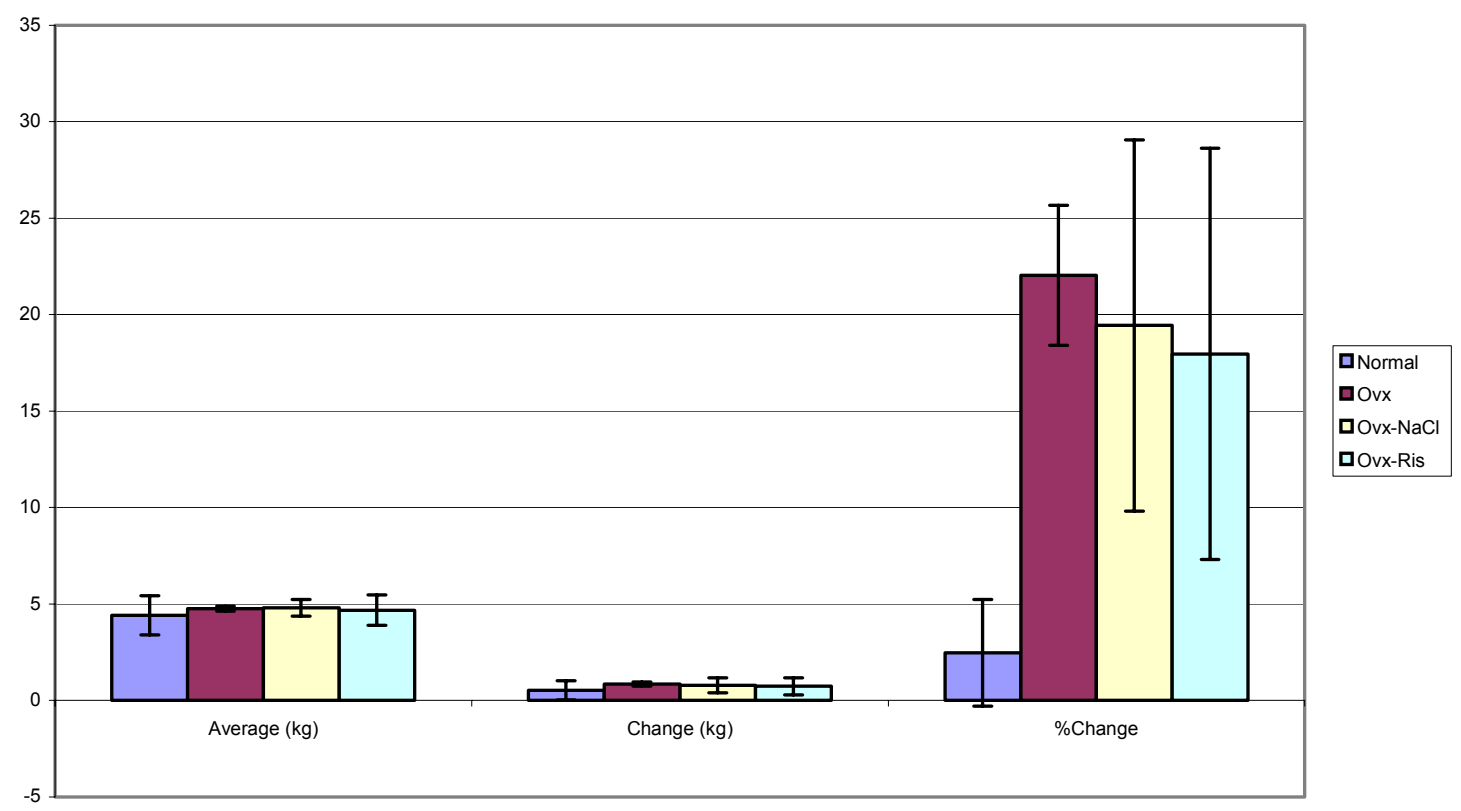

Figure 7.6-1: Mass Results for Groups II and III

\subsection{Comparison of Results}

The compliance is the inverse of the slope of the linear portion of the fracture toughness data, as shown previously. A lower compliance value implies a stiffer material. When the compliance is plotted versus the body mass, a relationship becomes evident as seen in figures 7.7-1 and 7.7-2. 


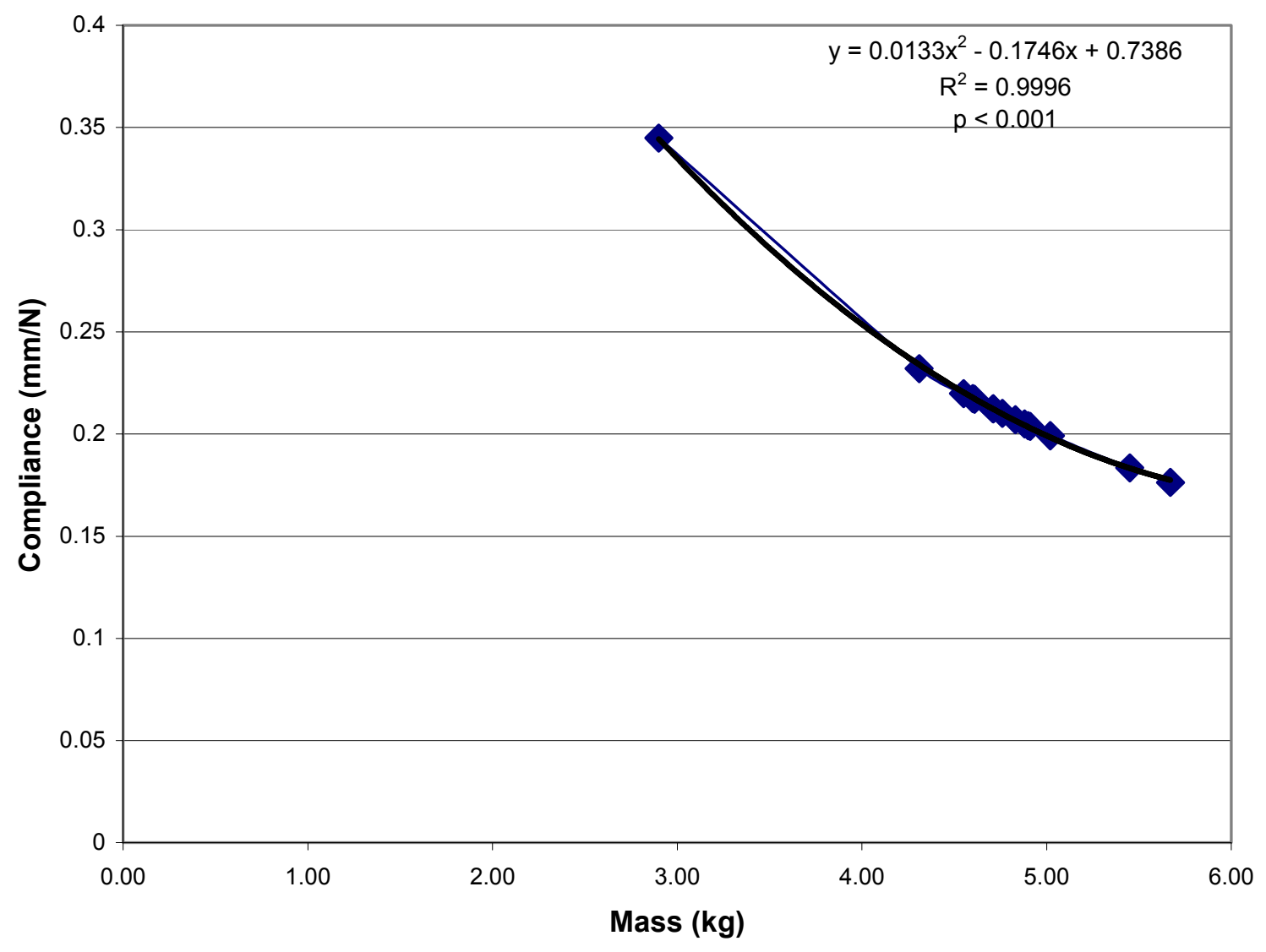

Figure 7.7-1: Compliance versus body mass for Group III, shown with a second degree polynomial fit. 


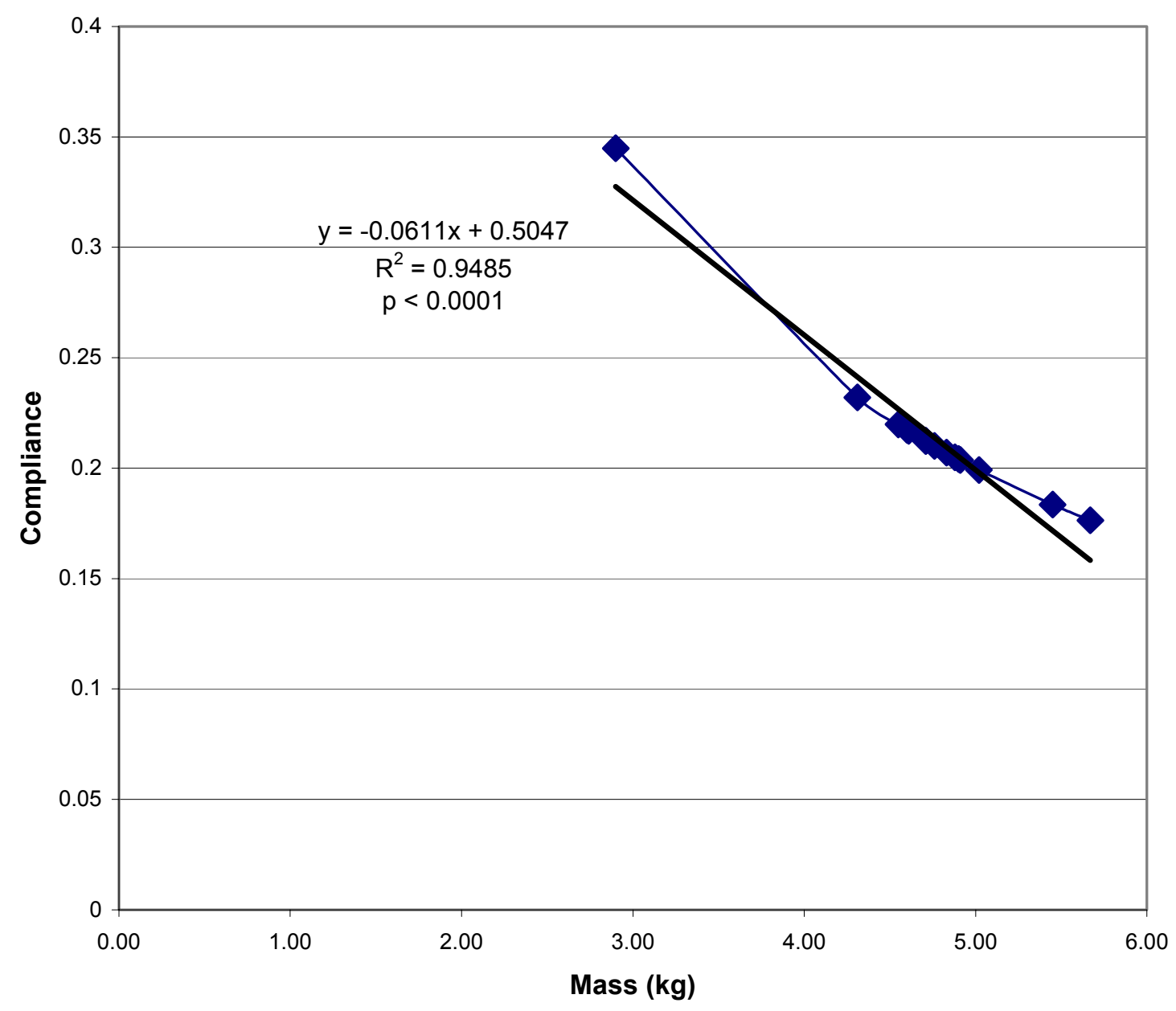

Figure 7.7-2: Compliance versus body mass data for Group III, with a linear trend line added.

To better understand the mechanisms of bone fragility in the estrogen deficient rabbit, relationships were investigated between various experimental measures. No significant relationships were found, other than the compliance versus mass as shown in figures 7.7-1 and 7.7-2, but some graphs of interest are:

- Load versus Mass for Groups II and III (Figure 7.7-3)

- Femoral Head Displacement versus Body Mass for Groups II and III (Figure $7.7-4)$

- Femoral Head Displacement versus Body Mass for Group III (Figure 7.7-5) 
- $\mathrm{BMD}$ and BMC versus Body Mass (Figure 7.7-6)

- Stress Intensity Factor versus Po for Group I (Figure 7.7-7)

- Stress Intensity Factor versus Po for Group II (Figure 7.7-8)

- Po versus Body Mass for Group II and III (Figure 7.7-9).

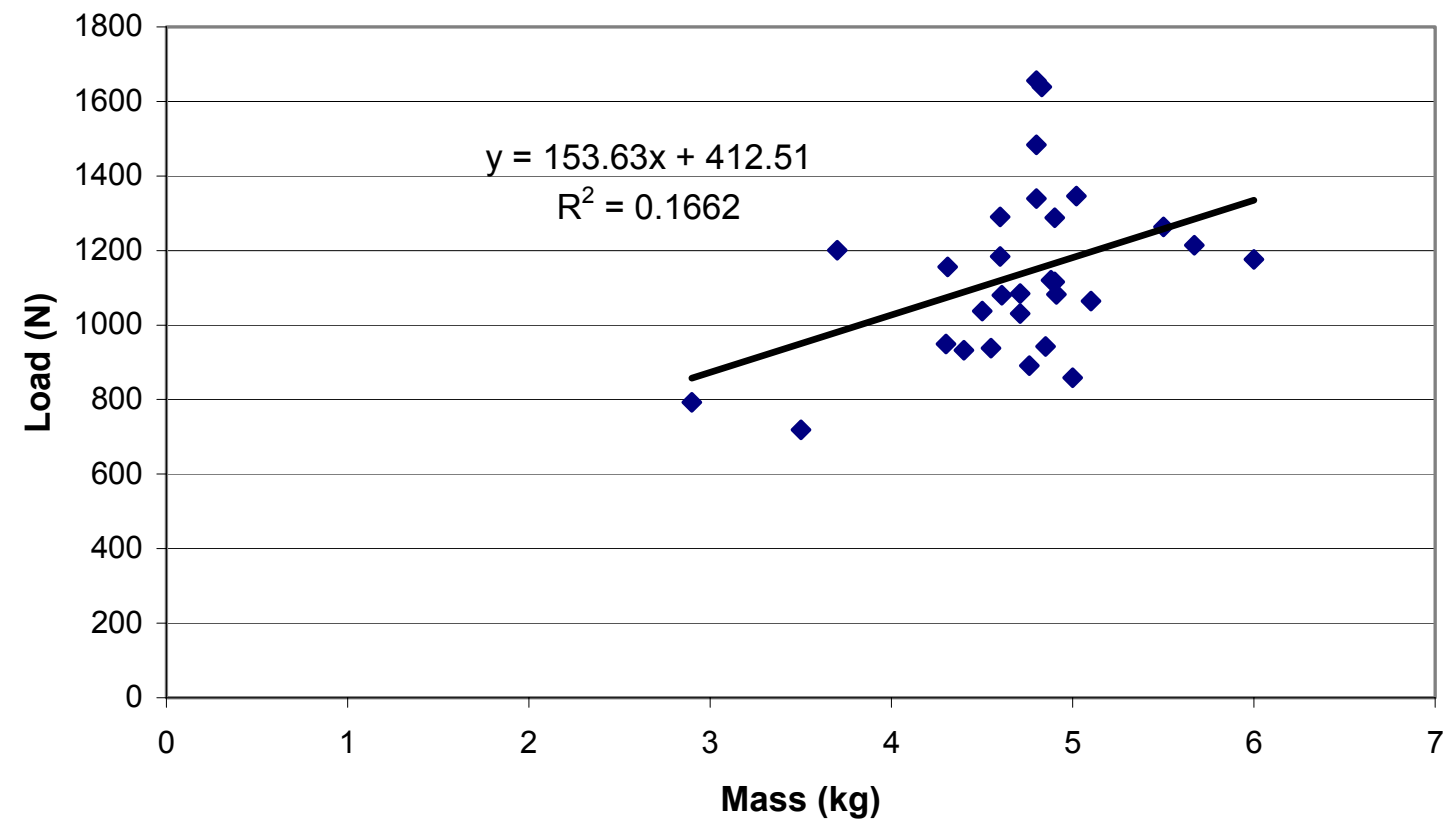

Figure 7.7-3: Load versus mass for Groups II and III with linear fit. 


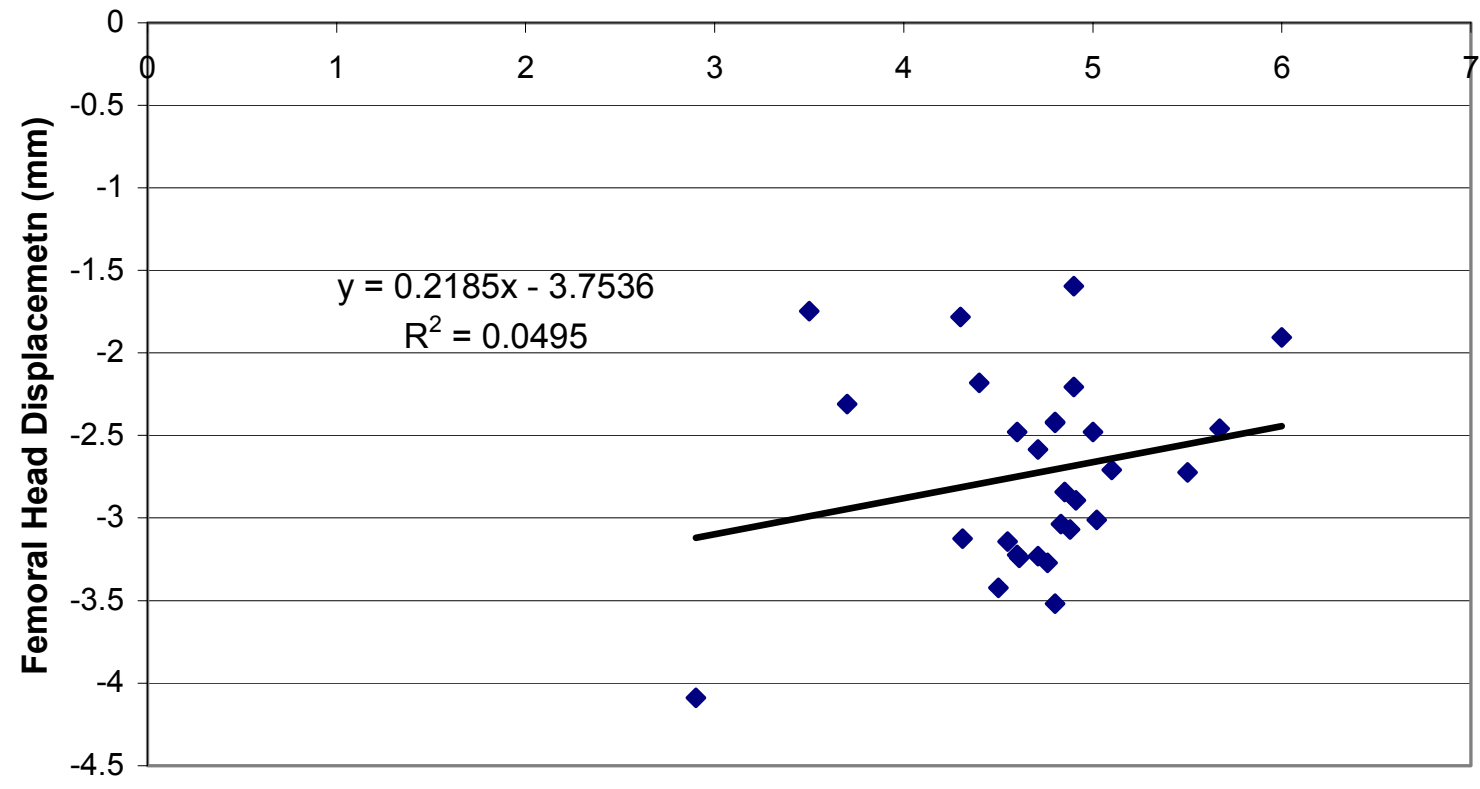

Body Mass (kg)

Figure 7.7-4: Femoral head displacement data for Groups II and III versus body mass.

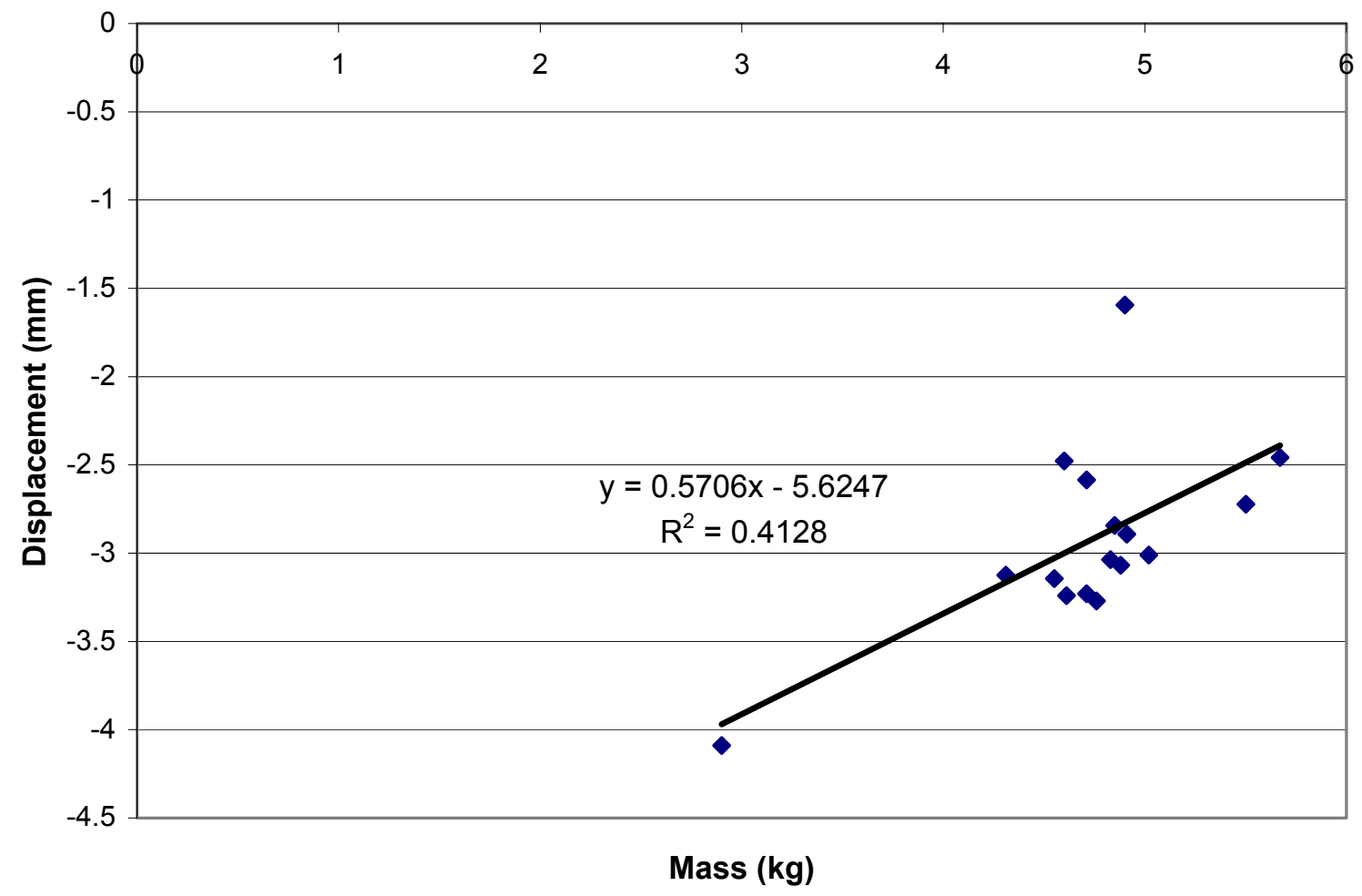


Figure 7.7-5: Displacement of the femoral head at fracture of Group III versus body mass

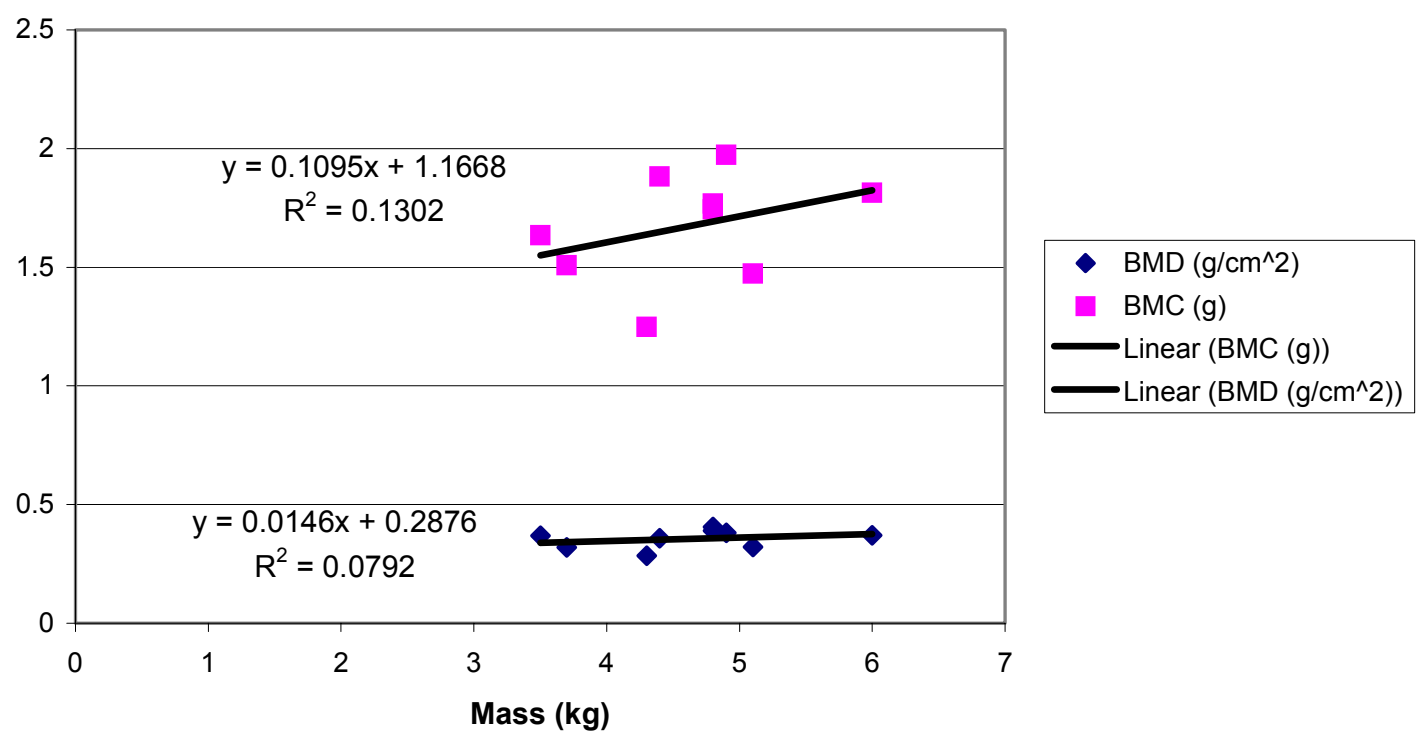

Figure 7.7-6: Plot of BMD and BMC versus body mass for Group II. 


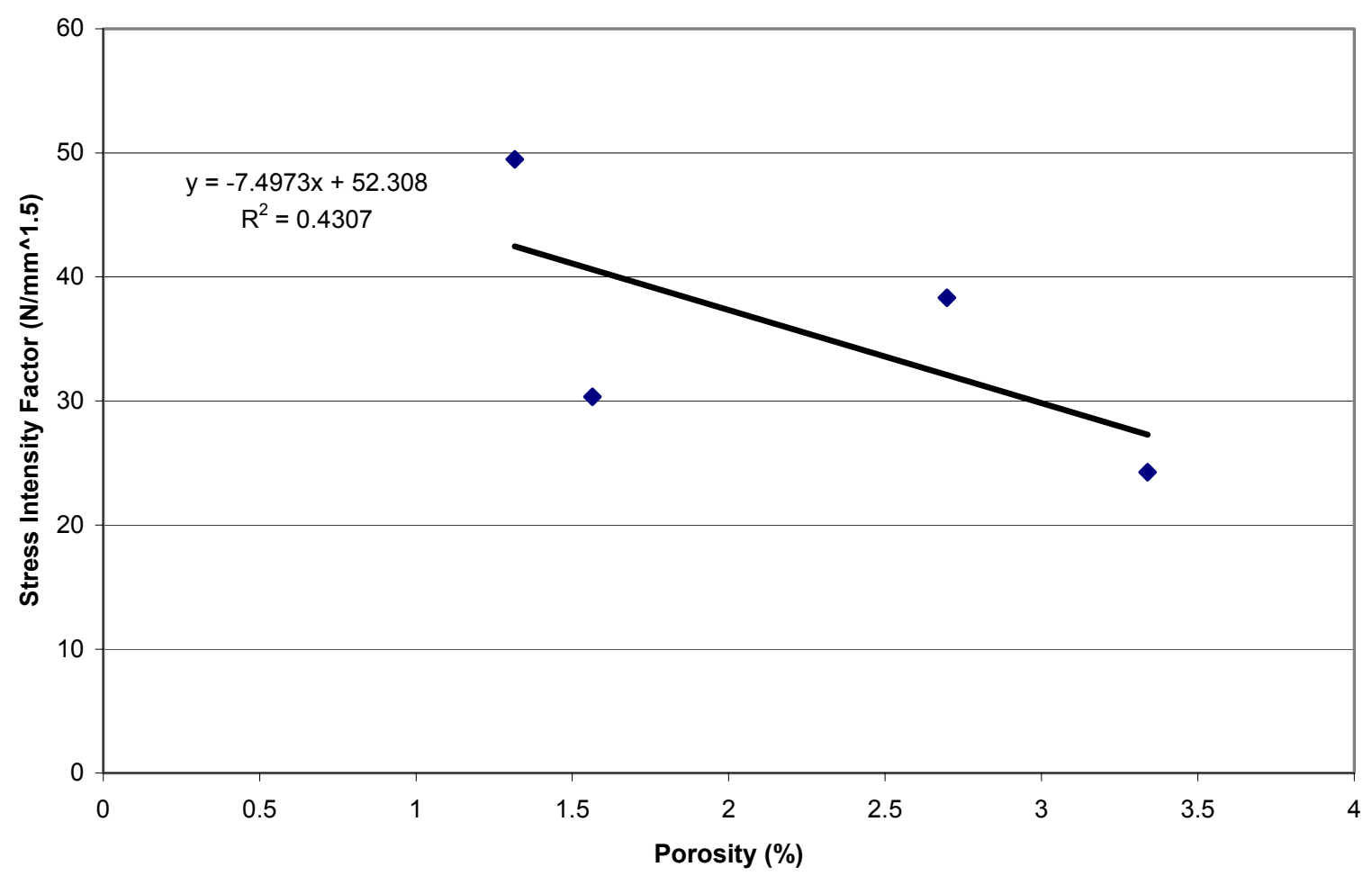

Figure 7.7-7: Stress Intensity Factor versus \%Po for Group I.

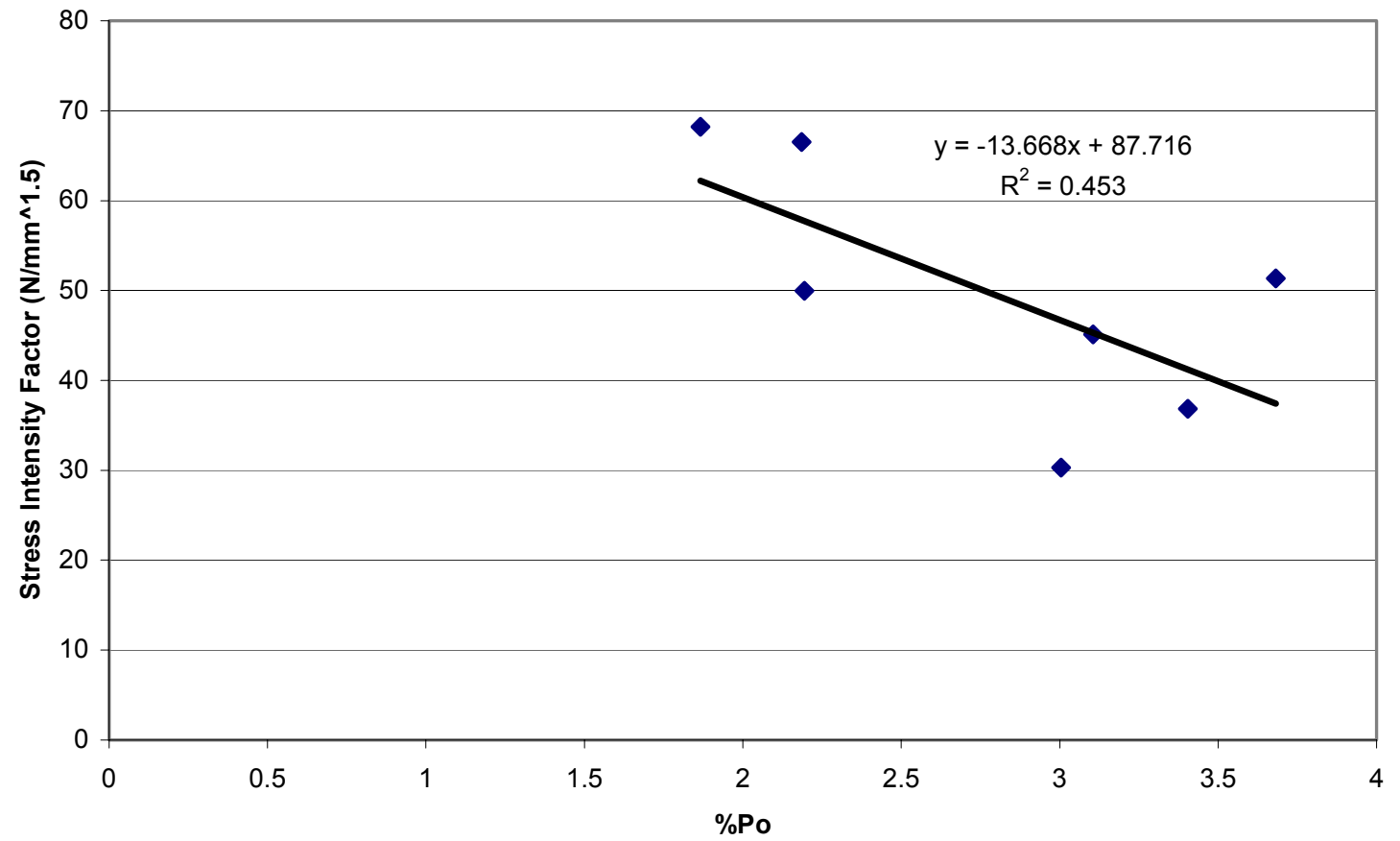


Figure 7.7-8: The stress intensity factor versus the \%Po for Group II.

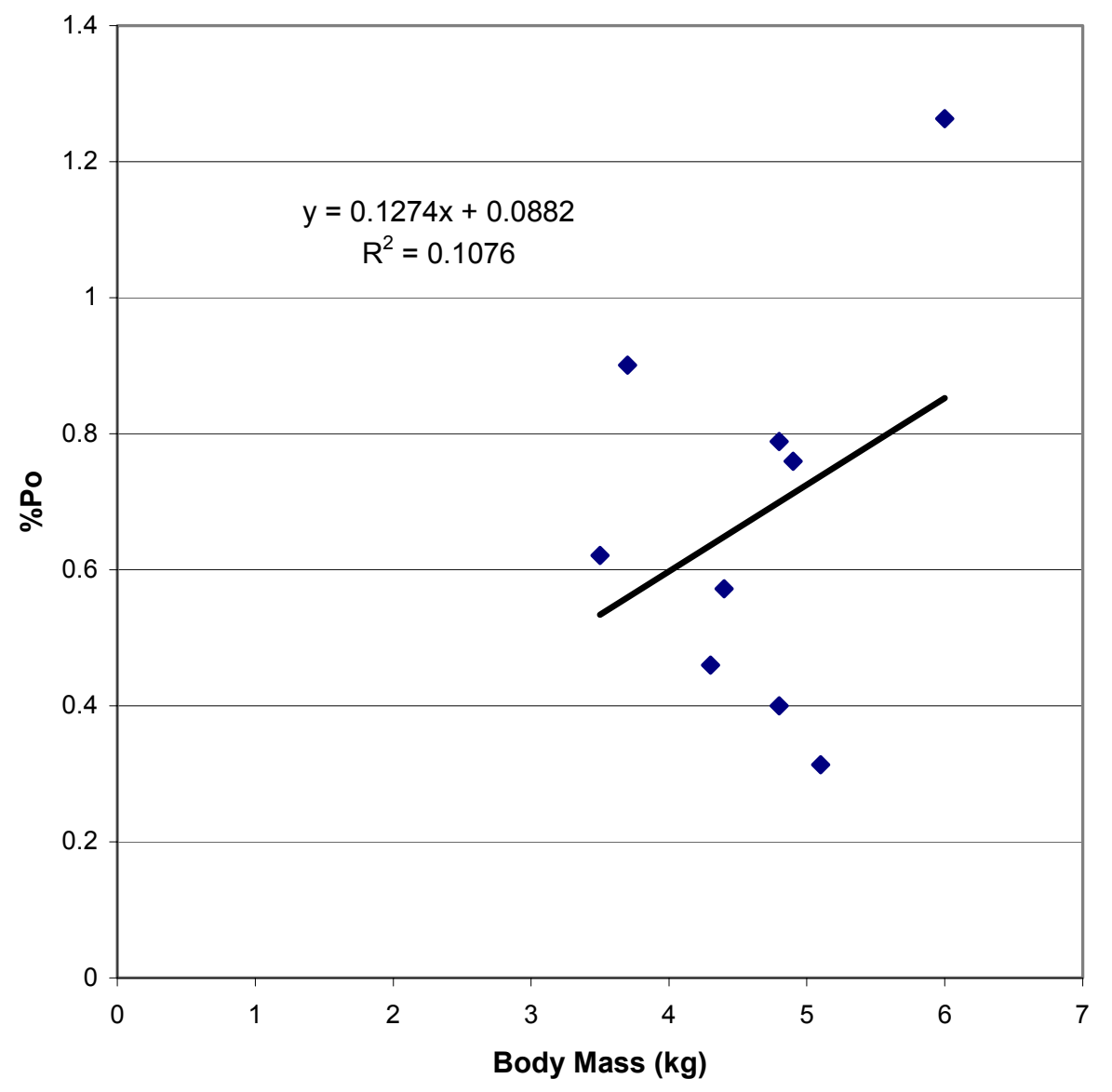

Figure 7.7-9: Relationship of \%Po versus body mass for Group II. 
7.8 Torsion Testing Data (Cain, R, et al, 2003)

Another research project was being performed, using one of the tibias from

Group III, by R Cain, et al. This project was to investigate the bone composition, and torsional values for the estrogen deficient rabbit. The results, although not significant, show the relationship of body mass to torque and angle of fracture in figure $7.8-1$.

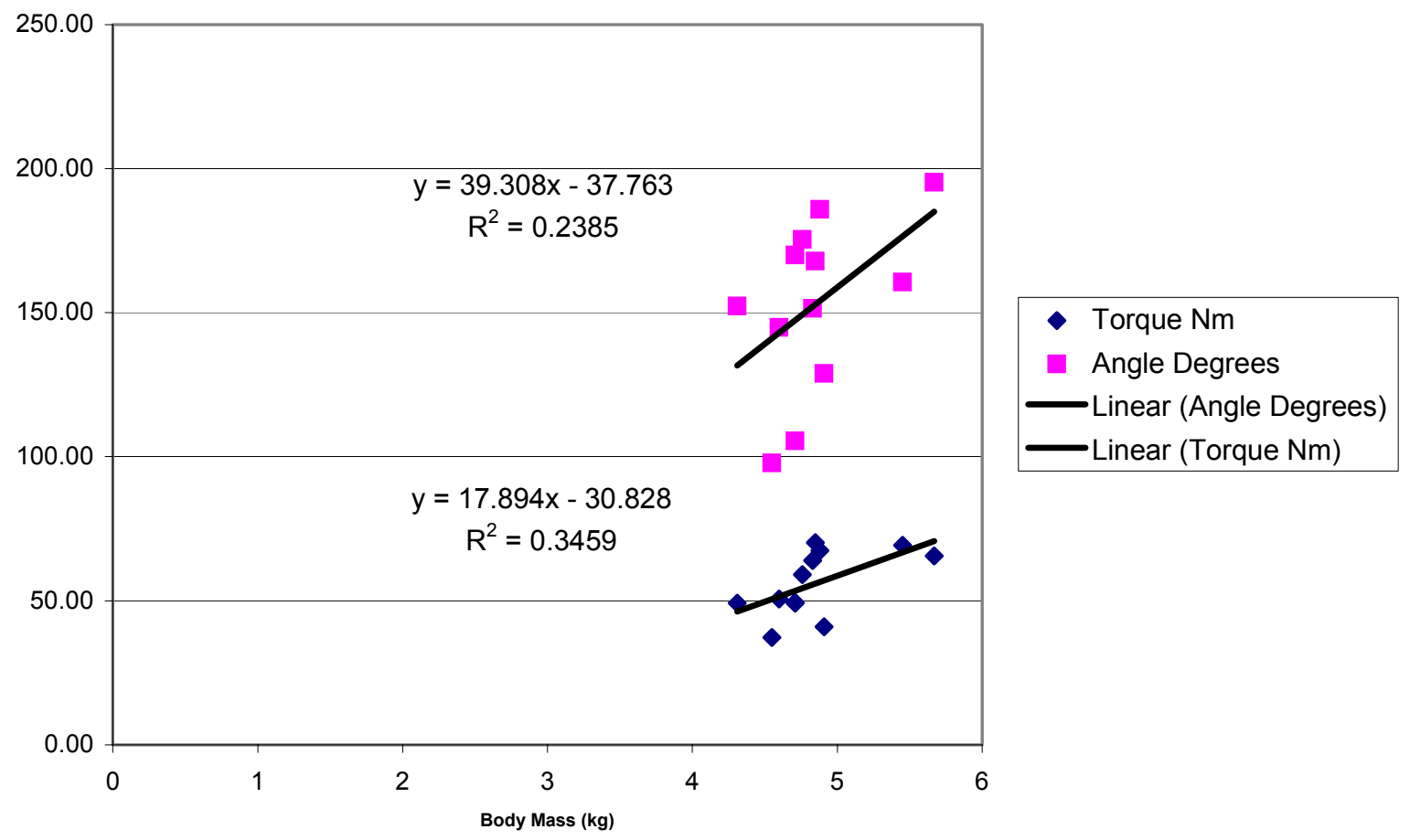

Figure 7.8-1: Torsional test data versus body mass for Group III. 


\section{CHAPTER 8: DISCUSSION}

\subsection{Discussion Fracture Toughness Data}

The data shows a trend that the Risedronate treatment increases fracture toughness of the bones, and this is also shown microscopically by the histomorphometric measures, but the model does not have enough numbers to prove statistical significance. The compliance data implies that there is a strong correlation between body mass and bone properties, as can be seen in the figures 7.7-1, and 7.72. Hui et al. (2002) showed that decrease in bone mineral density can be offset by increases in body mass. Bauer et al (1993), Shiraki et al (1991), Russel-Aulet et al (1993), Klementti et al (1997), Reid et al (1995), and Felson et al (1993) have all shown that bone mass is greatly effected by body mass. The increase in body mass of the estrogen deficient rabbits could be a reason for the lack of difference in the experimental groups.

Although Mashiba et al (2001) found a increase in bone mass and strength in rabbits after only one remodeling cycle (70 days), and Hirano et al showed favorable effects in rabbits after 140 days (1999) and after five months (2000), these results may not apply to our study, because they used an anabolic agent and an intact rabbit model. Lugero, et al (2000) using an overectomized rabbit model found no significant difference in BMD in the rabbit tibia after 4 months, and believe this maybe from the particular $\mathrm{R} / \mathrm{F}$ balance dynamic of the rabbit and the need for longer periods of time for the difference to manifest. A guinea pig take approximately 6 months for a BMD difference to be found. Cao, et al (2000) found no significant diffence in cortical BMD after 4 and 12 weeks, but found a significant difference in 
trabecular bone mass. This experiment also found no significant difference in BMD of the femur for Group II, and this lack of change BMD could be a reason for the lack of difference in the fracture toughness values between groups.

Fracture toughness, as found by Yeni and others, is dependent on many different factures and the exact mechanism for failure and the primary cause is still not known. More study is necessary to find the mechanism of change in fracture resistance.

\subsection{Discussion of Histomorphometry Data}

The bone specimens from the estrogen deficient animals would be expected to be more porous than those from the normal control specimens. The increased porosity would then translate to decreased fracture toughness. The results of our testing do not show this. The lack of the hypothesized results could be from a lack of sufficient time for the increased level of resorption to outpace formation sufficiently for a greater amount of porosity than the normal control.

\subsection{Discussion of Femoral Neck Data}

The femoral neck data showed a decrease in stiffness, but not a decrease in ultimate strength, since the ultimate load at fracture was not significantly different, but the displacement of the femoral head was significantly larger for the Ovx control groups, when compared to Normal and Ovx-Ris. This data is similar to that found by Bagi, et al (1997) in their paper about femoral neck strength of estrogen deficient rats. The Ovx animals in their study had a significantly lower BMD at the end of their study (12 weeks), but the ultimate strength was not significantly different between the Normal and Ovx groups, but the Ovx group was significantly less stiff. Crabtree et al 
(2001) found that the main factor in hip fracture was cortical bone and not trabecular bone as it would have been thought. The relatively slower change of the cortical bone in the rabbits could be a reason for the lack of difference in ultimate strength, even if stiffness may decrease, which could be due to architectural changes of the trabecular bone.

\subsection{Discussion of BMD testing of bones}

The BMD in Group II found from DEXA were not significantly different between groups, but the BMD has a slight correlation with the fracture toughness values, but does not have a high level of significance. The lack of significance could be from a lack of numbers, or there may not be a relationship, but the relationship has been well established, so it is likely the former and not the latter.

The BMC's found by Ruthanne Cain, et al (2003) for Group III were not significantly different for any treatment group, which implies that the 140 day time period may not be long enough for a difference to be detected by the test. The sample size may also be too small, since the beginning BMD is not known, and the lack of difference could be caused by chance, since the peak BMD for each animal differs.

Lugero, et al (2000) using an overectomized rabbit model found no significant difference in BMD in the rabbit tibia after 4 months, and believe this maybe from the particular R/F balance dynamic of the rabbit and the need for longer periods of time for the difference to manifest. A guinea pig take approximately 6 months for a BMD difference to be found. Cao, et al (2000) found no significant difference in cortical BMD after 4 and 12 weeks, but found a significant difference in trabecular bone mass. 


\subsection{Discussion of Weights}

The body mass of the animal seems to be a very important parameter in considering the properties of the bones. The animals in the Ovx groups gained a larger percentage of weight than their non-Ovx (intact) counterparts. Estrogen deficiency causes a decrease in bone mineral density, through an increase in bone resorption. Estrogen deficiency also cause and increase in body mass, which has been shown to cause an increase in bone mineral density. For the Ovx control groups, the two effects on BMD may have been offsetting, such that the bone quality was not significantly different than that of the normal rabbit. The Ovx animals treated with risedronate had the increase in body mass, which would cause an increase in BMD, but the drugs counteracts the increased resorption caused by estrogen deficiency, thus the net change in BMD is positive, since there is no negative change to cause a decrease in properties. The changes are evident in the comparisons of fracture toughness, histomorphometric properties, and to some extent, the stiffness values from the femoral neck testing. 


\subsection{Limitations}

Limitations of this study include:

1. The number of specimens is relatively low for the amount of scatter in the data. A larger sample size may bring about significance.

2. The effects of machining on the fracture toughness of the specimens is not known. The methodology of machining is the same for each specimen, so it should not effect results for the comparison within groups.

3. The specimens do not satisfy all of the ASTM requirements for fracture toughness test specimens, so they cannot be compared to other engineering materials.

4. A razor blade was used to initiate the precrack. The use of the razor blade to initiate the crack may affect toughness, and this type of crack may not be seen in vivo.

5. The period of time ( 20 weeks) may not have been sufficiently long to be able to see mechanical differences between treatment groups.

6. Bone Mineral Density was not tested at the beginning of the experiment. The final BMD may or may not have changed, and the peak density could have affected the outcome.

7. Blood and/or urine samples were never taken for testing of Calcium levels as a marker of bone turnover.

8. No dynamic histomorphometry of these bones were performed. The successful use of markers could give insight into the mechanisms of estrogen deficiency and drug treatment on resorption and formation.

9. The body composition and its change with ovariectomy and time are not known 10. The levels of circulating hormones were never measured. 
11. No cancellous bone histomorphometry was performed to perhaps explain some of the femoral neck fracture data. 


\subsection{Recommendations for Future Study}

Although this study has expanded the knowledge of the use of an ovarectomized rabbit model, and in the testing of bone specimens from said model, other relationships and causes for observations should be investigated. Some suggestions for future investigation include, but not limited to:

1. Analyze the biochemical parameters of the tibia and femur. Some of the differences in fracture toughness may be do to the collagen makeup.

Biochemical analysis may also lend insight to the effect of bisphosphonates on the rabbit bone physiology.

2. Investigate other machining methods. Care and research went into the design of the machining procedure, but this does not mean that the technique is perfected.

3. Dynamic histomorphometry should be performed. Dynamic histomorphometry would allow for the study of mineralization rates, and their effect on fracture toughness.

4. Bone mineral density should be measured at the beginning of the experiment to investigate BMD change and the changes effect on fracture toughness.

5. Characterize the femoral neck and head geometry. The archetetural of the head and neck region could have a major effect on the strength and rigidity of the structure.

6. Determine clinical applications for predicting fracture in humans.

7. Use varying lengths of time for testing, including tests of longer duration to determine the change in fracture toughness with time after ovarectomy. 
8. Investigate the blood hormone levels, since estrogen is an important hormone, but it is not the only regulating hormone.

9. Measure the body composition of the animals, and determine if this has an effect on the fracture toughness, and/or the circulating levels of hormones.

10. Perform histomorphometry of the trabecular bone, to determine if the change effects the femoral neck fracture results.

11. Investigate other material tests, including other fracture modes, and whole bone tests, such as three point bending.

12. Fracture toughness of Ovx and Ovx-Ris bone should be investigated in other directions, besides just the longitudinal direction, since the bone fibers may be reorienting themselves with the new loading enviroment. 


\subsection{Contributions}

This study contributed to the expanding knowledge of fracture toughness of estrogen and drug treated rabbits in the following ways.

1. There is a correlation between the compliance and the body mass of the animal.

2. There seems to be a relationship between fracture type and body mass.

3. Various testing procedures were standardized, which could allow future testing. 


\section{REFERENCES}

Albright JA and Skinner HCW (1987), "Bone: Structural Organization and Remodeling Dynamics," The Scientific Basis of Orthopaedics $2^{\text {nd }}$ (ed JA

Albright and RA Brand) Appleton \& Lange; Norwalk, CT, pp. $161-198$.

Anderson TL (1991). Fracture Mechanics: Fundamentals and Applications. CRC, Boca Raton, FL.

Avioli LV (1987). The Osteoporotic Syndrome: Detection, Prevention, and Treatment. $2^{\text {nd }}$ ed., Grune and Stratton, New York, NY, p. 39, 1987.

Bagi, CM, et al. (1997). "Effect of Estrogen Deficiency on Cancellous and Cortical Bone Structure and Strength of the Femoral Neck in Rats." Calif Tissue Int. 61 (4): 336-344.

Bain SD and CT Rubin (1990), "Metabolic Modulation of Disuse Osteoporosis: Endocrine - Dependent Site Specificity on Bone Remodeling." J Bone Min Res 5: 1069 - 1075 .

Barth RW, et al (1992). "Osteon Morphometry in Females with Femoral Neck Fractures," Clin Ortho Rel Res. 283: 178- 186.

Bauer, DC (1993). "Factors Associated with Appendicular Bone Mass in Older Women." Ann Intern Med. 118: 657-665.

Behiri JC and W Bonfield (1980). "Crack Velocity Dependence of Longitudinal Fracture in Bone," J Mat Sci, 15: 1841 - 1849.

--- (1982). “Fracture Mechanics of Cortical Bone,” Biomechanics: Principles and Applications (ed. Huiske R, et al.), pp. $247-251$.

--- (1984) "Fracture Mechanics of Bone: The Effects of Density, Specimen Thickness, and Crack Velocity on Longitudinal Fracture”. J Biomechanics 17:25-34.

--- (1989) "Orientation Dependence of the Fracture Mechanics of Cortical Bone”. $J$. Biomechanics, 22: 863-872.

Bell KL, et al (1999). "Intracapsular Hip Fracture: Increased Cortical Remodeling in the Thinned and Porous Anterior Region of the Femoral Neck," Osteoporosis Int. 10(3): $248-257$. 
Black DM, et al (1996). "Effects of Alendronate Risk of Fracture in Women with Existing Vertebral Fractures: Results of the Fracture Intervention Trial." Lancet. 348: 1535 - 1541.

Bonfield W and Datta PK (1974). "Impact Fracture of Compact Bone in a Shock Tube," J Mat Sci, 9: 1609 - 1614.

--- (1976). “Fracture Toughness of Compact Bone,” J Biomech, 9: 131 - 134.

Brown C (1995). "Fracture Toughness of Human Cortical Bone from the Proximal Femur.” Master's Thesis. West Virginia University. Morgantown, WV.

Buckwater JA and RR Cooper (1987). "The Cells and Matrices of Skeletal Connective Tissues," The Scientific Basis of Orthopaedics $2^{\text {nd }}$ (ed JA Albright and RA Brand) Appleton \& Lange; Norwalk, CT, pp. 1-29.

Burr DB, et al (2001). "Intermittently Administered Human Parathyroid Hormone (134) Treatment Increases Intracortical Bone Turnover and Porosity without Reducing Bone Strength in the Humerus of Overectomized Cynomologus Monkeys." J Bone Miner Res. 16(1):157-165.

Cain R, et al (2003). "Torsional Bone Strength and Composition of Estrogen Deficient Rabbits," Unpublished Data.

Cao T, et al (2001). "Bone Mineral Density in Mandibles of Ovariectomized Rabbits.” Clin Oral Impl Res. 12: 604-608.

Crabtree N, et al (2001). "Integracapsular Hip Fracture and the Region-specific Loss of Cortical Bone: Analysis by Peripheral Quantitative Compute Tomography," J Bone Mineral Res 16: 1318- 1328.

Cummings ST, et al (1998). "Effects of Alendronate on Risk of Fracture in Women with Low Bone Density but without Vertebral Fractures." JAMA. 280: 2077 -2082 .

Dempster DW and Lindsay R (1993). "Pathogenesis of Osteoporosis." Lancet 341: $797-801,1993$.

Energy Information Administration " World Gross Domestic Product at Market Exchange Rates (1991-2000). www.eia.doe.gov/emeu/iea/tableb2.html downloaded $1 / 15 / 03$ updated 4/23/02

Erisen EF, et al (1994). Bone Histomorphometry. Raven: New York, NY. 
Felson, DT, et al (1993). "Effects of Weight and Body Mass Index on Bone Mineral Density in Men and Women: The Framingham Study." J Bone and Miner Res. 8: 567-573.

Fleisch, H (2000). Bisphosphonates in Bone Disease: From the Laboratory to the Patient. San Diego, CA: Academic, 2000.

Fogelmen, I, et al (2000). "Risedronate Reverses Bone Loss in Postmenopausal Women with Low Bone Mass: Results from a Multinational, Double-blind, Placebo Controlled Trial.” JCEM. 2000; 85:1895 - 1900.

Genant, HK. Cooper C, Poor G, et al. "Interim report and recommendations of the World Health Organization task-force for osteoporosis." Osteoporosis Int 1999: 10: 259-264.

Geusens, P, et al (1999), "Risedronate Increases BMD at the Hip and Spin in Elderly, Osteoporotic Women." (Abstract) Arthritis Rheum. 1999; 42 (Supplement 9); S287.

Hirano T, et al (1999). “Anabolic Effects of Human Biosynthetic Parathyroid Hormone Fragment (1-34), LY333334, on Remodeling and Mechanical Properties of Cortical Bone in Rabbits." J Bone and Min Res. 14: 536-545.

--- (2000). "Changes in Geometry and Cortical Porosity in Adult, Ovary-Intact Rabbits after 5 Months Treatment with L333334 (hPTH 1-34)." Calcif Tissue Int. 66: 456-460.

Harris, ST, et al. (1999), "Effects of Residronate Treatment on Vertebral and Nonvertebral Fractures in Women in Postmenopausal Osteoporosis: A Randomized Controlled Trial.” JAMA. 1999; 282: 1344 - 1352.

Hosking D, et al (1998). "Prevention of Bone Loss with Alendronate in Postmenopausal Women Under 60 Years of Age: Early Postmenopausal Intervention Cohort Study Group." N Engl J Med. 338: 485 - 492.

Hui, SL, et al. (2002). "Bone Loss at the Femoral Neck in Premenopausal White Women: Effects of Weight Change and Sex-Hormone Levels." J Clin Endo and Met. 87 (4) 1539-1543.

Klemetti E, et al. (1997). "Relationship Between Body Mass Index and the Remaining Alveolar Ridge." J Oral Rehab 24:11:808-812.

Li D and Wu H (2001). "[Apoptotic Cells and Related Factors in Ovarectomized Rat Osteoporosis Model]," Chung-Hua Nei Ko Tsa Chih Chinese Journal of Internal Medicine. 40(2): 98 - 100. 
Liberman UA, et al (1995). "Effects of Oral Alendronate on BMD and the Incidence of Fractures in Postmenopausal Women Who Are Not Undergoing Hormonal Replacement Therapy," N Engl J Med. 333: 1437 - 1443.

Lugero GG, et al (2000). "Histomorphometric Evaluation of Titanium Implants in Osteoporotic Rabbits." Implant Dent. 9(4): 303-309.

Mashiba, T, et al (2001). "Effects of Human Parathyroid Hormone (1-34), LY333334, on Bone Mass, Remodeling, and Mechanical Properties of Cortical Bone During the First Remodeling Cycle in Rabbits," Bone 28 (5) : 538 - 547.

McClung M, et al (1998). “Alendronate Prevents Postmenopausal Bone Loss in Women Without Osteoporosis: A Double-blind, Randomized, Controlled Trial: Alendronate Osteoporosis Prevention Study Group." Ann Intern Med. 128: $253-261$.

Moyle DD and AJ Gavens (1986). "Fracture Properties of Bovine Tibial Bone," $J$ Biomech, 19: 919 -927.

Mortensen, L, et al (1998). "Risedronate Increases Bone Mass in an Early Postmenopausal Population: Two Years of Treatment Plus One Year Followup." J Clinical Endorcrinol Metab. 1998; 83: 396 - 402.

Muhlbauer, RC, et al (1971). "The Effects of Diphosphonates, Polyphosphonates, and Calcitonin on 'Immobilization' Osteoporosis in Rats," Eur J Clin Invest, $1: 336-344$.

Nestle B, et al (2000). "[Development of an Osteoporosis Animal Model for the Jaw Area," Mund Kiefer Gesichtchir 4 suppl 2: S501 - S503.

NIH Consensus Statement: "Osteoporosis Prevention, Diagnosis, and Therapy," 17(1): $1-45,2000$.

NIH ORBD NRC “Fast Facts on Osteoporosis" www.osteo.org updated 9/2002 downloaded on 1/15/03.

Norman TL, et al (1991). "Mode I Fracture Toughness of Human Bone," Advances in Bioengineering (ed. Vanderby R), v. 20, BED, ASME, New York, NY, pp. $361-364$.

--- (1992). "Effect of Groove on Bone Fracture Toughness," J Biomech, 25: 1489 1492.

--- (1995a). "Fracture Toughness of Human Bone Under Tension," J Biomech, 28(3): $309-320$. 
--- (1996). "Resistance to Crack Growth in Human Cortical Bone is Greater in Shear than in Tension," J Biomech, 29(8): 1023 - 1031.

---(1997). "Microdamage of Human Cortical Bone: Incidence and Morphology in Long Bones," Bone 20(3): 309 - 320.

Okumura H, et al. (1986). "The Effects of Immobilization on Osteoporosis in Rats." Jpn J Bone Min Metab. 4: 75-82.

Parfitt AM, et al (1987). "Bone Histomorphometry: Standardization of Nomenclature, Symbols, and Units.” J Bone Miner Res 2: 595-610,

Parfitt AM (1983). "Steological Basis of Bone Histomorphometry: Theory of Quantitative Microscopy and Reconstruction of the Third Dimension." Bone Histomorphometry: Techniques and Interpretations. Recker, RR, ed. CRC: Boca Raton, FL, pp . 53-88.

Pols HAP et al (1999). "Multinational, Placebo-Controlled, Randomized Trial of the Effects of Alendronate on Bone Density and Fracture Risk in Postmenopausal Women with Low Bone Mass: Results of the FOSIT Study." Osteoporos Int. 9: $461-468$.

Ravn P, et al (1999). "Alendronate and Estrogen-progestin in the Long-term Prevention of Bone Loss: Four-year Results from the Early Postmenopausal Intervention Cohort Study: A Randomized, Controlled Trial.” Ann Intern Med, 131: 935 - 942.

Reid IR et al. (1995). "Regular Exercise Dissociates Fat Mass and Bone Density in Premenopausal Women." J Clin Endo and Met. 80 (6): 1764-1768.

Reginister, JY, et al (2000). "Randomized Trial of the Effects of Risedronate on Vertebral and Nonvertebral Fractures in Women with Postmenopausal Osteoporosis". Osteoporosis Int. 2000; 11: 83-91.

Russel-Aulet, M, et al. (1993). "Bone Mineral Density and Mass in a Cross-Sectional Study of White and Asian Women.” J Bone and Miner Res. 8: 575-582.

Saville PD (1969). "Changes in Skeletal Mass and Fragility with Castration in the Rat: A Model of Osteoporosis." J Am Geriatr Soc 17: 155-156

Schoutens A, et al (1984). "Growth and Bone Haemodynamics Responses to Castration in Male Rates: Reversibility of Testosterone." Acta Endocrinol. 107: $428-432$. 
Shiraki, M, et al. (1991). "Relationship between Body Size and Bone Mineral Density with special reference to Sex Hormones and Calcium Regulating Hormones in Elderly Females." Endocrnol Jpn. 38: 343-349.

Smith El and C Gilligan (1989). "Mechanical Forces and Bone." Bone Mineral Res 6: $139-173$.

Stevenson JC (1990). "Pathogenesis, Prevention and Treatment of Osteoporosis." Ob Gyn. 75 (4 Suppl.): 36S - 41S; discussion 51S - 52S.

Vashishth, D (1991). Mode I Fracture Toughness of Human Bone, Master's Thesis, West Virginia Univerisity, Morgantown, WV.

Wang, Z (1995). "Microstructure and Microdamage of Human Cortical Bone," Master's Thesis, West Virginia University, Morgantown, WV.

Weinreb M, et al (1989). "Osteopenia in the Immobilized Rat Hindlimb is Associated with Increased Bone Resorption and Decreased Bone Formation," Bone. 10: 187 - 194.

Wingerd, BD and G Stein (ill.). Rabbit Dissection Manual. Baltimore, MD: John Hopkins, 1985.

Wronski TJ, et al (1985). "Skeletal Alterations in Overectomized Rats," Calcif Tissue Int 37: $324-328$.

Yang X, et al (1997). "[Primary Study on the Use of Ovarectomized Rabbits for Establishment of Osteoporosis Model]," Sheng Wu I Hsueh Kung Cheng Hsueh Tsa Chia \& Journal of Biomedical Engineering 14(4): 353 - 358.

Yeni, YN, et al (1997) "Influence of Bone Morphology on Fracture Toughness of the Human Femur and Tibia," Bone 21: 5: 453-459.

Yeni, YN, et al (1998) "Influence of Bone Composition and Apparent Density on Fracture Toughness of the Human Femur and Tibia," Bone 22: 1: 78-84.

Yeni, YN (1998). "Fracture Mechanics of Human Cortical Bone: The Relationship of Geometry, Microstructure, and Composition with the Fracture of the Tibia, Femoral Shaft, and the Femoral Neck," Dissertation, West Virginia University, Morgantown, WV. 


\section{APPENDIX A: H \& E STAINING PROCEDURE}

This procedure is for $\mathrm{H} \& \mathrm{E}$ staining of plastic embedded bone sections of 80 $-100 \mu \mathrm{m}$, that have been subsequently ground and polished to a final thickness of $\sim 50 \mu \mathrm{m}$.

The section is first rinsed in water, and then allowed to soak in Harris' Hematoxylin for 15 minutes on a platform shaker at $95 \mathrm{rpm}$. The section is then placed in gently running water for five minutes. After the rinse, the section is dipped gently 20 times in Acid Alcohol, which is a solution of $10 \mathrm{ml} \mathrm{HCL}$ to $1990 \mathrm{~mL}$ of distilled water. The specimen is then placed in a running water rinse for 8 minutes. The specimen is then dipped gently 15 times in Ammonia Water, which is a solution of $3 \mathrm{~mL}$ ammonium hydroxide to $1000 \mathrm{~mL}$ tap water. The specimen is again placed in a running water rinse for 15 minutes. After the rinse, the specimen soaked in Eosin for 6 minutes. After the Eosin bath, the specimen goes through a series of dipping in order 80\% Alcohol, 95\% Alcohol, 100\% Alcohol, 100\% Alcohol, Xylene for 10, 15, 15,15 , and 15 dips respectively. 


\section{APPENDIX B: PLASTIC EMBEDDING PROCEDURE}

\section{Introduction:}

Microscopic investigation necessitates the thin sectioning of the material that is desired to be studied. The problem of sectioning is multifaceted, since often the material sample, although large by microscope terms, is much too small for conventional machining techniques. Fragility of the structures, which are desired for investigation, also pose a problem, since these can be destroyed during the sectioning process.

Plastic embedding of the material is one way that these limitations can be overcome. The plastic gives support to the sectioned structures, which helps keep them from being destroyed, and it gives extra length and width such that the specimen can be clamped and sectioned.

\section{Procedure:}

1. Specimens are fixed in $10 \%$ neutral buffered formalin.

2. The specimens are place in a Hypercenter XP tissue processor (Shandon, Pittsburgh, PA) for processing which includes:
a. Dehydration in alcohol
b. Clearing with Xylene
c. Infiltration with methymethacrylate (MMA)

3. Specimens are embedded in MMA (100 ml MMA to 0.2 g Perkadox)

4. Specimens are left in vacuum oven for 1-2 hours to remove air bubbles

5. Specimens are place in water bath $(36 \mathrm{oC})$ overnight for polymerization 


\section{APPENDIX C: MMA EMBEDDED CROSS-SECTION POLISHING PROCEDURE}

1. Cut Sections From Plastic Embedded Bone. Make the cuts at 45 marks $(450 \mu \mathrm{m})$, which will give a final thickness of $120 \mu \mathrm{m}$.

2. Store the sections in plastic cassettes labeled with the specimen number in a large beaker of distilled water.

3. Use forceps to pick up the specimen and gently place on the 800\# sandpaper. Spray a small puddle of distilled on the sand paper. Begin polishing circular motion, add some pressure. Keep polishing for four mins. Turn over three times ( $1 \mathrm{~min} 20 \mathrm{sec}$ per side).

4. Put the specimen on the nylon cloth. Spray 2-3 drops of 3 micron polishing solution (green) on the cloth. Polish using circular motion. Polish for 6 minutes, turning three times (every 2 mins).

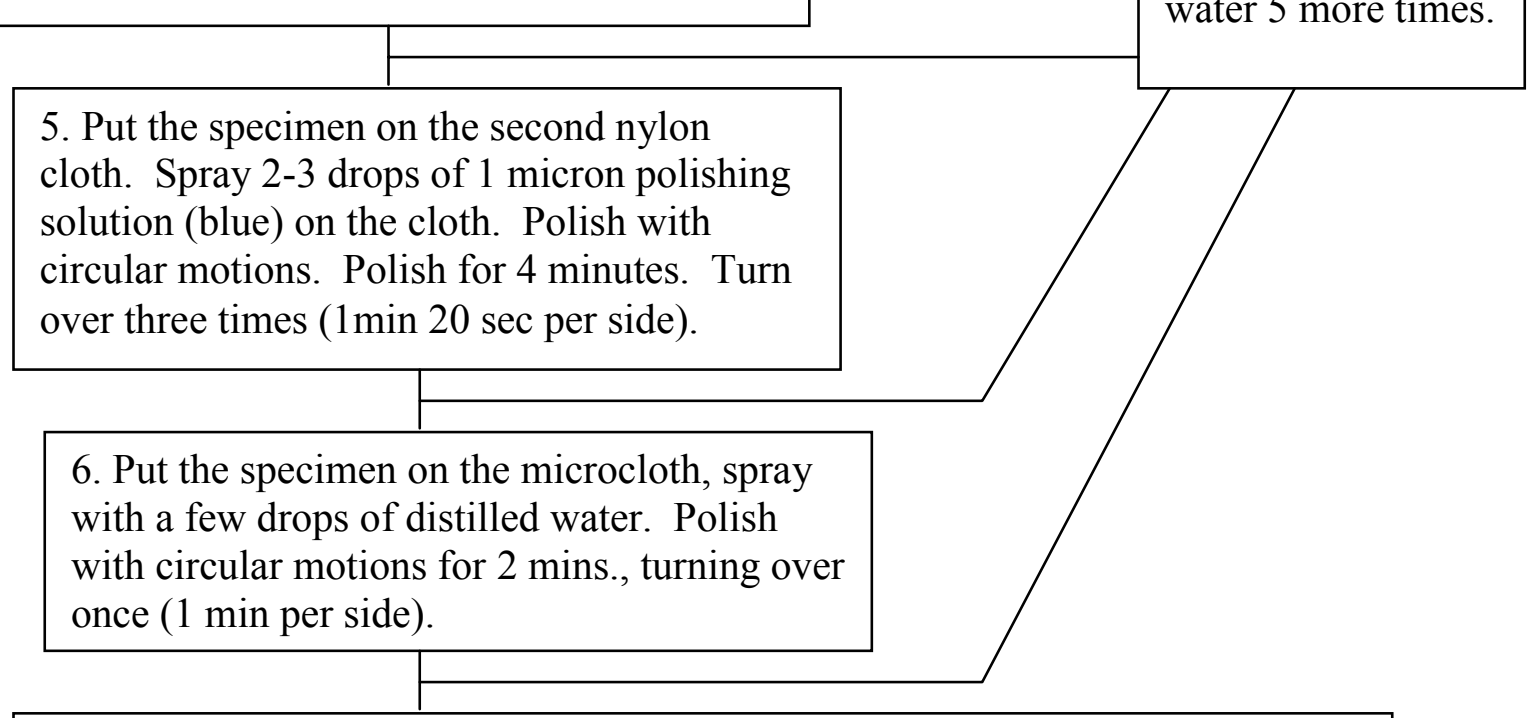

7. Dry the specimen on a napkin for approximately five minutes. Check on the microscope $40 x$ to make sure there are no scratches. If there are scratches repeat steps three through five. If there are not scratches mount on a slide labeled with the specimen number with flourmount and cover slip. If it is to be stained, place the specimen back in the cassette and store in a small beaker of distilled water. 


\section{APPENDIX D: IN-VIVO STAIN PREPARATION}

Two different stains were used in this study for the purpose of dynamic histomorphometry, tetracycline and Calcein.

Tetracycline:

1. Mix 2.5 grams of powdered tetracycline in $100 \mathrm{ml}$ of phosphorous buffered saline (PBS).

2. Stir using magnetic stirrer for several minutes (15 - 30 mins).

3. Use buffers to bring the $\mathrm{pH}$ to normal biological level (7.4). Note: This step is very important, because tetracycline is very acidic.

4. Using filters put the solution into sterile vials.

5. Refrigerate $\left(4{ }^{\circ} \mathrm{C}\right)$ until used.

6. Dosing is give in the same manner as the risedronate $1 \mathrm{ml} / \mathrm{kg}$

7. Injections can be given subcutaneously or intraperitoneally.

\section{Calcein:}

1. Make $100 \mathrm{ml}$ of $2 \%$ sodium bicarbonate and distilled water $\left(2 \mathrm{mg} \mathrm{NaH} \mathrm{NO}_{3}\right.$ in 100 $\mathrm{ml}$ of distilled water).

2. Mix 1.5 grams of powdered calcein in $100 \mathrm{ml}$ of the solution made in step 1 .

3. Stir using a magnetic stirrer for several minutes (15-30 mins).

4. Using filters put the solution into sterile vials

5. Refrigerate $\left(4{ }^{\circ} \mathrm{C}\right)$ until used

6. Dosing is given in the same manner as the risedronate $1 \mathrm{ml} / \mathrm{kg}$.

7. Injections can be given subcutaneous or intraperitoneal. 